UNIVERSIDADE DE SÃO PAULO

FACULDADE DE FILOSOFIA, CIÊNCIAS E LETRAS DE RIBEIRÃO PRETO DEPARTAMENTO DE PSICOLOGIA PROGRAMA DE PÓS-GRADUAÇÃO EM PSICOLOGIA

Necessidades de Treinamento de Líderes de Projeto em Empresa de Pesquisa, Desenvolvimento e Inovação

MÔNICA AUN DE AZEVEDO

RIBEIRÃO PRETO

2017 


\title{
Necessidades de Treinamento de Líderes de Projeto em Empresa de Pesquisa, Desenvolvimento e Inovação
}

\author{
MÔNICA AUN DE AZEVEDO
}

Dissertação apresentada ao Programa de Pós-Graduação de Psicologia do Departamento de Psicologia da Faculdade de Filosofia, Ciências e Letras de Ribeirão Preto da Universidade de São Paulo, como parte das exigências para a obtenção do título de Mestre em Ciências. Área de concentração: Psicologia. Orientadora: Prof. ${ }^{a}$ Dr. ${ }^{a}$ Thaís Zerbini

\author{
RIBEIRÃO PRETO
}

2017 
Autorizo a reprodução e divulgação total ou parcial deste trabalho, por qualquer meio convencional ou eletrônico, para fins de estudo e pesquisa, desde que citada a fonte.

Azevedo, Monica Aun de

Necessidades de Treinamento de Líderes de Projeto em Empresa de Pesquisa, Desenvolvimento e Inovação. Ribeirão Preto, 2017. 140 p.

Dissertação de Mestrado, apresentada à Faculdade de Filosofia, Ciências e Letras de Ribeirão Preto/USP. Área de concentração: Psicologia.

Orientador: Thaís Zerbini.

1. Treinamento. 2. Análise de necessidades de treinamento 3. Competência. 4. Líder de projeto. 5. Pesquisa Desenvolvimento e Inovação. 
Nome: Azevedo, M. A. A.

Título: Necessidades de Treinamento de Líderes de Projeto em Empresa de Pesquisa, Desenvolvimento e Inovação

Dissertação apresentada à Faculdade de Filosofia, Ciências e Letras de Ribeirão Preto da Universidade de São Paulo para obtenção do título de Mestre em Psicologia

Aprovada em: 15/01/2018

Banca Examinadora:

Profa. Dra. Thaís Zerbini (Orientadora)

Instituição: Faculdade de Filosofia Ciências e Letras de Ribeirão Preto/ Universidade de São Paulo

Dra. Daniela Biaggioni Lopes

Instituição: Empresa Brasileira de Pesquisa Agropecuária

Profa. Dra. Lara Barros Martins

Instituição: Departamento de Psicologia/ Faculdade Meridional

Profa. Dra. Marina Greghi Sticca

Instituição: Faculdade de Filosofia Ciências e Letras de Ribeirão Preto/ Universidade de São Paulo 


\section{Agradecimentos}

A Deus, fonte de infindável energia em todos os momentos, por guiar meus passos, me dar força para persistir e progredir.

A minha família, minha base, especialmente aos meus pais, sempre presentes, por me dar apoio e compartilhar de cada conquista.

À orientadora, Thaís Zerbini, por todo conhecimento transmitido, orientação e dedicação durante esse período de crescimento.

À banca examinadora, pela leitura cuidadosa do trabalho e pelas contribuições ao seu aperfeiçoamento.

À Embrapa, pela grande oportunidade e incentivo para que este projeto se tornasse realidade, e por me conceder a liberação integral das atividades profissionais para realizar este estudo.

A todos os professores do Programa de Pós-graduação em Psicologia da Universidade de São Paulo- USP-RP, e da Universidade de Brasília - UnB, pelos conhecimentos transmitidos.

À Profa. Marina Sticca, pelo apoio e conhecimentos transmitidos.

À Lara Martins e Cecília Pagotto, pela contribuição na fase de análise de dados.

A todo o grupo que integrou o Laboratório de Psicologia Organizacional e do Trabalho (LabPOT) nesse período, pelas oportunidades de discussões e troca de experiências em reuniões e grupos de estudo.

Aos colegas da Embrapa, por me apoiar, incentivar, dividir experiências profissionais, proporcionar reflexões, importante em todas as etapas deste trabalho; à Maíra, que gentilmente participou como conselheira acadêmica desse processo de formação intelectual.

Ao grupo de pesquisadores que colaborou com este estudo, no processo de entrevista e validação de instrumento, e na condução da coleta de dados.

Aos servidores da FFCLRP-USP, pelo auxílio durante o período de curso.

Aos meus amigos de todas as horas, e aos que fiz em Ribeirão Preto - em especial Wania Lopes; aqueles que conheci na USP, na UnB e na Embrapa, que me acompanharam durante essa fase: pela torcida, e por fazer minha vida mais divertida.

A todos que contribuíram direta ou indiretamente para a realização deste trabalho. 


\section{Sumário}

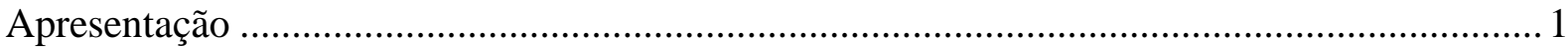

Capítulo 1 - Treinamento, desenvolvimento e educação (TD\&E) .........................................5

1.1 - Definições, características e evolução ........................................................................ 5

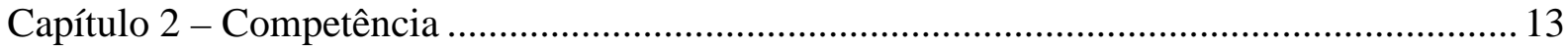

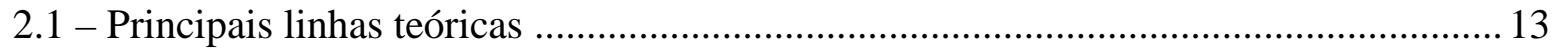

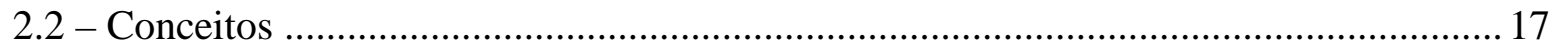

2.3 - Contextualização: competência no cenário da pesquisa ...........................................22

Capítulo 3 - Avaliação de necessidades de treinamento (ANT) ........................................... 29

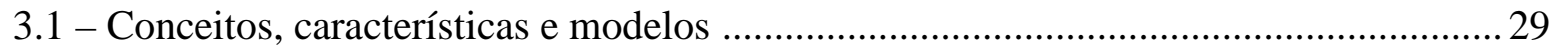

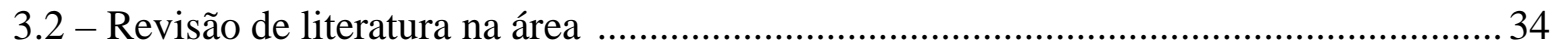

Capítulo 4 - Características Metodológicas da Pesquisa …......................................................55

4.1 - Delimitação do problema, objetivos de pesquisa e modelo de investigação ..............55

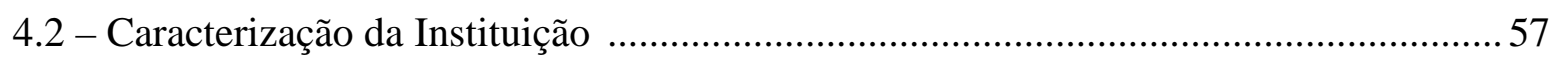

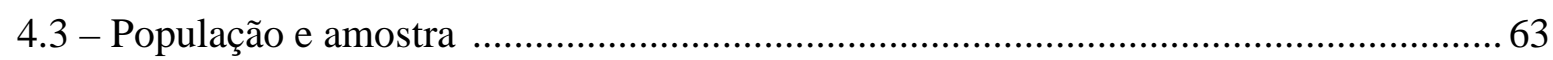

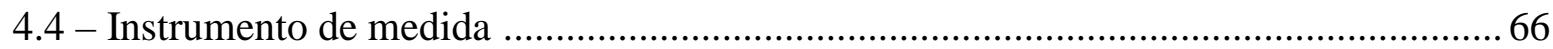

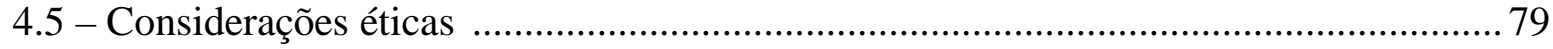

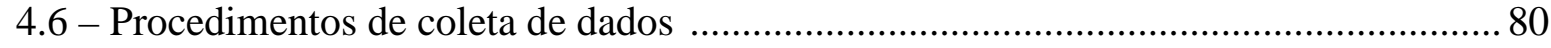

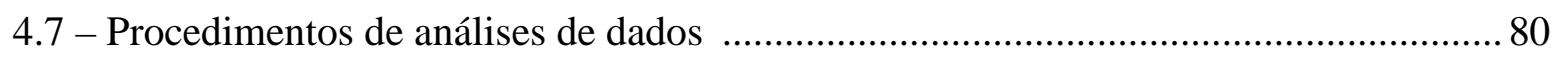

4.7.1 - Procedimentos de análises exploratórias e fatoriais da estrutura empírica do

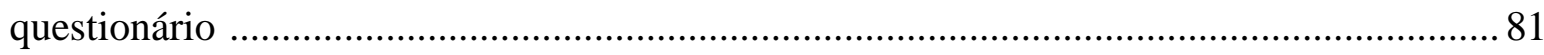

4.7.2 - Procedimentos de análises dos testes de regressão múltipla ............................ 84

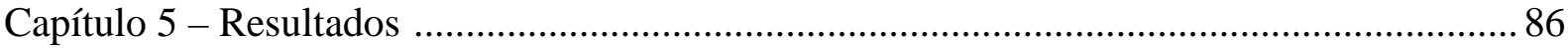

5.1 - Procedimentos de construção do instrumento ............................................................ 86

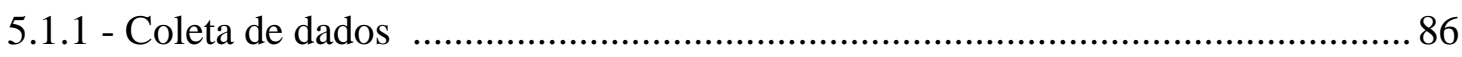

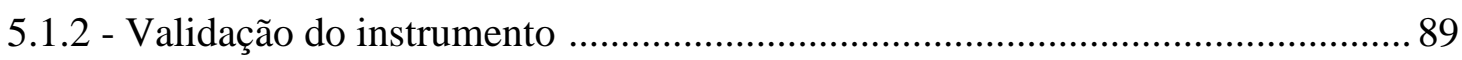

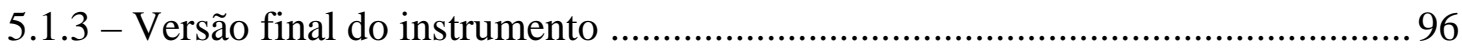

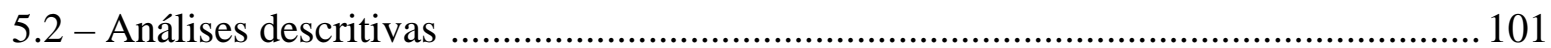

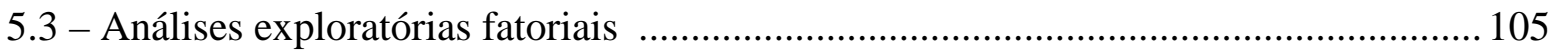

5.4 - Cálculos dos índices de prioridades de treinamento (IPG) ..................................... 113

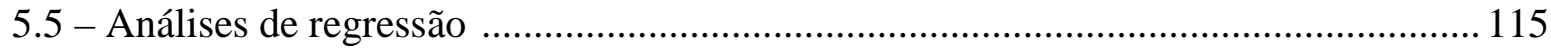

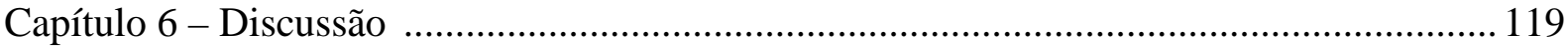




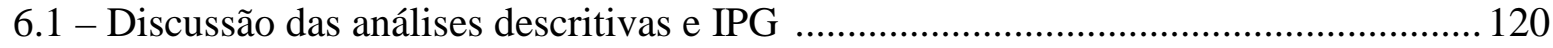

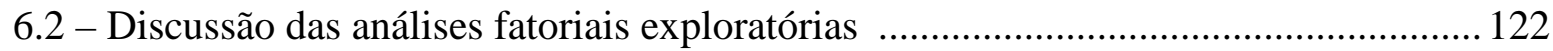

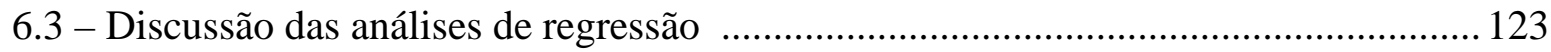

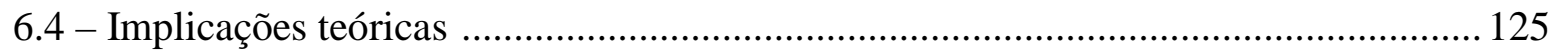

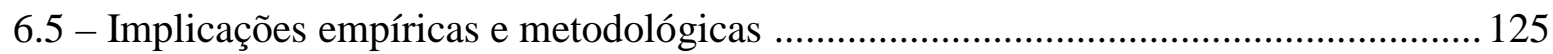

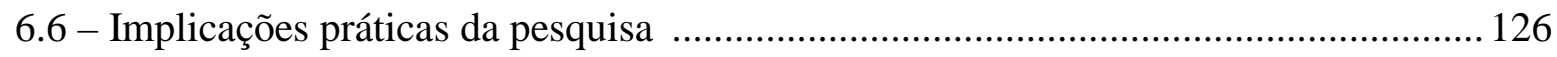

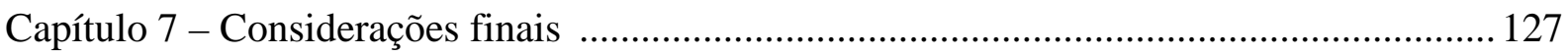

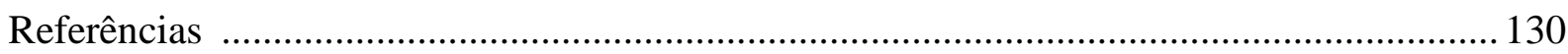

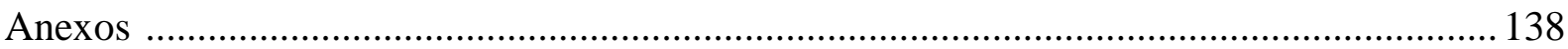




\section{Lista de Figuras}

Figura 1 - Organização dos capítulos da dissertação ............................................................ 3

Figura 2 - Relações entre conceitos e soluções educacionais ............................................. 6

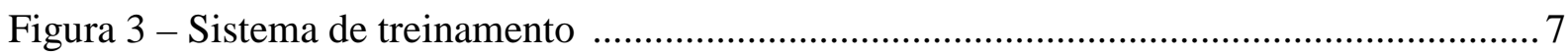

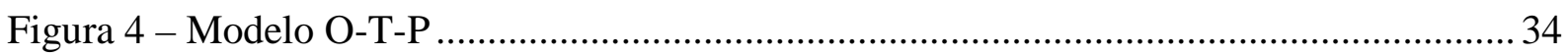

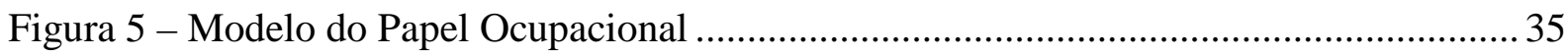

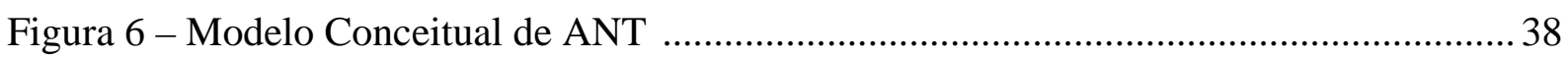

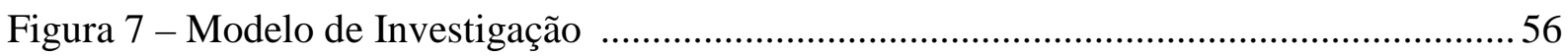

Figura 8 - Distribuição de valores próprios da escala de importância do CompLP ............. 106

Figura 9 - Distribuição de valores próprios da escala de domínio do CompLP .................... 110

Figura 10 - Gráfico do IPG das competências do CompLP ................................................ 114

Figura 11 - Modelo de predição proposto ..................................................................... 117

Figura 12 - Relacionamento entre as variáveis do Modelo que apresentam maior poder preditivo 


\section{Lista de Tabelas}

Tabela 1 - Correntes teóricas na concepção de competência ................................................ 16

Tabela 2 - Definições de competências, segundo análise de Campos (2015) ........................ 17

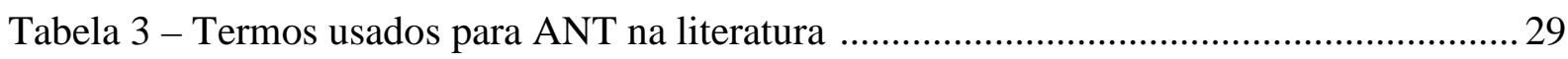

Tabela 4 - Modelos de ANT - estudos no contexto internacional ......................................... 40

Tabela 5 - Modelos de ANT - estudos no contexto nacional ................................................... 42

Tabela 6 - Estudos selecionados para a revisão de literatura de ANT ……............................ 43

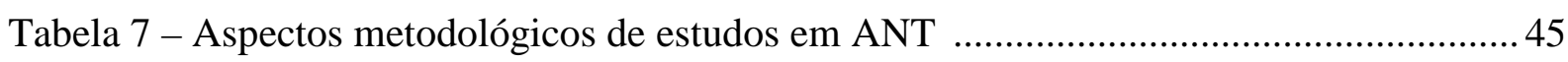

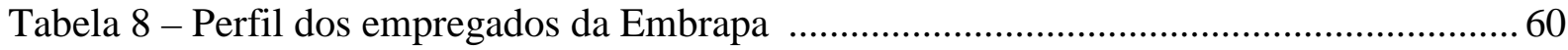

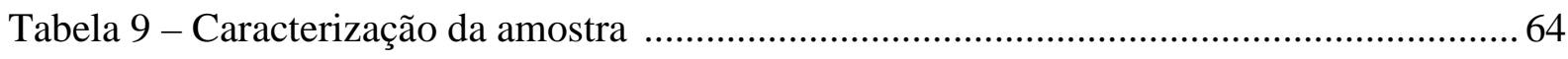

Tabela 10 - Informações obtidas nas entrevistas de coletas de dados e análise de conteúdo .69

Tabela 11 - Critérios psicométricos para construção de itens do questionário ........................ 77

Tabela 12 - Construção de itens do instrumento: resultado de coleta de dados ..................... 86

Tabela 13 - Relação dos itens do questionário e temas recorrentes identificados na coleta de

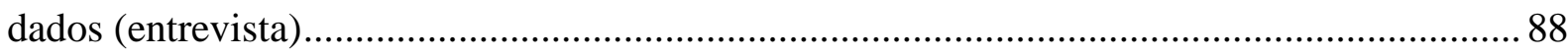

Tabela 14 - Versão dos itens do instrumento após validação semântica ................................ 91

Tabela 15 - Versão dos itens do instrumento após validação por juízes - etapa 1 .................. 92

Tabela 16 - Versão dos itens do instrumento após validação por juízes - etapa 2 .................. 93

Tabela 17 - Dados descritivos dos itens relativos à escala de importância do CompLP ...... 101

Tabela 18 - Dados descritivos dos itens relativos à escala de domínio do CompLP ............. 103

Tabela 19 - Valores próprios empíricos e aleatórios dos primeiros cinco componentes da

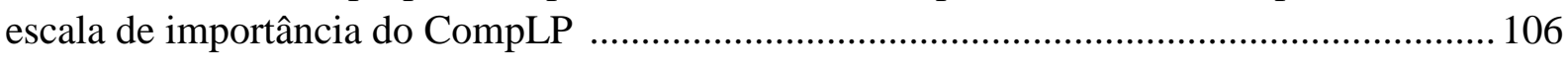

Tabela 20 - Estrutura empírica da escala de importância do CompLP ................................. 107

Tabela 21 - Valores próprios empíricos e aleatórios dos primeiros cinco componentes da

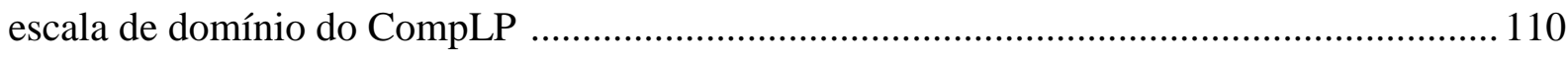

Tabela 22 - Estrutura empírica da escala de domínio do CompLP .................................... 111

Tabela 23 - Índice de Prioridade de Treinamento (IPG) ..................................................... 113

Tabela 24 - Necessidades de treinamento identificadas .................................................. 115

Tabela 25 - Regressão múltipla padrão para o Modelo de investigação proposto ................. 116

Tabela 26 - Relação de predição das variáveis antecedentes (variáveis sociodemográficas da clientela) para as necessidades de treinamento identificadas . 


\section{Resumo}

Azevedo, M. A. A. (2017). Necessidades de Treinamento de Líderes de Projeto em Empresa de Pesquisa, Desenvolvimento e Inovação. Dissertação de Mestrado, Departamento de Psicologia, Universidade de São Paulo, Ribeirão Preto.

A gestão dos projetos de Pesquisa, Desenvolvimento e Inovação (PD\&I) tem sido objeto de preocupação das organizações em virtude da necessidade de compatibilizar objetivos estratégicos e recursos, assim como assegurar a ênfase no desenvolvimento de projetos prioritários, em virtude das crescentes demandas da sociedade. A literatura sobre gestão de projetos apresenta, de forma recorrente, além da importância da figura do líder no desempenho dos projetos como um dos principais agentes condicionantes para o alcance dos resultados, a necessidade constante de aprimoramento da capacidade de atuação desses atores. O aprimoramento da qualificação de profissionais, campo da gestão de programas de Treinamento, Desenvolvimento e Educação (TD\&E), tem na etapa de Avaliação de Necessidades de Treinamento (ANT) o processo essencial para a identificação e a priorização de esforços e investimentos realizados na formação de pessoas. Apesar de sua importância, a ANT ainda é pouco desenvolvida nas organizações e possui carência de pesquisas empíricas. Nesse sentido, esta pesquisa objetivou investigar as lacunas de competências de líderes de projeto, com o intuito de conhecer a predição das variáveis características da clientela (sociodemográficas e funcionais) sobre a necessidade de treinamento, no contexto de uma instituição de PD\&I. Procurou contribuir, desta forma, com elementos no campo da gestão dos projetos, com o avanço da ANT ao conduzir o processo de investigação para avaliar as necessidades de treinamento dos líderes de projeto, fornecer subsídios para a instituição-alvo, no intuito de propiciar informações para o planejamento e desenvolvimento de programa de treinamento e capacitação mais efetivo, voltado à clientela-alvo da pesquisa. Foram traçados cinco objetivos específicos: construir o instrumento de Competências de Líderes de Projeto (CompLP); verificar evidências de validade do instrumento; identificar as lacunas de competências dos líderes de projeto da Embrapa; conhecer o perfil da clientela; identificar as variáveis que influenciam a aquisição de conhecimentos, habilidades e atitudes - CHAs. A partir da identificação das competências características do líder de projeto, e da validação do instrumento, obteve-se um questionário com 25 itens. Obtidos bons índices psicométricos de validação do instrumento, a pesquisa foi aplicada na Embrapa, e contou com uma amostra de 300 indivíduos. Os índices de prioridade geral (IPG) de treinamento apresentaram valores baixos (menores que 13,8) para as 25 competências que integram o instrumento. De acordo com a auto percepção da amostra, não há necessidade de treinamento de ordem superior, no entanto com elevada divergência de opinião entre os respondentes. A partir das análises do modelo de predição com as oito competências identificadas para desenvolvimento (IPG - 10,3 a 10,86), concluiu-se que a área de atuação dos líderes de projeto na Empresa explica a necessidade de treinamento nas competências em geral, e as variáveis que mais significativamente contribuem para o modelo de predição $(\mathrm{R} 2=7 \%)$ são idade, cargo, tempo de trabalho e tempo de experiência como líder de projeto. $\mathrm{O}$ objetivo geral e os objetivos específicos do estudo foram alcançados. Ao final, limitações do estudo são discutidas.

Palavras-chave: Treinamento. Avaliação de necessidades de treinamento. Competência. Líder de projeto. Gestão de projetos. Pesquisa, Desenvolvimento e Inovação. 


\begin{abstract}
Azevedo, M. A. A. (2017). Training Needs of Project Leaders in Research, Development and Innovation Institution. Dissertação de Mestrado, Departamento de Psicologia, Universidade de São Paulo, Ribeirão Preto.
\end{abstract}

The management of research, development and innovation projects has been a concern of organizations due to the need to reconcile strategic objectives and resources, as well as to ensure the emphasis in the development of priority projects, in order to assure the growing demands of society. The literature on project management presents, in a recurrent way, besides the importance of the figure of the leader in the performance of projects, as one of the main conditioning agents for the achievement of results, the constant need to improve the capacity of these actors to act. The improvement of the qualification of professionals, field of program management of training, has in the training needs analysis - TNA stage the essential process for the identification and prioritization of efforts and investments made in the training of workers. Despite its importance, the TNA is still underdeveloped in organizations and lacks empirical research. In this sense, this research aimed to investigate the skills gaps of project leaders with the purpose of knowing the prediction of the characteristic variables of the clientele (sociodemographic and functional characteristics) about the need for training, in the context of a research, development and innovation institution. It sought to contribute, with elements in the field of research project management, with TNA advancing in conducting the research process to evaluate the training needs of project leaders, to provide subsidies to the target institution in order to plann and develop effectives training programes, aimed at the target clientele of the research. Five specific objectives were outlined: build the Project Leadership Competency tool (CompLP); check evidence of validity of the CompLP instrument; identify the skills gaps of Embrapa project leaders; know the profile of the clientele; identify the variables that influence the acquisition of CHAs. Based on the identification of competencies characteristic of the project leader, and the validation phases of the instrument, a questionnaire with 25 items was obtained. After obtaining good psychometric indexes of instrument validation, the research was applied at Embrapa, and had a sample of 300 individuals. The general priority-training index (GPI) presented low values (less than 13.8) for the 25 competences that make up the instrument. Thus, according to the self-perception of the sample, there are no higher-order training needs, however with a high divergence of opinion among the respondents. From the analysis of the prediction model with the eight competencies identified for development (IPG - 10.3 to 10.86), it was concluded that the area of performance of the project leaders in the institution explains the need for training in skills in general, and the variables that most significantly contribute to the prediction model $(\mathrm{R} 2=7 \%)$ are age, position, working time, and time of experience as a project leader. The overall objective and the specific objectives of the study were achieved. At the end, study issues are discussed.

Key-words: Training. Training needs analysis. Competence. Project leader. Project Management. Research. Development and Innovation. 


\section{Apresentação}

A necessidade crescente pela transformação do conhecimento científico em resultados práticos para a sociedade e pela geração de inovações que possam contribuir para o fortalecimento da competitividade no âmbito do setor produtivo nacional constitui um grande e complexo desafio a ser enfrentado pelas instituições de pesquisa. Essas instituições trabalham com foco na geração de conhecimento, e têm no projeto sua unidade de organização de trabalho e produção.

A gestão dos projetos de PD\&I tem sido objeto de preocupação das organizações, em virtude da necessidade de compatibilizar objetivos estratégicos, recursos, assim como assegurar a ênfase no desenvolvimento de projetos prioritários, frente a crescentes e emergentes demandas da sociedade (Dendena, Ferreira, Guimarães, Castro \& Versiani, 2013). A gestão de pesquisa para a inovação exige que o gestor conduza diversos objetivos e variáveis operacionais próprias da organização, que influenciam no planejamento e nas decisões do projeto.

A literatura sobre gestão de projetos apresenta, de forma recorrente, a importância da figura do gestor no desempenho dos projetos, que é considerado como um dos principais agentes condicionantes de desempenho de projetos (Moraes \& Kruglianskasb, 2012; Jordão, Pelegrini, Jordão \& Jeunon, 2015; Oliveira, Alencar \& Costa, 2016; Rolstadas, Tommelein, Schiefloe \& Ballard, 2014). O exercício da liderança pelo gestor de projetos pode ser um dos fatores críticos de sucesso para o alcance das metas estabelecidas para o projeto, de forma a associá-lo à influência de seu comportamento, a sua motivação e suas habilidades.

As competências inerentes ao papel do gestor de projetos, com padrões de competências individuais foram identificadas em algumas das principais associações e institutos dedicados à área de Gestão de Projetos. Dentre os mais difundidos estão a linha base de competências (Competence Baseline), da International Project Management Association (IPMA) e o Project Manager Competency Development Framework (PMCDF), do Project Management Institute (PMI).

Outros autores abarcam CHAs do gestor de projetos e pautam seus estudos em indicadores de sucesso do projeto, e na necessidade de aprimoramento da capacidade de atuação de seus atores (Oliveira et al. 2016; Russo, Ruiz \& Cunha, 2005). Identificam a 
necessidade de desenvolvimento do conhecimento técnico de projetos, o conhecimento de resolução de problemas e o conhecimento de melhoria contínua.

A área de TD\&E abrange oportunidades de aprendizagem aos profissionais, visando a melhoria de seu desempenho (Borges-Andrade, 2006) tanto a nível individual, quanto de equipes (Aguinis \& Kraiger, 2009). As ações educacionais constituem em estratégias da empresa para garantir a manutenção da competitividade no mercado por meio do investimento na qualificação de pessoal e no desenvolvimento de competências aderentes aos objetivos organizacionais (Abbad, Zerbini \& Souza, 2010).

A etapa de ANT integra o sistema de TD\&E, e é nesta etapa que se identificam as lacunas dos repertórios dos CHAs disponíveis para determinados grupos e equipes profissionais, ou para o trabalho individual (Abbad, Freitas \& Pilati, 2006). A análise da literatura sobre ANT revela que a evolução na área de conhecimento avançou mais significativamente nos últimos anos, mas sua produção científica ainda necessita de atenção (Ferreira, 2009); aponta, também, que poucos estudos se dedicaram a propor modelos eficazes de predição sobre fatores que influenciam a necessidade de treinamento do indivíduo (Magalhães \& Borges-Andrade, 2001; Silva \& Meneses, 2012).

A presente pesquisa estuda a necessidade de desenvolvimento de líderes de projeto no contexto de organizações de PD\&I. A proposta é investigar esse contexto por meio da avaliação de necessidades de treinamento da clientela, e as variáveis que influenciam essa demanda (variáveis sociodemográficas e variáveis funcionais).

Nesse sentido, este estudo se propõe a contribuir com a compreensão de aspectos citados anteriormente, como a gestão dos projetos de PD\&I, com o avanço da ANT ao conduzir o processo de investigação para avaliar as necessidades de treinamento dos líderes de projeto, e compreender a relação das variáveis que integram as características da clientela (características sociodemográficas e funcionais) nessa demanda, no contexto de PD\&I.

Por meio desse estudo, pretende-se atingir os seguintes objetivos: construir o instrumento de competências de líderes de projeto; verificar evidências de validade do instrumento; identificar as lacunas de competências dos líderes de projeto; analisar o perfil da clientela de líderes de projeto da instituição-alvo; e identificar as variáveis que influenciam a aquisição de CHAs. 
Espera-se, ainda, fornecer subsídios para a instituição-alvo, no intuito de propiciar informações para o planejamento e desenvolvimento de programa de treinamento e capacitação mais efetivos, voltados a clientela-alvo da pesquisa.

Com o objetivo de facilitar o acompanhamento do texto, a Figura 1 demonstra a organização dos capítulos.

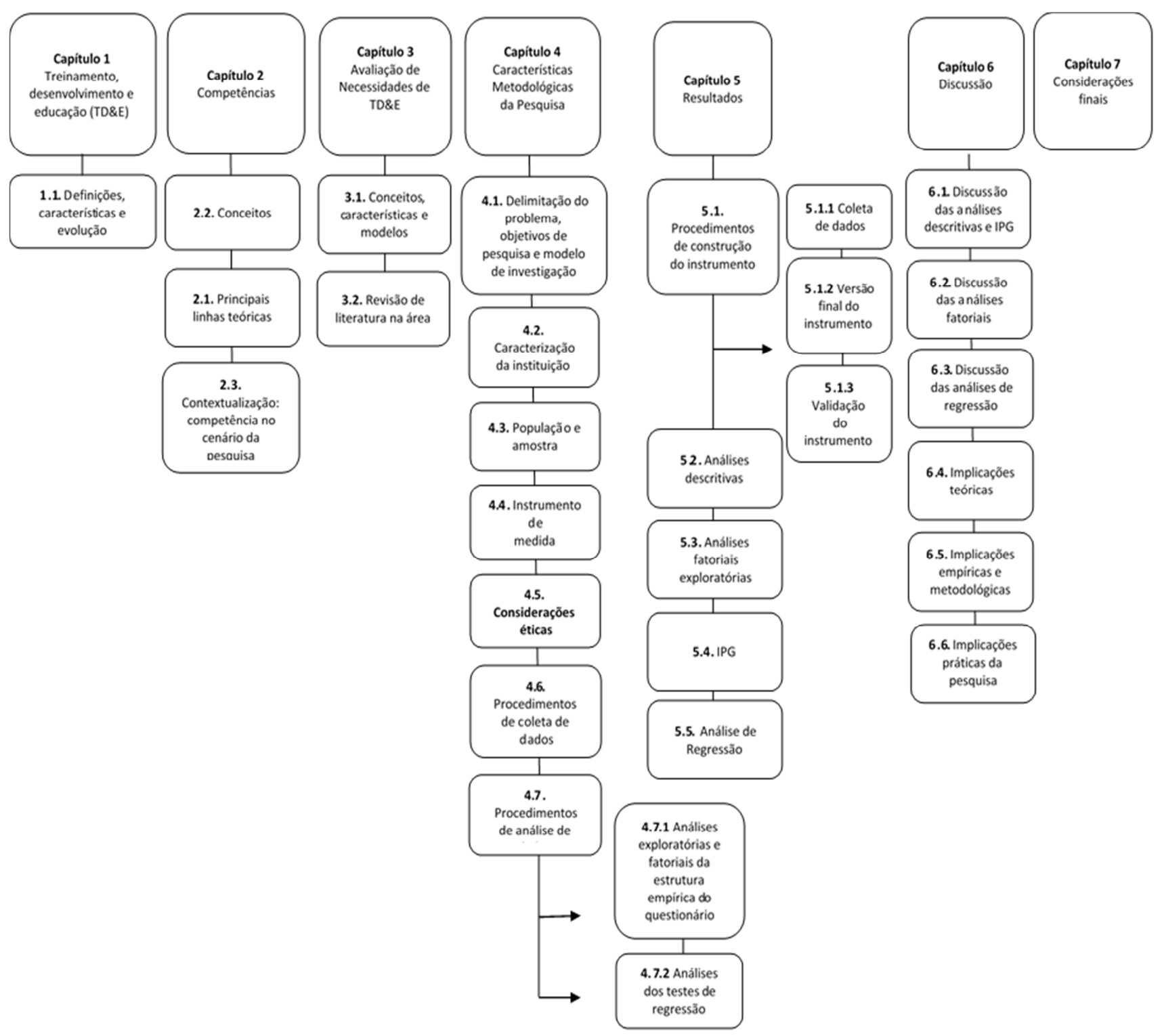

Figura 1 - Organização dos capítulos da dissertação. 
O Capítulo 1 dispõe sobre as características e os componentes do sistema de TD\&E, bem como a evolução dos estudos na área de conhecimento, campo desta pesquisa.

O Capítulo 2 trata das principais linhas teóricas e conceitos sobre competência, aprofundando para o cômputo da presente pesquisa. São abordados, desta forma, estudos em contextos de PD\&I para a clientela estudada - lideres/gestores de projetos.

A ANT é detalhada no capítulo 3, em suas características e modelos já propostos na literatura científica. Aborda, também, a evolução de estudos realizados no campo de pesquisa na área.

O detalhamento acerca do problema de pesquisa, justificativa, objetivo geral e objetivos específicos são expostos no capítulo 4, bem como são delimitadas as características da organização-alvo, a população e a amostra da pesquisa. Estão dispostos no capítulo, da mesma forma, o instrumento de medida utilizado, os cuidados éticos adotados no estudo e os procedimentos de coleta e análise estatística dos dados.

O capítulo 5 descreve os resultados da pesquisa, obtidos por meio dos procedimentos de construção do instrumento; resultados obtidos das análises descritivas, análises exploratórias fatoriais, cálculo do índice de IPG de treinamento, e análise de regressão.

Estão presentes no capítulo 6 as discussões tecidas entre os principais resultados desta pesquisa, os objetivos propostos, e os resultados obtidos em estudos apresentados na literatura.

No capítulo 7, por fim, são dispostas as conclusões obtidas neste estudo, além das principais contribuições e limitações identificadas, e a proposta de uma agenda de pesquisa para estudos futuros. 


\section{CAPÍTULO 1. TREINAMENTO, DESENVOLVIMENTO E EDUCAÇÃO}

\section{Objetivo do capítulo 1}

O presente capítulo tem como objetivo caracterizar o processo de aprendizagem induzida no trabalho - ações de treinamento e desenvolvimento. Nesse âmbito, trata das definições de TD\&E, os elementos que compõem seu subsistema, e os avanços obtidos na área de conhecimento.

\subsection{Definiçõos, características e evolução}

$\mathrm{O}$ investimento das organizações em ações de treinamento se relaciona à crescente necessidade de modelos competitivos de atuação no panorama socioeconômico e tecnológico. As mudanças no contexto promovem impactos internos às organizações, repercutindo na necessidade de fomentar respostas que garantam sua sustentabilidade, por meio de políticas de gestão estratégicas voltadas a seu corpo profissional. Portanto, torna-se relevante às organizações promover ações de aprimoramento, com foco no desenvolvimento de competências estratégicas, de forma a preparar profissionais capazes de mobilizar sua capacidade de produzir resultados de valor agregado (Meneses \& Zerbini, 2009; Silva et al., 2012).

Tradicionalmente desenvolvidas por meios formais de eventos ou sistemas instrucionais, as ações educacionais são realizadas, também, por meio de ações informais de aprendizagem, devido à necessidade de redução de custos por parte das organizações e, igualmente, pela demanda de celeridade de capacitação, maximizando resultados (Abbad \& Borges-Andrade, 2004; Junior \& Borges-Andrade, 2008; Salas \& Cannon-Bowers, 2001). Esse tipo de ação educacional tem ganhado espaço no cenário organizacional (Noe, Clarke \& Klein, 2013).

Treinamento pode ser entendido como o processo que facilita ao aprendizado do empregado, contribuindo ao desenvolvimento de desempenhos favoráveis ao alcance dos objetivos da organização (McGehee \& Thayer, 1999). Goldstein (2001) destaca no conceito a aquisição dos CHAs designada ao aperfeiçoamento da performance, aspecto corroborado por Ferdous e Razzak (2012) e Zanelli, Borges-Andrade e Bastos (2014). Estes últimos autores evidenciam a utilização de tecnologia instrucional para superar deficiências de desempenho 
no trabalho, preparar empregados para novas funções, adaptar a mão de obra para novas tecnologias, ou até mesmo promover o crescimento do pessoal da organização.

A identidade da grande área de conhecimento se consolidou em caráter mais abrangente em 1970, quando o termo treinamento passou-se a tratar a ideia de desenvolvimento proposta por Nadler (Vargas \& Abbad, 2006). A conceituação que envolve TD\&E faz menção à particularidade de cada elemento - treinamento, desenvolvimento e educação. Faz-se necessário, então, caracterizá-los separadamente: Treinamento é destinado a melhorar o desempenho enquanto no cargo atual; Desenvolvimento consiste em ações de aprendizagem planejadas e direcionadas para o crescimento pessoal do empregado sem, no entanto, estabelecer relação com o trabalho. Quanto à Educação, refere-se à oportunidade oferecida pela organização com o intuito de capacitar o empregado a atuar em um novo cargo. O que distingue os conceitos, desta forma, é a finalidade a que se dispõem (Abbad et al., 2004; Nadler, 1984; Sallorenzo, 2000).

Outros conceitos adjacentes, que envolvem ações de indução de aprendizagem, pertencem à esfera de TD\&E, tais como informação e instrução. Informação pode ser entendida por módulos ou unidades organizadas de conteúdo e instrução representa a organização sistemática de uma ação educacional realizada por planejadores instrucionais (Meneses, Zerbini \& Abbad, 2010; Vargas et al., 2006).

No intuito de vislumbrar a relação dos conceitos evidenciados, com base na abrangência de cada estrutura do conhecimento, Vargas et al. (2006) propuseram um diagrama englobando as ações de indução de aprendizagem. A Figura 2 demonstra essa proposta

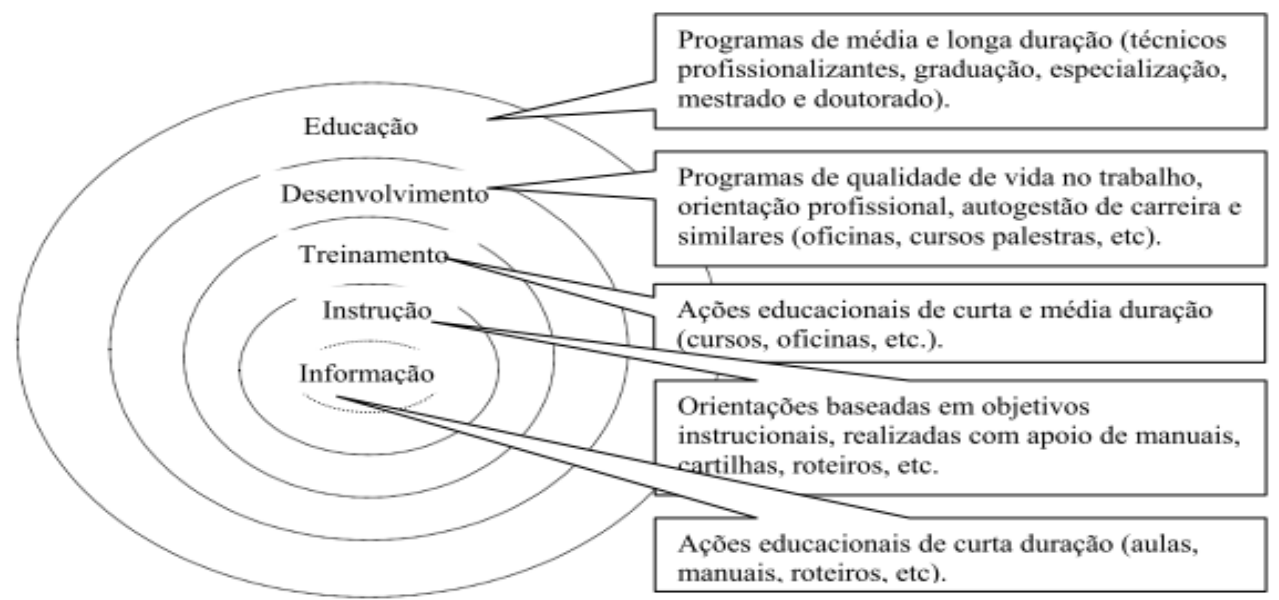

Figura 2. Relação entre conceitos e soluções educacionais (Fonte: Vargas et al., 2006). 
De acordo com as autoras, a proposta configura as ações de Educação com um nível de complexidade maior, em abrangência tanto para o crescimento profissional, tanto para o nível pessoal do indivíduo, constituindo, por exemplo, ações educacionais que visam a aprendizagem de longa duração. As ações de aprendizagem na esfera do Desenvolvimento, no caso, são voltadas ao apoio do crescimento pessoal sem, no entanto, utilizar estratégias da organização para direcionar o caminho profissional do indivíduo - tais como oficinas, palestras, ações para a orientação profissional, apresentando níveis de complexidade mais simples. Com relação aos outros elementos, a informação é organizada em conteúdos, os quais integram a instrução - estabelecimento de objetivos instrucionais - e execução de procedimentos de ensino, ao qual subsidia a sistematização do treinamento.

Como apresentado por Borges-Andrade (1996) TD\&E tem como referencial a abordagem sistêmica, que prevê a articulação e a retroalimentação de seus elementos componentes: insumos, processamentos e resultados. Desta forma, o subsistema de treinamento possui três etapas, interdependentes entre si, as quais compreendem a ANT; o planejamento e a execução; e a avaliação de TD\&E (Borges-Andrade, 2006; Borges-Andrade \& Abbad, 1996; Meneses, et al. 2010). A Figura 3 demonstra a composição do Sistema.

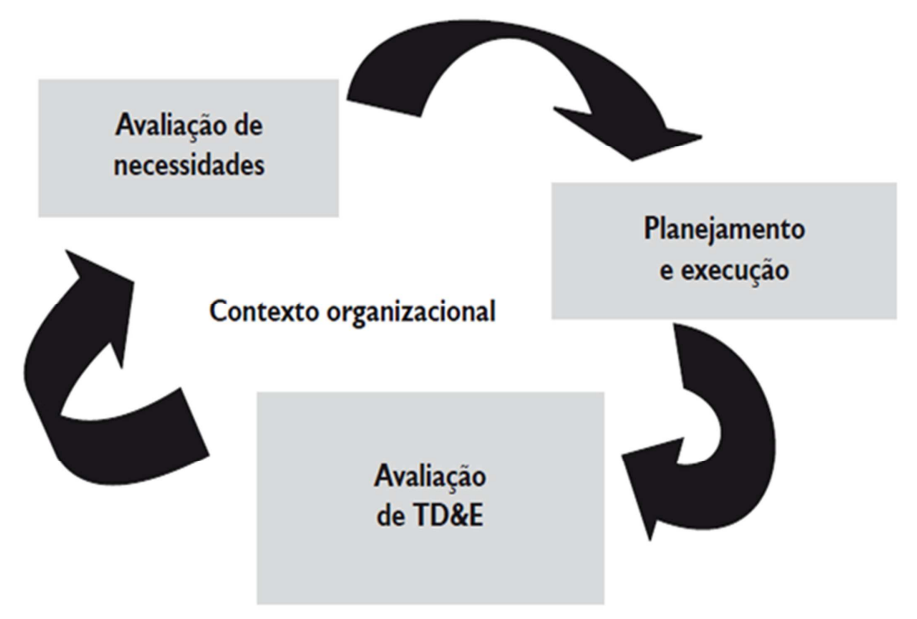

Figura 3. Sistema de treinamento (Fonte: Borges-Andrade, 2006).

A ANT pode ser definida como o levantamento sistemático de CHAs nos níveis organizacional, de tarefas e individual (Modelo O-T-P), por meio do diagnóstico das discrepâncias entre os desempenhos reais e aqueles esperados pela organização (Meneses et al., 2010; Pilati, 2006). Desta forma, é nesta etapa em que se identificam as lacunas de 
competências necessárias para cumprir os objetivos da organização; onde o potencial treinamento é necessário, qual conteúdo deve ser treinado, bem como quem deve participar do treinamento. $\mathrm{Na}$ análise organizacional, o enfoque é abrangente, cujo processo enfatiza o alinhamento do treinamento com a estratégia da organização; já a análise de tarefas enfoca os processos de trabalho, por meio do mapeamento dos conjuntos de CHAs necessários para o desempenho da tarefa; e a análise individual é dedicada à identificação das necessidades dos CHAs nos indivíduos, para que possam aprimorar o desempenho de seu trabalho (Meneses et al. 2010). O Modelo O-T-P, proposto por McGehee e Thayer ainda em 1961, continua atual.

A etapa de Planejamento e Execução consiste na definição de objetivos e conteúdos, da sequência de ensino, de meios e estratégias instrucionais adequados ao alcance dos objetivos do curso. Segundo os mesmos autores citados, para o cumprimento desta etapa, algumas ações devem ser tomadas: definição de objetivos instrucionais; seleção da modalidade de entrega; análise, classificação, e ordenação dos objetivos instrucionais; seleção de estratégias e meios instrucionais; definição de critérios de aprendizagem; desenvolvimento e validação de materiais instrucionais; e, enfim, execução da ação educacional.

A Avaliação de Treinamento subsidia o sistema de TD\&E sobre lacunas de aprendizagem, questões acerca do tutor, estratégias de ensino, do planejamento, da aplicabilidade das habilidades aprendidas no contexto do trabalho, além de informações sobre quais os aspectos que facilitam esse processo. Aguinis et al. (2009) evidenciam que os resultados obtidos nesta etapa maximizam os benefícios do treinamento, e os mantém documentados, promovendo assim informações para a organização sobre o investimento nas ações educacionais. O modelo clássico de avaliação de treinamento foi proposto por Kirkpatrick (1976), e é estruturado em quatro níveis de avaliação: reação, aprendizagem, comportamento e resultados. Esse modelo, mais tradicional, foi concebido envolvendo variáveis de resultados de treinamento. Analogamente, outros modelos surgiram, com a mesma natureza e poucas variações.

Ampliando a ótica analítica do processo de avaliação do treinamento, Goldstein (1991) e Tannenbaum e Yukl (1992) criticaram os modelos clássicos, concluindo que, para a transferência para o trabalho do conhecimento e das habilidades adquiridas no treinamento, é necessário considerar outros fatores no processo. Desta forma, outros modelos de avaliação foram propostos, considerando variáveis do ambiente e relacionadas às características da clientela (Meneses et al, 2010). 
A evolução da área do conhecimento de TD\&E pode ser observada por meio de revisões de literatura de grandes autores, que discorreram estudos realizados à época. No que se refere à ANT, Campbell (1971), relatou a prática de técnicas de incidentes críticos para identificar necessidades de capacitação à época. Outro aspecto pontuado pelo autor foram as novas propostas de modelos por especificação do desempenho, em nível de tarefas. Wexley (1984) também identificou avanços significativos na metodologia de análise de tarefas, especificamente pela análise de conteúdo, na qual diferentes especialistas julgariam a importância dos CHAs para o desempenho profissional. No que tange a análise individual, o autor relatou uma abordagem para gestores que destacava comportamentos observáveis, com a utilização da técnica de incidentes críticos, com o emprego de heteroavaliação. Foi reconhecida pelo autor a importância da multiplicidade das fontes de informação para ANT. Na revisão de Tannenbaum et al. (1992), foi constatada que a ideia original da análise organizacional, de prover informação sobre quando e onde o treinamento era necessário na organização, deu lugar a um novo conceito: a análise da influência dos programas de treinamento na mudança de comportamento no trabalho. Com relação às análises individuais, evidenciaram que podem contribuir como recurso na identificação de pré-requisitos necessários para garantir o benefício do treinamento (atitude, conhecimento e motivação). Como exemplo, indivíduos que não têm habilidades básicas ou motivação antes do treinamento têm menos probabilidade de obter sucesso e podem exigir preparação antes de entrar em um programa de treinamento. Em revisão conduzida por Salas et al. (2001) foi apresentada uma nova perspectiva da análise de tarefas: a análise cognitiva de tarefas conjunto de procedimentos para entender o processo mental e seus requisitos para o desempenho de um trabalho.

De acordo com autores clássicos, alguns eventos que ocorrem antes do treinamento podem ter influência importante sobre seus resultados. Dentre as características individuais que podem influenciar o processo de aprendizagem no treinamento, cita-se treinabilidade, capacidade cognitiva, autoeficácia, motivação, atitudes e expectativas.

A teoria motivacional, identificada como característica individual do treinando, foi descrita por Campbell (1971) em sua revisão. Estudos sugeriram que o efeito do reforço no aprendizado pode ser imediato por um processo de estabelecimento de objetivos - quanto mais desafiante o objetivo, mais chance de sucesso. 
Wexley (1984), em sua revisão sobre o tema, abordou a motivação, associando a ela o conceito de treinabilidade. Tannenbaum et al. (1992) apresentaram estudos que registraram o uso da estrutura da expectância para o estudo da motivação no treinamento. Os resultados demonstraram que treinandos com altos índices de motivação para o treinamento mostraram melhor aprendizado e índices mais positivos de reação ao curso. Outra pesquisa relatada pelo autor trouxe o construto de auto-eficácia, que se refere à auto declaração da crença na habilidade de desempenhar determinada tarefa. Afirma, ainda, que poderia ser um preditor do sucesso do treinamento.

No que diz respeito ao planejamento, deva-se levar em conta os objetivos de aprendizagem, as características dos treinandos, conhecimentos sobre os processos de aprendizagem, e considerações práticas, tais quais restrições e relação custo-benefício, segundo Tannenbaum et al. (1992). Campbell (1971) já citava a importância da relação das diferenças individuais e o processo de aprendizagem: são importantes para compreender o processo diferenciado de aprendizagem dos indivíduos.

Mais especificamente, Campbell (1971) citou a utilização da taxonomia para processos de aprendizagem. Em seus relatos, o mesmo revisor também descreve diversas técnicas de treinamento identificadas durante o período por ele estudado: formação no local de trabalho, rotação de funções, palestras, conferências, seminários, simulação, programação instrucional, treinamentos formais, programas de treinamento interno. Outra abordagem trazida pelo autor é a instrução assistida pelo computador, que possibilita interação com o aprendiz, com modo de resolução de problemas e tutorial. Diversos métodos também foram citados, como Grid de Gestão, televisão e outros.

Wexley (1984) abordou o modelo behaviorista como método de treinamento, que incorporou conceitos da teoria da aprendizagem social: modelagem, simulação, reforço social e transferência positiva de aprendizagem. Resultados de estudos mostraram que a modelagem do comportamento pode ser um efetivo dispositivo de treinamentos, apesar de haver sugestões de outras pesquisas.

No mesmo período, foram identificadas, ainda, algumas pesquisas conduzidas acerca de instrução por computador, realizadas com a força aérea, outras com escolas navais, e com pessoal de bordo. Concluíram que o tempo gasto com o computador foi menor do que com o método convencional de ensino, se utilizado o mesmo material didático, sem diferenças significativas entre as notas dos treinandos nos dois métodos. As novas tendências 
metodológicas na área de treinamento foram corroboradas por Salas et al. (2001), em sua revisão, que relataram que os treinamentos na época utilizavam videoconferências, vídeos e cursos online, com a utilização da internet ou a intranet.

Após introdução das estratégias e implementação de sistemas instrucionais, a avaliação do treinamento tornou-se uma prática fundamental para garantir a efetividade da ação educacional. O modelo de avaliação de Kirkpatrick (1976) se manteve predominante durante muitas décadas, abrangendo quatro níveis para a efetividade de treinamento: reação, aprendizagem, comportamento e resultados organizacionais. O critério mais comumente utilizado é o de reação (Campbell, 1971; Salas et al., 2001; Tannenbaum et al., 1992).

Considerando a influência das condições pós-treinamento na aplicação dos conhecimentos aprendidos e seu impacto nos resultados do treinamento, Salas et al. (2001) e Tannenbaum et al. (1992) afirmam que a efetividade de um programa de treinamento pode ser influenciada pelo ambiente pós-curso. As pesquisas passam a centrar esforços para aperfeiçoar métodos e procedimentos capazes de avaliar os treinamentos e analisar os eventos que asseguram a transferência e aplicação dos recentes CHAs adquiridos (Salas et al., 2001).

O estado técnico-científico que caracteriza a área de conhecimento atual sobre TD\&E demonstra que o processo tem atravessado diversas transformações. A natureza da tarefa mudou, em termos de complexidade, o que provoca no profissional a necessidade de se preparar para trabalhos mais dinâmicos. Os avanços tecnológicos permitem também o aprendizado a qualquer tempo em qualquer lugar. A área de conhecimento não é tida apenas como um veículo para aumentar a capacidade individual, mas também um meio de garantir a efetividade da equipe e a vantagem competitiva da organização no mercado (Bell, Tannenbaum, Ford, Noe, \& Kraiger, 2017).

Aponta-se, no entanto, algumas limitações no tocante aos processos de TD\&E, como a lacuna de avaliações sistemáticas de necessidades de treinamento. Esse aspecto acaba por prejudicar a efetividade do treinamento e o alinhamento as estratégias organizacionais, já que a etapa é essencial para garanti-los. Evidenciam-se, também, poucos esforços voltados à avaliação de aprendizagem e ao investimento no planejamento instrucional de cursos presenciais e a distância (Abbad, Carvalho \& Zerbini, 2006; Abbad et al., 2003; Meneses et al., 2010).

Este estudo pretende identificar as variáveis preditoras das necessidades de treinamento para um grupo de profissionais integrantes da organização campo de estudo, 
fundamental para fornecer subsídios ao planejamento de ações educacionais adequadas à clientela alvo, colaborando para o alinhamento estratégico, a efetividade de TD\&E e a então potencialização de seus recursos. 


\section{CAPÍTULO 2. COMPETÊNCIAS}

\section{Objetivos do capítulo 2}

Neste capítulo apresentam-se as principais vertentes teóricas da competência no contexto histórico, bem como uma análise de diversos conceitos utilizados por autores interessados no tema. São ilustrados, ainda, alguns estudos desenvolvidos na identificação e no mapeamento de competências de gestores de projeto, clientela-alvo deste estudo.

\subsection{Principais linhas teóricas}

A economia baseada no conhecimento institui, no contexto do trabalho, a competência de seus profissionais como principal recurso para o diferencial de atuação. A aquisição e desenvolvimento de competências tornou-se um componente essencial das estratégias organizacionais, já que podem ser utilizadas para traduzir sua essência em questões relacionadas ao trabalho e ao indivíduo, de forma a facilitar seu entendimento e implementação (Chouhan \& Srivastava, 2014).

O estudo da competência tem interessado a diversas áreas do conhecimento, tais como a sociologia da educação, a administração estratégica e a gestão de pessoas (Campos \& Abbad, 2014). Para a sociologia, o enfoque recai sobre a análise de competências relevantes à sociedade; para a administração, a abordagem é direcionada à relação da competência com a estratégia da organização; e a gestão de pessoas enfatiza a análise no nível do indivíduo e das equipes de trabalho, além das relações entre competência e aprendizagem e pelo estudo dos processos pelos quais o indivíduo adquire ou desenvolve a competência (Abbad, Loiola, Zerbini, \& Borges-Andrade, 2013).

O foco deste trabalho advém da análise da competência a nível micro, com foco no indivíduo, considerando o componente de aquisição e desenvolvimento de competências, campo de investigação utilizado no processo de análise de necessidades de treinamento em TD\&E.

A dimensão individual remonta ao primeiro debate iniciado por McClelland, em 1973. $\mathrm{O}$ autor conceituou competência do indivíduo como uma característica subjacente a uma pessoa que pode ser relacionada com desempenho superior na realização de uma tarefa ou em determinada situação (Fleury \& Fleury, 2004). Essas características são aptidões (talento 
natural, passível de aprimoramento), habilidades (aplicação prática de um talento) e conhecimento (o saber necessário para realizar algo). O trabalho de McClelland assinalou o início da evolução da utilização do conceito de competência no âmbito profissional (Brandão, 2012; Fleury \& Fleury, 2001; Stevens, 2012).

De acordo com Fleury et al. (2001), estudos desenvolvidos por Boyatzis (1982), na mesma linha de McClelland, conduziram à elaboração de um modelo de competências utilizado para avaliação e desenvolvimento de gestores, que contemplava uma lista de qualificações e características relacionadas a função de gestão e a características do ambiente interno.

Em uma contribuição do conceito ligado a desempenho, Gilbert (1978) definiu competência em um aspecto mais vasto de melhoria de desempenho em nível individual, organizacional e social. Estudos realizados por ZemKe (1982) e Dubois (1993) aplicaram o conceito de competência à educação e formação de profissionais, com interesse na linha comportamental de teóricos como Skinner (1968) e Mager (1984), e trabalhos de Maslow (1954). O conceito de competências foi associado, ainda, a estratégia empresarial por trabalhos como o de Prahalad e Hamel (1990), que introduziu o conceito de competências essenciais (core competences), e o sistema de gestão por competências, de acordo com Rosa, Cortivo e Godoi (2006).

A pesquisa no tema foi consolidada na Europa com a publicação do trabalho de Zarifian, em 1999 (Brandão, 2012 apud Silva, 2016). Zarifian (2001) apresentou, em seus estudos, alguns conceitos para o conteúdo do trabalho, essenciais à concepção de competência. Dentre eles, o conceito de evento: o que ocorre de maneira imprevista no sistema de produção. Para o autor, competência consiste em um entendimento prático de situações que se apoiam em conhecimentos adquiridos e os transforma à medida que aumenta a diversidade de situações. A noção de evento passa a ser o centro da lógica da competência consiste em um comportamento social frente a situações inesperadas, não prescritas pelo cargo. A abordagem do autor associa competência aos saberes, com ênfase na iniciativa do indivíduo, e capacidade de agir nas diversas situações e de mobilizar outras pessoas, demonstrando suas competências.

Em uma visão análoga do conceito, Le Boterf (2003) evidencia que o indivíduo pode buscar complementos para os seus recursos pessoais em aspectos ligados ao meio, caso não possua o conhecimento adequado para realizar a ação competente. Sob este aspecto, a 
competência incide em saber associar esses recursos para produzir uma ação competente. Considerando o enfoque reverenciado pelo autor, competência pode ser entendida como a combinação de recursos pessoais, tais como conhecimentos, habilidades, qualidades, experiências, capacidades cognitivas, recursos emocionais, e outros; e recursos pertencentes ao meio, tais como tecnologias, banco de dados, livros, relacionamentos.

Observa-se que, desde o trabalho desenvolvido por McClelland (1973), frente à diversidade de campos de pesquisa no domínio da competência, o conceito foi sofrendo variações ao longo do tempo por estudos de autores expoentes como Boyatzis (1982), Zarifian (2001) e LeBortef (2003). Basicamente, duas escolas teóricas se formaram em torno do tema: a norte-americana e a francesa (Dutra, 2004).

A escola representada pelos autores norte-americanos, tendo como precursores McClelland e Boyatzis entende competência como o conjunto de qualificações ou características subjacentes a pessoa - conhecimentos, habilidades e atitudes (Brandão, BorgesAndrade, Freitas \& Vieira, 2010), responsáveis por um desempenho superior, considerando conhecimentos como um corpo organizado de informações de natureza técnica ou administrativa; habilidades como capacidade de desempenhar operações de trabalho, incluindo comportamentos motores ou verbais; e atitudes como predisposições favoráveis (ou não) em relação a um objeto, pessoa, fato ou sobre a organização (Magalhães et al., 2001). Nesta abordagem, a competência representa um estoque de recursos que torna o indivíduo apto a realizar um trabalho (Campos et al., 2014).

Para a corrente francesa, constituída por autores como Zarifian (2001) e LeBortef (2003), o entendimento do conceito de competência reside na capacidade de realizar algo no contexto de trabalho de forma a obter sucesso, evidenciando o aspecto do desempenho na prática da competência (Brandão, 2009; Fleury et al., 2001; Oderich, 2005). A compreensão abrange a mobilização do repertório do indivíduo, articulado com o intento organizacional, para produzir resultados e agregar valor ao patrimônio da organização (Brandão \& Guimarães, 2001; Fleury, 2000). Esta vertente trata a competência como a entrega para a organização, considerando aquilo que ele produz no trabalho, e não seus atributos ou qualificações (Brandão et al., 2010).

Uma terceira perspectiva para a definição de competência, em uma visão integradora das concepções defendidas pelas correntes americana e francesa, relaciona atributos pessoais ao contexto em que são utilizados, isto é, ao desempenho da pessoa no trabalho (Brandão et 
al., 2010; Gonczi; 1999; Santos \& Borges-Andrade, 2012). Sob essa perspectiva, a competência consiste não somente no conjunto de CHAs necessários ao desenvolvimento do trabalho; envolve, ainda, o desempenho do indivíduo no contexto de trabalho, considerando comportamento e realizações decorrentes (Carbone, Brandão, Leite \& Vilhena, 2005). Desta forma, esta concepção consiste na inter-relação de CHAs, manifestas por meio do desempenho profissional em contexto organizacional, de forma a agregar valor ao indivíduo e ao negócio (Brandão \& Borges-Andrade, 2008). Esta linha teórica é a mais defendida e utilizada no Brasil (Brandão, 2009; Oderich, 2005).

A Tabela 1 resume as grandes linhas teóricas no domínio da competência.

Tabela 1- Correntes teóricas na concepção de competência.

\begin{tabular}{ccc}
\hline Principais autores & Concepção & Corrente teórica \\
MacClelland (1973) e Boyatzis & Conjunto de qualificações ou características & Americana \\
(1982) & de um profissional (conhecimentos, \\
habilidades e atitudes) que permitem a & (ênfase em atributos \\
realização de um determinado trabalho. & pessoais) \\
Le Boterf (2003), & Capacidade de combinar e mobilizar & Francesa \\
Zarifian (2001) & adequadamente os recursos já desenvolvidos & (ênfase no desempenho \\
& entregue e no contexto) \\
& Combinação sinérgica de atributos & \\
& individuais (conhecimentos, habilidades e & Integradora \\
& atitudes) expressas pelo desempenho & (ênfase em atributos \\
& profissional no contexto organizacional, que & pessoais, no desempenho \\
& entregue e no contexto)
\end{tabular}

Fonte: Elaborada pela autora com base na literatura.

Paralelamente à dimensão teórica da competência, o conceito não tem encontrado consenso entre os pesquisadores do tema (Stevens, 2012; Succar, Sher \& Williams, 2013). A seguir serão revisitadas propostas por alguns autores, concepções de competências no nível individual, cujas manifestações se dão no ambiente de trabalho. 


\subsection{Conceitos}

O termo competência tem sido abordado em campos distintos de estudo, orientado a diversas aplicações e correntes e, da mesma forma, na perspectiva conceitual, tem assumido várias definições na literatura especializada.

Essa pluralidade conceitual e fragmentação teórica têm sido abordadas na produção científica, com o intuito de facilitar a compreensão das diferenças e convergências de utilização do conceito (Brito, Paiva \& Leone, 2012; Campos, 2015; Stevens, 2012; Succar et al., 2013).

Campos (2015) realizou uma análise de utilização do conceito na literatura científica especializada, considerando trabalhos voltados às competências individuais e manifestas no contexto do trabalho. A Tabela 2 ilustra as definições identificadas nesse trabalho, destacando sua dimensão conceitual.

Tabela 2 - Definições de competência segundo análise de Campos (2015).

\begin{tabular}{ll}
\hline Autor & Definição \\
\hline Amaro (2008) & $\begin{array}{l}\text { Competência profissional é entendida como os conhecimentos, as } \\
\text { habilidades e as atitudes que são mobilizados pelos trabalhadores para a } \\
\text { realização de uma ação específica. }\end{array}$ \\
Abbad e Borges-Andrade & $\begin{array}{l}\text { Competência é uma combinação de conhecimentos, habilidades e atitudes } \\
\text { (CHAs) que um indivíduo mobiliza para alcançar um determinado propósito }\end{array}$ \\
& $\begin{array}{l}\text { no trabalho. } \\
\text { Araújo (2009) }\end{array}$ \\
& $\begin{array}{l}\text { Competência refere-se ao conjunto de conhecimentos, habilidades e atitudes } \\
\text { (isto é, conjunto de capacidades humanas) que justificam um alto } \\
\text { desempenho, acreditando-se que os melhores desempenhos estão } \\
\text { fundamentados na inteligência humana e na personalidade das pessoas. }\end{array}$
\end{tabular}

Ansorena Cao (1996, como citado em Trujillo, 2000)

Boyatzis (1982)

Brophy e Kiely (2002)
Competência é uma habilidade ou atributo pessoal da conduta do sujeito, que se pode definir como característica de seu comportamento, e, sob as quais, o comportamento orientado para a tarefa pode se classificar de forma lógica e confiável.

Competência é uma característica subjacente de um indivíduo (que pode ser um motivo, traço, habilidade, aspecto de sua autoimagem, papel social, ou conjunto de conhecimentos) causalmente relacionados a efetividade e/ou desempenho superior no trabalho.

Competências são habilidades, conhecimentos, comportamentos e atitudes requeridas para desempenhar um papel de forma efetiva. 
Tabela 2 - Definições de competência segundo análise de Campos (2015) (cont.).

Autor

Burnett e Dutsch (2006)

Brandão e

BorgesAndrade (2007)

Boog (1991, como citado em Campos et al., 2008)

Bergenhenegouwen (1996)

Cheetam e Chivers, (2005, como citado em De Coi et al., 2007)

Carbone, Brandão, Leite, e Vilhena, (2005, como citado em Mutti, 2008)

Durrand (1998)

Dutra, Hipólito e Silva (2000)

Ducci (1996)

Fleury e Fleury (2001)

Freitas e Brandão (2006)

Gomes (2003, como citado em Freire, 2010) Definição

Competência se refere a características subjacentes a um indivíduo relacionadas ao trabalho (ex: habilidades, conhecimentos, atitudes, crenças, motivos e traços) que o possibilitam um desempenho bem-sucedido no trabalho, em que "bem-sucedido" é entendido como estando em consonância com as funções estratégicas da organização (ex: visão, missão, singularidade, orientação para o futuro, sucesso ou sobrevivência).

Competência representa um conjunto de conhecimentos, habilidades e atitudes necessários para exercer certa atividade e, também o desempenho expresso pelo indivíduo em termos de comportamentos adotados no trabalho e realizações decorrentes.

O conceito de competência está ligado à qualidade de quem é capaz de apreciar e resolver certo assunto, fazer determinada coisa; significa capacidade, habilidade, aptidão e idoneidade.

Competências individuais dizem respeito a características fundamentais da personalidade que são inerentes às ações das pessoas em relação a todos os tipos de tarefas e situações; especialidades e habilidades; motivos e qualidades.

Competência é o desempenho efetivo dentro de um domínio/contexto em diferentes níveis de proficiência.

Competências são combinações sinérgicas de conhecimentos, habilidades e atitudes, expressas pelo desempenho profissional dentro de determinado contexto organizacional, que agregam valor às pessoas e às organizações.

Competência diz respeito ao conjunto de conhecimentos, habilidades e atitudes interdependentes e necessárias à consecução de determinado propósito, dentro de um contexto organizacional específico.

Competência é a capacidade da pessoa em gerar resultados dentro dos objetivos estratégicos e organizacionais da empresa.

A competência é mais do que a soma de todos esses componentes (conhecimentos, habilidades, destrezas e atitudes): é uma síntese que resulta de combinação, interação e prática de tais componentes em uma situação real, enfatizando o resultado e não o insumo.

Competência é definida como um saber agir responsável e reconhecido, que implica mobilizar, integrar, transferir conhecimentos, recursos, habilidades, que agreguem valor econômico à organização, e valor social ao indivíduo.

Competências podem ser entendidas como combinações sinérgicas de conhecimentos, habilidades e atitudes, expressas pelo desempenho profissional dentro de um contexto organizacional, que agregam valor a pessoas e organizações.

Competência é constituída de várias habilidades articuladas e direcionadas à ação solucionadora, em uma determinada situação. 
Tabela 2 - Definições de competência segundo análise de Campos (2015) (cont.).

\section{Autor}

Gilbert (1978, como

citado em Brandão, 2009)

Hoffmann (1999)

Haerem (1998)

Lawler III (1994)

Le Boterf (1994, como citado em Fleury e Fleury (2001)

Le Boterf (1999 como citado em Brandão, 2006)

Le Boterf (2003)

McClelland e Dailey (1972, como citado em Kilimnik \& Sant ${ }^{\text {ee Anna, }}$ 2006)

Mirabile (1997)

McLagan (1997)

Murray (2003) Definição

Competência é expressa em função do desempenho ou comportamento da pessoa no trabalho.

Competências são definidas como desempenho observável, padrão ou qualidade do resultado do desempenho da pessoa, e os atributos subjacentes a uma pessoa.

Competência é a habilidade e a vontade de transformar conhecimento em resultados práticos.

Competências são características demonstráveis de um indivíduo, que incluem conhecimentos, habilidades e comportamentos ligados diretamente com o desempenho.

Competência é um saber agir responsável e que é reconhecido pelos outros. Implica saber como mobilizar, integrar e transferir os conhecimentos, recursos e habilidades, num contexto profissional determinado. A competência não reside nos recursos (saberes, conhecimentos, capacidades, habilidades) a serem mobilizados, mas na própria mobilização desses recursos.

A competência da pessoa é decorrente da aplicação conjunta, no trabalho, de conhecimentos, habilidades e atitudes (saber, saber-fazer, saber-ser). São manifestadas em ações ou comportamentos executados em determinadas atividades ou tarefas.

A competência é uma ação ou um conjunto de ações finalizado sobre uma utilidade, sobre uma finalidade que tem um sentido para o profissional que terão um impacto sobre os desempenhos realizados. Para que haja competência, é preciso que haja colocação em jogo de um repertório de recursos (conhecimentos, capacidades cognitivas, capacidades relacionais, etc.).

Competência é um conjunto de características individuais observáveis, como conhecimentos, habilidades, objetivos e valores, capazes de predizer e/ou causar um desempenho efetivo ou superior no trabalho ou em outras situações da vida.

Competências são conhecimentos, habilidades, capacidade ou característica associada com alto desempenho no trabalho, como resolução de problema, pensamento analítico ou liderança.

Uma competência é o agrupamento de conhecimentos, habilidades e atitudes inter-relacionados que se correlacionam com a efetividade do desempenho no trabalho, que pode ser medido e avaliado, e que pode ser aperfeiçoado através de treinamento e desenvolvimento.

As competências pessoais englobam atributos, habilidades e comportamentos de pessoas para desempenhar uma função ou tarefa de um trabalho em sentido designado, mas superior. 
Tabela 2 - Definições de competência segundo análise de Campos (2015) (cont.).

\section{Autor}

Nisembaum (2000, como citado em Bruno-Faria e Brandão, 2003)

Nordhaug (1998, como citado em Lima \& Borges-Andrade, 2006) Parry (1996)

Perrenoud (2001, como citado em Kilimnik, Sant ${ }^{e ` A n n a, ~ \& ~ L u z, ~ 2004) ~}$

Perrenoud (1997)

Perrenoud (2002)

Ruas et al. (2005)

Rodríguez \& Feliú (1996, como citado em Trujillo, 2000)

Rabaglio (2001, como citado em Campos et al., 2008)

Ruas (1999, como citado em Porto, 2001)

Sparrow (1997, como citado em Vakola, Soderquist \& Prastacos, 2007)

Spencer e Spencer (1993)

Sparrow e Bognanno (1994, como citado em Brandão \& Guimarães, 2001)

\section{Definição}

Competências representam combinações sinérgicas de conhecimentos, habilidades e atitudes, expressas pelo desempenho profissional, dentro de determinado contexto organizacional.

Competência é o composto de conhecimentos, habilidades e atitudes humanas que podem servir a propósitos produtivos em organizações.

Competências são um agrupamento de conhecimentos, habilidades e atitudes (CHA) que afeta a maior parte do trabalho de uma pessoa (um papel ou responsabilidade), que se correlacionam com desempenho no trabalho, que podem ser mensuradas considerando padrões bem aceitos, e que possam ser melhoradas através de treinamento e desenvolvimento.

Competência é a capacidade de um indivíduo de mobilizar o todo ou parte de seus recursos cognitivos e afetivos para enfrentar situações complexas, o que exige a conceituação precisa desses recursos, das relações que devem ser estabelecidas entre eles e da natureza do "saber mobilizar".

Competência é uma capacidade de agir eficazmente em um determinado tipo de situação, apoiada em conhecimentos, mas sem limitar-se a eles.

A competência é uma aptidão para dominar um conjunto de situações e de processos complexos agindo com discernimento.

Competência é a capacidade de mobilizar, integrar e colocar em ação conhecimentos, habilidades e formas de atuar do indivíduo com a finalidade de atingir e/ou superar desempenhos esperados pela organização.

Competências são conjuntos de conhecimentos, habilidades, disposições e condutas que possui uma pessoa, e que a permite a realização exitosa de uma atividade.

Competência envolve um conjunto de conhecimentos, habilidades e comportamentos que o indivíduo precisa desempenhar com eficácia para determinadas tarefas e em qualquer situação.

Competência é a capacidade de mobilizar e aplicar conhecimentos e capacidades numa condição particular, aonde se colocam recursos e restrições próprias à situação específica.

Competência é o repertório comportamental das pessoas, isto é, seus conjuntos de padrões comportamentais que se relacionam com o desempenho no trabalho e distingue desempenho excelente de mediano.

Competências são características subjacentes ao indivíduo que se relacionam causalmente a um padrão de eficácia e/ou a um desempenho superior em um trabalho ou situação.

Competências representam atitudes identificadas como relevantes para a obtenção de alto desempenho em um trabalho específico ao longo de uma carreira profissional ou no contexto de uma estratégia corporativa. 
Tabela 2 - Definições de competência segundo análise de Campos (2015) (cont.).

Autor

Sant ${ }^{e c}$ Anna (2002)

Sargis (2000, como citado em Miranda, 2004)

Stuart e Lindsay (1997)

Swieringa e Wierdsma (1995, como citado em Porto, 2001)

Sveiby (1998, como citado em Okimoto, 2004)

Tejada Fernández (1999)

Trujillo (2000)

Vakola, Soderquist e Prastacos (2007)

Vasconcelos, Cavalcante e Monte (2011)

Wynne e Stringer (1997, como citado em Brophy \& Kiely, 2002)

\section{Definição}

Competência é a resultante da combinação de múltiplos saberes: saber-fazer, saber-agir, saber-ser - capazes de propiciarem respostas com bom êxito, por parte dos indivíduos, aos desafios advindos dos processos de reestruturação e modernização produtiva em voga.

Competência é a capacidade de mobilizar um conjunto de recursos com o objetivo de realizar uma atividade.

Competência é uma declaração de valor atribuído a outro dentro de uma organização em particular; o valor que é colocado em um gerente que é capaz de desempenhar e "ser" de maneira que são altamente valorizadas e exigidas pela organização.

Competência se refere não só ao que as pessoas sabem e compreendem, mas também pelo que podem fazer (capacidades), o que tem vontade de fazer e o que são (personalidade e atitudes).

A competência de um indivíduo é formada por cinco elementos mutuamente dependentes: o conhecimento explícito, habilidades, experiências, julgamentos de valor e rede social.

Competência refere-se a funções, tarefas e atuação de um profissional; incumbência para desenvolver, adequada e idoneamente, suas funções de trabalho; suficiência, que é resultado e objetivo de um processo de capacitação e qualificação.

Uma competência é o que faz com que a pessoa seja competente para realizar um trabalho ou uma atividade, exitosos por si mesmos, o que pode significar a conjugação de conhecimentos, habilidades, disposições e condutas específicas. Se falha algum destes aspectos, e os mesmos se requerem para alcançar algo, já não é mais competente.

Uma competência individual relacionada ao trabalho é o conjunto subjacente de padrões de comportamento de um empregado relacionados a efetividade e/ou ao desempenho superior no trabalho, atuando tanto no nível individual quanto coletivo (efetividade/ desempenho superior ambos no trabalho solitário e no interpessoal), e que proporcionam à organização em que são implementadas e aplicadas, vantagens competitivas sustentáveis.

Uma competência pode ser entendida como o conjunto de conhecimentos, habilidades e atitudes que contribuem para que haja resposta adequada às demandas do trabalho que um indivíduo exerce.

Competências são coisas que as pessoas têm que ser, saber e fazer, para alcançar os resultados requeridos no seu trabalho. 
Tabela 2 - Definições de competência segundo análise de Campos (2015) (cont.).

\begin{tabular}{ll}
\hline Autor & Definição \\
\hline Zarifian (2008) & $\begin{array}{l}\text { A competência é "o tomar iniciativa" e o "assumir responsabilidade" do } \\
\text { indivíduo diante de situações profissionais com as quais se depara. A } \\
\text { competência é um entendimento prático de situações que se apoia em } \\
\text { conhecimentos adquiridos e os transforma na medida em que aumenta a } \\
\text { diversidade das situações. }\end{array}$ \\
$\begin{array}{ll}\text { Zarifian (1996, como } \\
\text { citado em Lima e Borges- } \\
\text { Andrade (2006) }\end{array}$ & $\begin{array}{l}\text { Competência é assumir responsabilidades frente a situações laborais } \\
\text { ao profissional lidar com eventos inéditos, surpreendentes, de natureza } \\
\text { singular. }\end{array}$ \\
\hline Fonte: Adaptado de Campos (2015).
\end{tabular}

Vale destacar que, apesar de muitas definições, é possível identificar algumas convergências nas diferentes abordagens: como construto, refere-se a atributos e a resultados, é aprendida, referem-se a conhecimentos, habilidades e atitudes, e outras características pessoais; está relacionada ao desempenho superior; está associada ao contexto de trabalho, e varia de acordo com a situação; seu desenvolvimento e manifestação estão relacionados as demandas no trabalho. Ainda, pode-se relacionar competência como resultados de processos formais e informais de aprendizagem no contexto de trabalho.

O conceito de competência que norteia a presente pesquisa é o conjunto de conhecimentos (corpo organizado de informações requerido para o desempenho da atividade); habilidades (atividades de natureza psicomotoras ou cognitivas) e atitudes (conjunto de crenças, normas, valores e regras que orientam o comportamento individual), necessárias ao desempenho esperado no trabalho (Meneses et al., 2010).

A competência do indivíduo integra a linha de análise deste estudo, que utiliza a ANT como meio para pesquisar as necessidades de treinamento dos líderes técnicos. As competências individuais serão mapeadas com o objetivo de construir o instrumento utilizado nesse processo.

\subsection{Contextualização: Competências no cenário da pesquisa}

Em se tratando da competência no enfoque desta pesquisa, no cenário da PD\&I, voltada à clientela de líderes de projeto, será apresentada uma breve caracterização de cenário e relato de estudos desenvolvidos no tema. 
As instituições que desenvolvem atividades de pesquisa contam com a necessidade de priorização da atividade de gestão de projetos. $\mathrm{O}$ investimento otimizado de recursos consiste em um desafio para essas instituições, as quais necessitam ter competência para escolher adequadamente os projetos nos quais serão investidos os recursos, de forma a obter os melhores resultados. No caso de instituições públicas de pesquisa, torna-se ainda mais importante contar com um processo eficaz de gerenciamento dos projetos de PD\&I em função da intensa competição por recursos entre instituições e países, o aumento da demanda de pesquisa em função de novas fronteiras do conhecimento, e principalmente, pela necessidade de justificar sua existência e continuidade junto à sociedade. Desta forma, a manutenção da competência do líder de projeto é fundamental ao do sucesso da gestão de projetos.

A organização-alvo, cenário desta pesquisa, trabalha e se organiza por projeto, cujo produto é o conhecimento e a inovação, com a responsabilidade de prover retorno a comunidade cientifica e à sociedade. Desta forma, sugere-se que a identificação das competências e delineamento do perfil dos profissionais que fazem a gestão dessas unidades de trabalho, cuja atribuição está à frente de seus projetos, consiste em subsídio para compor uma estratégia de gestão.

O gestor de projetos tem como responsabilidade a entrega de todos os componentes de um projeto; estabelecer o escopo do trabalho, planejá-lo e determinar os recursos exigidos, obter os recursos a serem alocados e então gerenciar a conclusão das tarefas exigidas, de forma a garantir a resolução de problemas (Newton, 2011). Para efeitos deste estudo, o líder de projetos e o gestor de projetos se equivalem em atribuição.

O Project Management Institute (PMI), entidade que fomenta o debate sobre o tema Gestão de Projetos, define gestão de projeto como um método que visa atingir os resultados, por meio da aplicação de conhecimentos, habilidades e ferramentas às atividades do projeto, $\mathrm{o}$ qual é representado por um modelo de gestão, perpassando a iniciação, o planejamento, a execução, o monitoramento, o controle e o encerramento.

Sob a ótica do PMI, as competências são definidas em relação ao grau de conhecimento técnico de gestão de projeto, em relação ao desempenho e em relação ao comportamento durante a realização do projeto. O PMI possui um modelo que trata especificamente do desenvolvimento de competências de gerentes de projetos, o Project Management Competence Development Framework - PMCDF, que está em sua $2^{\mathrm{a}}$ edição, publicada em 2007. As competências de conhecimento técnico de gestão de projeto são 
certificadas com o teste do PMI; as de desempenho são as obtidas com o sucesso do projeto, e abrangem o planejamento, a execução, o monitoramento e controle e o encerramento do projeto; e as competências pessoais são relacionadas ao comportamento do gestor durante a execução do projeto - comunicação, liderança, gestão, habilidade cognitiva, efetividade e profissionalismo (Cartwright \& Yinger, 2007).

$\mathrm{Na}$ visão da National Competence Baseline (NBC), Referencial Brasileiro de Competências para a International Project Management Association (IPMA), associação internacional com foco na capacitação profissional na área de gerenciamento de projetos, as competências são definidas em relação às técnicas e ao comportamento focado nos aspectos pessoais e no contexto organizacional do projeto - 20 competências relacionadas a técnicas de gerenciamento de projetos, 11 competências contextuais, e 15 competências comportamentais.

Destacando alguns estudos desenvolvidos na área de projetos, pode-se inferir que os resultados esperados de um projeto são consequência das habilidades e desempenho de um gestor de projetos. Algumas pesquisas foram registradas corroborando essa máxima (Crawford, 2005; Moraes et al., 2012; Oliveira, et al., 2016; Santana \& Carvalho, 2016).

Crawford (2005) destaca que a efetividade dos projetos corrobora a competência do gerente de projetos, e divide suas características de desempenho superior em: conhecimento, habilidade, conhecimento e traços. Além disso, Lampel (2001) evidencia que, para alcançar o sucesso da entrega de resultados, é essencial aos líderes de projeto obter a competência técnica, empresarial, de negociação e analítica.

Um estudo realizado por Müller e Turner (2007) buscou demonstrar que o estilo de liderança do gestor de projeto influencia o sucesso do projeto; e diferentes estilos de liderança são apropriados para diferentes tipos de projetos. No modelo de pesquisa proposto pelos autores foi utilizado, como variável independente, um conjunto integrado de competências: emocionais (motivação, conscienciosidade, sensibilidade, influência, autoconsciência, resiliência emocional, intuição); de gestão (gestão de recursos, comunicação, desenvolvimento, capacidade de liderança, iniciativa); e intelectuais (perspectiva estratégica, visão sistêmica; análise crítica). O sucesso do projeto foi utilizado como a variável dependente no modelo e, como variáveis moderadoras, foram considerados os seis tipos de projeto - aplicação, impacto estratégico, estágio de ciclos de vida, complexidade, cultura e contratos. 
Resultados dessa pesquisa demonstraram que as competências emocionais tiveram uma contribuição significativa para o sucesso do projeto na maioria das situações estudadas, enquando as competências de gestão eram por vezes significantes, e as competências intelectuais eram ocasionalmente correlacionadas de forma negativa ao sucesso do projeto. Para todos os projetos, conscienciosidade, sensibilidade e comunicação foram significantemente correlacionadas ao alcance do sucesso do projeto, enquanto perspectiva estratégica e visão sistêmica não foram consideradas relevantes para o alcance do sucesso do projeto (resultados apontaram, inclusive, serem prejudiciais, exceto durante as fases de viabilidade e fechamento, segundo os autores). Concluem, ainda, que o gestor do projeto deve se concentrar em atividades com foco na tarefa, deixando desta forma o enfoque estratégico destinado a outros papéis de governança do projeto, como o patrocinador.

Silva (2010) descreveu, em sua pesquisa, resultados de um estudo na área, conduzido por Crawford (2005), no intuito de identificar competências comportamentais de líderes ou gestores de projetos de seus pares: as competências identificadas foram senso de responsabilidade; consciência política; relacionamento; consciência estratégica; avaliação interpessoal; e avaliação para a ação. O estudo vai ao encontro de elementos levantados por Lampel (2001) anteriormente.

Na mesma linha de Crawford (2005), investigações acerca de fatores de sucesso nas ações de gestão de projetos foram registradas por Toledo, Silva, Mendes e Jugend (2008). Seus relatos de pesquisa reforçaram a importância de competências técnicas e de gestão, a serem desenvolvidas pelo líder. Outros estudos desenvolvidos por Müller e Turner (2010), cumpriram a agenda de pesquisa de observações empíricas proposta por Toledo et al. (2008). Pesquisas com abordagem em competências para o desempenho em projetos são registradas, como estudos no campo da construção, que resultaram em competências orientadas à realização, pensamento analítico, e influência. Em experiências posteriores identificou-se que as competências inerentes ao líder de projeto podem exigir diferentes abordagens para sua gestão, atendendo às necessidades de determinado projeto. Esses resultados foram obtidos por meio de investigações, que demonstraram a correlação de dimensões da competência da liderança com a efetividade em diferentes tipos de projetos.

Turner, Müller e Dulewicz (2009) se propuseram a investigar as diferenças entre as competências do gestor de projetos e as do gestor funcional, por meio de um questionário validado com 414 líderes de projeto, cujas respostas foram comparadas às obtidas com os 
dados de mais de 1000 gestores funcionais. O estudo identificou que o perfil de líderes de projeto se identifica mais com as competências de consciência, sensibilidade e análise crítica, enquanto os gestores funcionais se identificam mais às competências de comunicação e desenvolvimento. Necessidades de treinamento para competências emocionais foram identificadas em ambos os estilos de gestão.

Müller et al. (2010) estudaram as competências dos gestores de projeto de membros das associações PMI, IPMA, Association of Project Management (APM) e American Society for the Advancement of Project Management (ASAPM) e de estudantes de pós-graduação de universidades do Reino Unido, Irlanda, Austrália, Nova Zelândia, Canadá e Estados Unidos, por meio de questionários online, para diferentes tipos de projeto. Os achados indicaram que o perfil de liderança varia de acordo com o tipo de projeto e sua complexidade.

Com o objetivo de entender a influência do estilo da liderança no sucesso do projeto, Yang, Huang e Wu (2011) realizaram entrevistas para analisar o desempenho dos projetos. Os autores relataram que o sucesso do projeto pode ser alcançado em termos de desempenho de prazo, custo, qualidade e satisfação dos atores envolvidos, com forte comunicação da equipe e colaboração, além de maior coesão da equipe. Os resultados indicam, ainda, que projetos de alta complexidade podem ser mais bem sucedidos caso haja bom nível de comunicação, colaboração e coesão da equipe.

Uma série de relatos baseados na escola de competências de liderança foi, posteriormente, proferida na área. Legitimando os primeiros relatos de Müller et al. (2010) o autor descreve diversas pesquisas demonstrando que há relação da competência e efetividade do desempenho da liderança em geral, na gestão de projetos em particular, no Real Força Aérea; no Royal Navy; na polícia britânica ou em projetos no setor financeiro. Comuns a todos esses estudos, diferentes competências de liderança se referem ao sucesso dos projetos em diferentes conteúdos.

Corroboram com a ideia ainda as investigações de Moraes et al. (2012), as quais apresentam os resultados de um questionário sobre o papel do gestor de projetos de TI como elemento condicionante do desempenho desses projetos. Os resultados encontrados mostram que a relação do perfil do gestor de projetos com o desempenho dos projetos é alterada pelo nível de maturidade da organização executante em gestão de projetos - onde há menor maturidade, há uma relação muito mais forte do perfil do gestor com o desempenho dos projetos. 
Araújo e Pedron (2016) estudaram as soft skills - competências comportamentais interpessoais e intrapessoais, enquanto hard skills compreendem o conhecimento e as competências técnicas (Rao, 2012) - no desenvolvimento das competências dos gerentes de projetos de TI. Por meio de uma pesquisa exploratória, gerentes de projetos de TI responderam a duas questões (1) "qual o impacto dos soft skills no gerenciamento de projetos de TI?" e (2) “o tipo de personalidade do gerente de projetos pode influenciar no desenvolvimento de seus soft skills?". Os resultados indicaram que liderança e comunicação são os soft skills mais importantes no gerenciamento de projetos para a amostra estudada.

Marzagão e Carvalho (2016) também focaram o tema de sua pesquisa nas competências comportamentais dos líderes de projeto, ao relacioná-las ao desempenho de projetos Seis Sigma em três países - Brasil, Chile e Colômbia. Os resultados apontaram que o sucesso dos projetos está associado às competências de inovação e direcionamento por parte dos líderes de projeto. O estudo contribuiu, adicionalmente, para o mapeamento das competências comportamentais em projetos Seis Sigma.

Oliveira et al. (2016) apresentaram uma proposta voltada à classificação de projetos e seleção de gerentes de projeto associada à essa classificação, de acordo com suas características e habilidades, semelhante aos estudos proferidos por Müller et al. (2010). Por meio dos resultados foi possível classificar os gestores de projetos em categorias específicas, permitindo assim uma gestão mais efetiva, pois diferentes projetos requerem diferentes níveis de habilidades.

Frente aos estudos dispostos, evidenciam-se resultados de estudos empíricos os quais destacam a relação direta das competências do líder de projetos ao sucesso dos projetos. Desta forma, seu estudo é essencial à efetividade de seus objetivos. Considerando o contexto do presente trabalho, o mapeamento de competências dos líderes técnicos e as características funcionais da clientela que compõem o modelo de investigação podem gerar uma agenda de pesquisa, corroborando as experiências relatadas por Müller et al. (2010), as quais identificaram competências que sugerem diferentes abordagens, dependendo das características do projeto.

A organização-alvo, cenário desta pesquisa, trabalha e se organiza por projeto, cujo produto é o conhecimento e a inovação, com a responsabilidade de prover retorno à comunidade científica e à sociedade. Desta forma, sugere-se que a identificação das competências e delineamento do perfil dos profissionais que fazem a gestão dessas unidades 
de trabalho, como subsídio para compor uma estratégia voltada para a efetividade dos projetos. 


\section{CAPÍTULO 3 - AVALIAÇÃO DE NECESSIDADES DE TREINAMENTO (ANT)}

\section{Objetivos do capítulo}

Este capítulo visa apresentar conceitos e características do processo de ANT. Trata, também, da nomenclatura utilizada na área, além dos principais modelos para sua realização. São dispostos estudos mais recentes, apresentando a evolução de pesquisa sobre o tema.

\subsection{Conceitos e Características}

A ANT apresenta, em sua conceitualização, uma abrangência de diferentes termos utilizados na literatura para o mesmo processo. Várias expressões fazem referência à discussão entre as categorias que o identificam: tanto na literatura de contexto nacional, quanto internacional se dá essa diferenciação. Estudos publicados por Ferreira (2009) e Iqbal e Khan (2011) abordam a utilização dessas nomenclaturas, conforme Tabela 3.

Tabela 3. Termos utilizados para ANT na literatura.

\begin{tabular}{|c|c|}
\hline Termos & Definições \\
\hline \multicolumn{2}{|r|}{ Literatura Nacional } \\
\hline $\begin{array}{l}\text { Levantamento de Necessidades de } \\
\text { Treinamento }\end{array}$ & $\begin{array}{l}\text { Coleta de informações visando a tomada de decisões para realização de } \\
\text { treinamento. Processo associado, geralmente, a utilização de listagens } \\
\text { de cursos (cardápios). }\end{array}$ \\
\hline $\begin{array}{l}\text { Análise de Necessidades de } \\
\text { Treinamento }\end{array}$ & $\begin{array}{l}\text { Mais empregado para destacar a natureza analítica do processo de } \\
\text { diagnóstico de necessidades e para se referir ao emprego de modelos } \\
\text { teóricos mais tradicionais de pesquisa. }\end{array}$ \\
\hline $\begin{array}{l}\text { Avaliação de Necessidades de } \\
\text { Treinamento }\end{array}$ & $\begin{array}{l}\text { Processo mais sistemático de avaliação, com nível maior de } \\
\text { profundidade - estuda a necessidade (cognitiva, afetiva e psicomotora), } \\
\text { magnitude e prioridade. }\end{array}$ \\
\hline \multicolumn{2}{|r|}{ Literatura Internacional } \\
\hline Need & $\begin{array}{l}\text { a) Gap entre resultados atuais e esperados } \\
\text { b) Gap entre aprendizado ou desempenho da condição atual e a } \\
\text { desejada, chamada necessidade; }\end{array}$ \\
\hline Needs Assessment & $\begin{array}{l}\text { a) Processo que identifica as necessidades e as prioriza. } \\
\text { b) Esforço que analisa e diagnostica a organização, a tarefa e o } \\
\text { indivíduo, para determinar se a solução é necessária e o que é melhor } \\
\text { para produzir resultados. }\end{array}$ \\
\hline
\end{tabular}


Tabela 3. Termos utilizados para ANT na literatura (cont.).

\begin{tabular}{ll}
\hline Termos & Definições \\
\hline & Literatura Internacional \\
\hline c) Significado de determinar o sistema de treinamento e \\
desenvolvimento necessário à organização, aos grupos e aos indivíduos \\
para torná-la competitiva, melhorar sua produtividade, promover a \\
satisfação do empregado, e aperfeiçoar o potencial de desenvolvimento \\
de carreira. \\
d) Identifica os gaps de capacidade, habilidade, performance e \\
necessidades em prioridade de resolução. \\
e) Processo formal para obter informação de dois estágios - o atual e o \\
desejado, comparando-os, identificando seus gaps, com base nas \\
prioridades das ações organizacionais.
\end{tabular}

\begin{tabular}{ll}
\hline Needs Analysis & a) Processo para determinar razões e causas das necessidades para que \\
& intervenções apropriadas possam ser identificadas e selecionadas. \\
& b) Necessidade de identificar causas e relações a outras demandas. Um \\
dos significados seria projetar habilidades entre os empregados. Pode \\
envolver o uso de entrevistas, testes psicológicos e outros.
\end{tabular}

Training Needs Assessment $\quad$ a) Estudo sistemático de um problema ou inovação, com a incorporação de dados e opiniões de várias fontes, para tomada de decisões efetivas ou recomendações.

b) Seleção de significados para treinamento, após determinar sua necessidade.

c) Identifica problemas específicos da organização, com a utilização de métodos para coleta de informações, as quais são utilizadas para determinar a efetiva necessidade de treinamento, além de fomentar intervenções desenvolvidas especificamente para resolver problemas os identificados.

d) Estudo do desenho e desenvolvimento instrucional destinado a programas informacionais, posterior à análise de desempenho.

\begin{tabular}{ll}
\hline Training Needs Analysis & $\begin{array}{l}\text { a) O primeiro passo para o processo de treinamento. Desenvolvido para } \\
\text { identificar os gaps de desempenho que podem ser remediados por } \\
\text { treinamento. Consiste na investigação e na análise de dados. }\end{array}$ \\
\hline Training Requirement Analysis & $\begin{array}{l}\text { a) Ajuda a determinar se o treinamento é a solução ou parte da solução } \\
\text { para a necessidade. A análise determina o que, quando, quando, como e } \\
\text { por quem o treinamento deve ser conduzido. }\end{array}$ \\
\hline Performance Analysis & $\begin{array}{l}\text { a) Pode ter origem tanto na organização quanto no indivíduo. A análise } \\
\text { significa verificar as deficiências de desempenho e então determinar o } \\
\text { meio mais apropriado de remediar essas deficiências. }\end{array}$ \\
b) A análise de desempenho provê o estudo preliminar da situação para \\
determinar se e quando o treinamento é demandado.
\end{tabular}

Fonte: Adaptado de Ferreira (2009) e Iqbal et al. (2011).

A diversidade dos termos e conceitos evidenciados aponta que, sob a ótica nacional, o enfoque mais completo acerca da análise das informações para diagnóstico destinado às soluções de desempenho do indivíduo é a avaliação de necessidades de treinamento: engloba, além da necessidade nos pilares cognitivo, psicomotor, e afetivo, a dimensão e a prioridade do atributo. 
Com relação ao enfoque internacional, os termos Need, Needs Analysis, Training Needs Analysis, e Training Requirement Analysis apresentados têm foco no indivíduo; os outros termos, de maneira geral, possuem alguma definição que extrapola o âmbito individual, ao remeter a análise ao contexto organizacional. Outro aspecto a ser destacado a partir de conceitos do termo Training Needs Assessment são evidências de que informações do processo de ANT com atenção ao treinando, atribuídas como subsídio ao design instrucional. A priorização de ações educacionais é outro ponto tratado em alguns conceitos, especificamente no termo Needs Assessment. Os conceitos apresentados também satisfazem à sistematização do processo, principalmente em definições sugeridas nas expressões Training Needs Assessment, Needs Analysis, e Needs Assessment.

Adicionalmente, outros autores da área de Psicologia Organizacional e do Trabalho POT contribuem com essa conceitualização. Wright e Geroy (1992) abordam o conceito de ANT como o processo organizacional que coleta e analisa informações que dão suporte sobre a tomada de decisão sobre a realização do treinamento, visando à melhoria do desempenho dos indivíduos, e agrega além do aspecto individual, elementos de grupo e organizacional. Meneses et al. (2010) reportam o conceito da visão sistêmica, argumentando que o processo é uma tentativa sistematizada para identificar as necessidades educacionais, seus motivos e soluções que possam satisfazer essa demanda.

A avaliação de necessidades de treinamento é a primeira etapa da abordagem de sistemas de treinamento, e se refere a um processo de investigação que deve ser amplamente realizado na organização, caso se deseje garantir a validade instrucional de todas as outras etapas que constituem uma ação de treinamento (Borges-Andrade \& Lima, 1983). Avaliar necessidades de treinamento exige a confrontação entre padrões de desempenho demonstrados pelos indivíduos e os demandados por suas organizações (Hoffman-Câmara, Abbad, Meneses \& Ferreira, 2010). De acordo com Clarke (2003), a ANT é considerada como o processo que fornece os insumos para responder onde será realizado o treinamento na organização, quem deve receber o treinamento e qual deve ser seu conteúdo.

Conforme abordado anteriormente, o processo de ANT compõe três análises - análise organizacional, análise de tarefas e análise individual. Abbad e Mourão (2012) citam o processo como a identificação de lacunas de competências humanas voltadas para o trabalho ou, em nível individual, gaps no repertório dos CHAs. As mesmas autoras acrescentam, ainda, a faceta do delineamento de ações de aprendizagem, por meio do estabelecimento de 
objetivos de ensino. As necessidades de treinamento podem decorrer de múltiplos aspectos: problemas de desempenho detectados podem ter sua origem em contingências como fatores externos à organização, como variáveis demográficas, ou variáveis de contexto interno, como falta de suporte organizacional. Esses aspectos consistem muitas vezes na carência de apoio organizacional ao desempenho, ou à transferência do conteúdo aprendido para o dia a dia do trabalho ocasionando, por exemplo, falta de motivação ou condições para a demonstração da competência. Desta forma, nota-se a importância de considerar fatores de ambiente ou de contexto antes de diagnosticar que as discrepâncias de desempenho são solucionadas exclusivamente por ações de treinamento (Lima \& Borges-Andrade, 2006).

A primeira etapa do processo de ANT, de análise organizacional, trata do alinhamento das ações de treinamento às estratégias e objetivos da organização. Vários programas de treinamento não atingem seus objetivos devido aos conflitos organizacionais, os quais poderiam ser identificados antes da implementação do treinamento. Salas et al (2001) destacam que conduzir uma análise organizacional é o primeiro passo do delineamento do treinamento, e consiste em uma etapa essencial para assegurar o sucesso do programa de treinamento. Avaliam que, no entanto, é necessária a condução de maior número de pesquisas na área, com vistas ao desenvolvimento de práticas de diagnóstico para tratar o contexto organizacional relativo ao treinamento.

A análise de tarefas preconiza a definição dos CHAs, as atividades realizadas em cargos, postos de trabalho, papeis ocupacionais ou espaços ocupacionais. Compreende as fases de 1) detalhamento das atribuições e responsabilidades ocupacionais; 2) descrição dos CHAs, necessários ao desempenho esperado no trabalho; e 3) processo de delimitação da relevância das competências (Meneses et al., 2010).

Os mesmos autores caracterizam que a análise individual investiga o grau de domínio dos CHAs identificados na análise de tarefas. Identifica as pessoas que necessitam de treinamento, e ainda podem diagnosticar se os treinandos em potencial possuem os prérequisitos necessários ao aproveitamento do curso.

A importância do processo de ANT para a efetividade do treinamento é enfatizada por vários autores que identificam que, no caso de falhas em seu processo, há repercussão negativa nos outros subsistemas integrantes de TD\&E (Abbad et al., 2006; Magalhães et al., 2001). 
Em perspectiva mais ampla, foram demonstrados benefícios do processo, desde que a etapa promove a capacidade pessoal, o respaldo da cultura organizacional e a coesão interna, de forma a manter o foco e o direcionamento para o investimento da organização em seus empregados (Bartram \& Gibson, 1994; Chen \& Hung, 2012). Pode-se dizer, ainda, que a ANT se constitui em importante instrumento de gestão, pois, se bem conduzida, relaciona as ações educacionais aos objetivos organizacionais, estabelecendo natureza estratégica à ação (Meneses \& Zerbini, 2009; Meneses et al., 2010). Além desses aspectos, Abbad et al. (2006) realçam o cunho prospectivo da ANT que, caso seja realizada de forma proativa às mudanças de contexto, promove assim oportunidade à organização de disponibilizar condições a seus empregados, por meio da realização de capacitação, projetando desta forma a dimensão estratégica a seus programas educacionais.

Outros autores dispõem sobre os objetivos desta etapa sob o prisma do sistema, intrínseco ao TD\&E, abordando o desenvolvimento de habilidades de gestores e empregados, a partir da satisfação das necessidades das organizações, aprimoramento as relações dos empregados, promoção da resolução de problemas, da mudança e do desenvolvimento de carreira (Chen et al., 2012).

Apesar de evidências de sua importância, estudos na área demonstram que, nas organizações, o processo tem sido conduzido de forma pouco sistemática, por tentativa e erro ou com base em "cardápios" (Ferreira, 2009; Taylor et al., 1998). De maneira análoga, esse campo tem avançado pouco nos últimos tempos, tanto na literatura quanto metodologicamente. A maioria dos estudos realizados tem focado em análises nos níveis do indivíduo e de tarefas, e abordagens mais escassas enfatizam necessidades em níveis mais abrangentes (Aguinis et al., 2009).

Os modelos metodológicos evidenciados pela literatura como os mais utilizados para o desenvolvimento da ANT contemplam o Modelo O-T-P (McGehee et al., 1961), o Modelo de Análise do Desempenho (Mager \& Pipe., 1983) e o Modelo do Papel Ocupacional (BorgesAndrade et al., 1983). Mais recentemente proposto, o Modelo Conceitual de Avaliação de Necessidades de Treinamento (Abbad et al., 2012) integra a apresentação dos Modelos de ANT na próxima seção. 


\subsection{Modelos Nacionais e Internacionais de ANT}

McGehee at al. (1961) introduziram uma estrutura para ANT baseando-se em três análises: aspectos organizacionais, das tarefas e das pessoas (Modelo O-T-P). No nível organizacional, a análise examina os objetivos e metas organizacionais, necessidades e recursos, bem como índices de eficiência para determinar onde o treinamento é necessário. Análises de tarefa estabelecem padrões de desempenho, de acordo com os conteúdos a serem adquiridos, e conforme as tarefas a serem desempenhadas, além de considerar o requisito necessário para aquela habilidade, e assim determinar o conteúdo do treinamento. Finalmente, por meio da análise individual, identifica-se quem na organização precisa ser treinado. $\mathrm{O}$ Modelo é ilustrado na Figura 4.

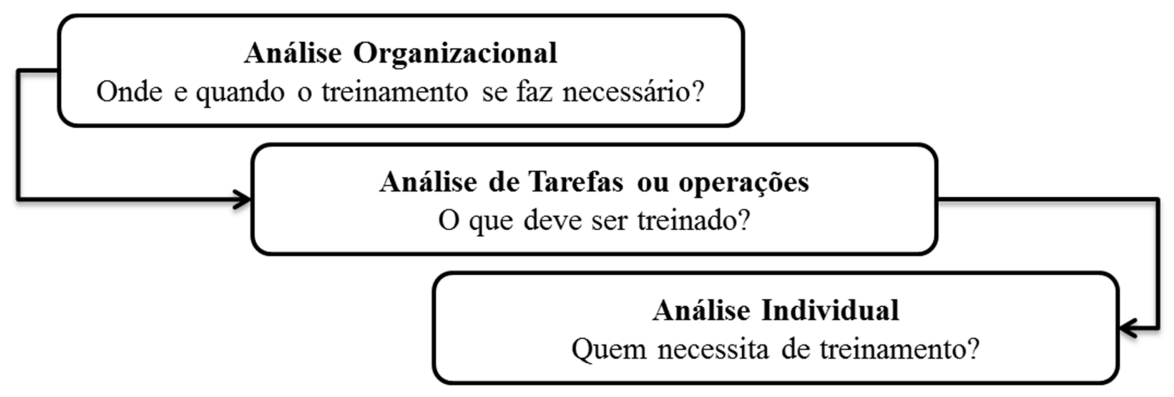

Figura 4. Modelo 0-T-P (Fonte: Adaptado de Meneses et al., 2010).

No entanto, o referido Modelo não possui metodologia sistemática de avaliação integrada nos diversos níveis de análise e, talvez, nesse sentido, as organizações não tenham uma prática sistematizada de sua utilização (Abbad et al, 2006), tendo progredido pouco nas últimas décadas, apesar de algumas derivações do Modelo em proposições teóricas e metodológicas, e sua utilização em pesquisas recentes.

Outra abordagem também foi descrita em publicações - a abordagem de análise de desempenho. Esse Modelo, baseado nos estudos anteriores, objetiva identificar as causas dos gaps de desempenho no trabalho. De acordo com essa concepção, a discrepância existente tem sua origem na lacuna de conhecimentos e habilidades do indivíduo sem, no entanto, necessariamente ser solucionada por meio de ação educacional. Os autores analisam que essa abordagem possui caráter corretivo e imediatista, e não prospectivo, e por isso sofre muitas críticas. Suas limitações residem na análise estritamente individual e na fata de metodologia para coletar as informações dos indivíduos. (Abbad et al., 2012; Taylor at al., 1998) 
O Modelo do Papel Ocupacional (Borges-Andrade et al., 1983) foi desenvolvido para realizar análise de tarefa e individual. O resultado da ANT com enfoque no papel ocupacional resulta em um conjunto de habilidades necessárias ao desempenho dos papéis ocupacionais em questão. As habilidades consistem nos problemas de desempenho ou nas discrepâncias identificadas pela organização. Este é o Modelo-base utilizado neste trabalho, evidenciado na Figura 5.

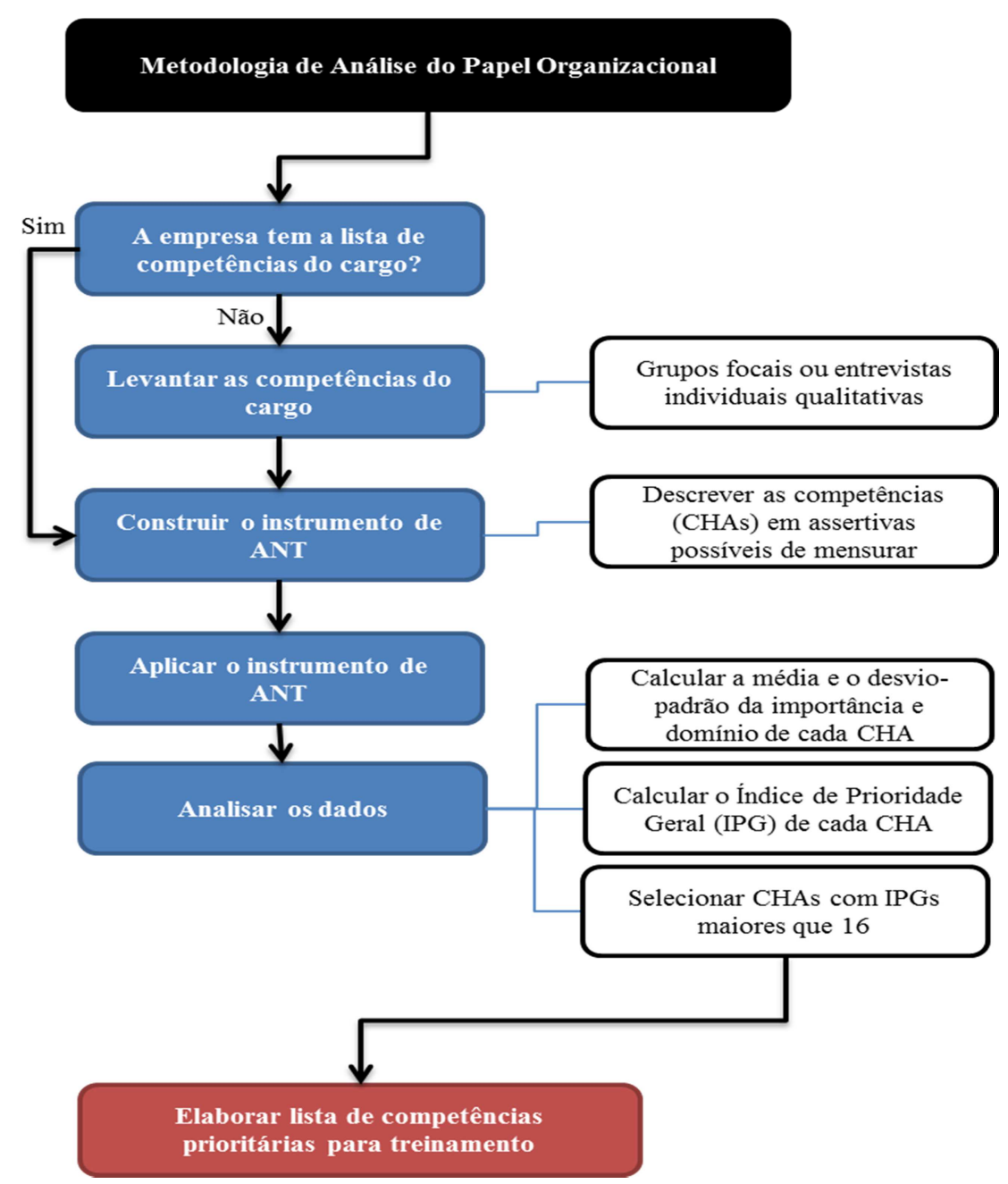

Figura 5. Modelo do Papel Ocupacional (Fonte: Adaptado de Borges-Andrade et al. (1983) e Vargas (2010).

Entende-se "Papel ocupacional" como o conjunto de expectativas e prescrições associadas à execução de tarefas em ambientes organizacionais. Sua análise consiste na identificação dos CHAs necessários ao desempenho do trabalho. Desta forma, significa a 
identificação das competências inerentes ao papel ocupacional para a execução das tarefas (Meneses et al., 2010).

A operacionalização do processo, disposta na figura acima, demonstra que, para a realização da análise de tarefas sob a abordagem desta metodologia, faz-se necessário a identificação das competências inerentes ao papel ocupacional de interesse (caso a organização não as tenha mapeado), a construção, validação e aplicação de um instrumento destinado à avaliação das discrepâncias de desempenho. Permite, ainda, priorizar os CHAs, ou seja, o que de fato é mais importante ser treinado em função de sua importância para o desempenho da tarefa, e de pouco domínio por parte do indivíduo.

Para mapeamento das competências, há algumas alternativas de estratégias a serem utilizadas: grupo focal, entrevistas individuais, reunião com ocupantes do cargo trabalhado. A identificação de competências se destina, nesta metodologia, à construção do instrumento de avaliação e necessidades de treinamento. Desta forma, as competências identificadas são utilizadas como referência para estruturar as frases integrantes do instrumento. Essas afirmativas, contendo os CHAs, são descritas em termos comportamentais, de forma que reflitam comportamentos humanos em contexto de trabalho. Sua composição deve integrar verbo e objeto de ação. Os itens serão, por conseguinte, associados a uma escala de julgamento (Borges-Andrade et al., 1983; Meneses et al., 2010).

Como aponta Cesnik (2014) em seu trabalho, a escala de julgamento avalia as afirmativas em duas dimensões: importância (relevância de cada atividade para o bom desempenho no trabalho) e domínio (a percepção em relação a quanto o indivíduo domina cada atividade descrita). A escala é do tipo "Likert", de cinco pontos. A escala de Importância varia de " 1 = Nada importante para o meu desempenho" até "5 = Totalmente importante para o meu desempenho"; enquanto a escala de Domínio varia de "1 = Não domino a habilidade" até "5 = Domino completamente a habilidade".

Borges-Andrade et al. (1983) apresentam o método que integra o Modelo. O cálculo do índice de prioridade, intitulado Índice de Prioridade Geral, possui um valor de importância e domínio, e é atribuído a cada competência. De acordo com a metodologia, CHAs com importância alta e domínio baixo são indicados para receber treinamento. O IPG = [Importância x Domínio invertido]/ número de funcionários por seção) para cada competência relacionada no instrumento pode variar entre 1 e 25 . As ações educacionais prioritárias, ou os 
indivíduos que precisam de treinamento pertencem ao grupo que obteve índices superiores a 16.

Outro aspecto sugerido pelos autores, sob a abordagem do método, é a possibilidade de relacionar as características individuais aos índices obtidos na escala de importância e domínio. Essa análise pode conferir resultados produtivos, tais como especificar os grupos indicados a cada ação educacional.

Com contribuições metodológicas do Modelo do Papel Ocupacional de BorgesAndrade e Lima (1983), além de bases metodológicas estabelecidas nas abordagens de McGehee et al. (1961), Ostroff e Ford (1989), e premissas de Abbad et al. (2012), Ferreira (2009) propôs um Modelo Teórico-metodológico para investigação de necessidades de treinamento em ambientes organizacionais. O Modelo proposto tem abordagem multinível, contemplando diferentes níveis do processo de ANT e necessidades de treinamento, classificando estas últimas conforme a taxonomia de resultados de aprendizagem de Bloom (Ferreira, 2009).

Ferreira (2009) descreve seu modelo, destacando que, dentre os níveis de processo, prevê a análise do contexto da organização como passo inicial do processo de ANT (nível macro); a análise de tarefas (nível meso) promove a identificação de mudanças nas tarefas, e o surgimento de novas tarefas, considerando o cenário dinâmico das organizações; e a mensuração de indicadores de competências individuais (nível micro), que abrange a descrição dos CHAs esperados. As lacunas de competências são mensuradas no modelo por meio da autoavaliação e heteroavaliação. Posteriormente, as necessidades devem então ser descritas e classificadas de acordo com os três domínios do indivíduo - cognitivo, afetivo e psicomotor (Bloom et al., 1972), permitindo assim o desenho eficaz as ações educacionais.

Outro Modelo apresentado consiste no Modelo Conceitual de ANT (Abbad et al., 2012), proposto pelas autoras com base na taxonomia de resultados de aprendizagem e, de forma análoga ao de Ferreira (2009), composto por diversos níveis de análise. As autoras apontam que o Modelo extrapola a análise de tarefas, e abrange a análise organizacional, e análise de grupo. A Figura 6 ilustra o Modelo. 


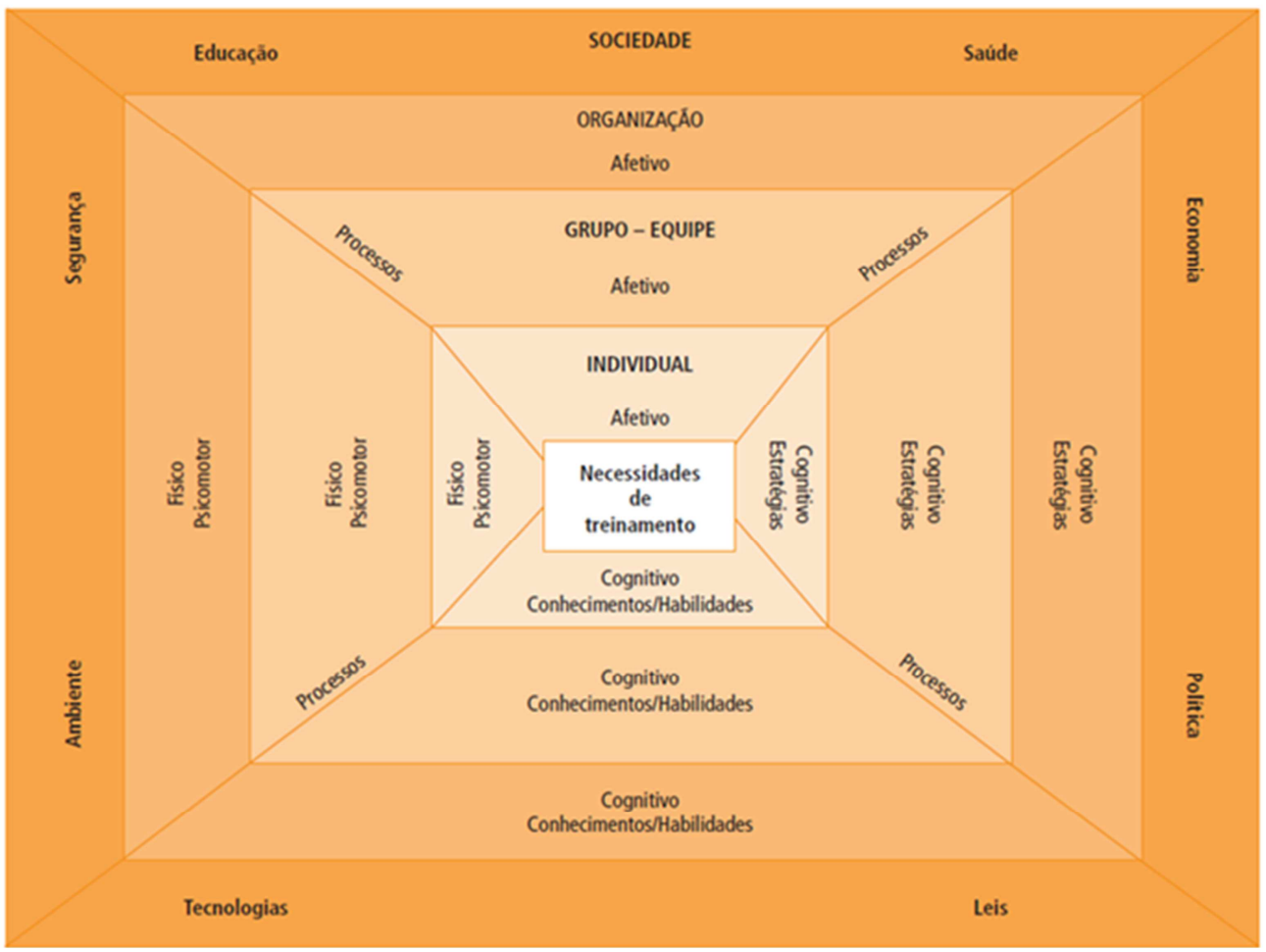

Figura 6. Modelo Conceitual de ANT (Fonte: Abbad et al., 2012).

Conforme demonstra a Figura 6, são nove as etapas estabelecidas no Modelo, as quais permitirão disponibilizar as informações necessárias ao desenho de situações de treinamento. Sua aplicação pretende fornecer subsídios ao delineamento de ações educacionais que possam promover o desenvolvimento no contexto do trabalho. Pretende-se, assim, vincular estudos empíricos a prática em organizações.

A literatura recente no campo da ANT permite observar que, apesar do registro de estudos publicados, tanto em âmbito nacional quanto internacional, bem como apresentadas experiências na área, ainda há uma agenda de pesquisa neste campo, principalmente de realização de análise de cunho organizacional. Esforços vêm sendo adotados nesse sentido, principalmente por pesquisadores do contexto nacional.

Com relação aos modelos metodológicos, o O-T-P proposto por McGehee et al. (1961) ainda é o mais utilizado. Alguns pesquisadores fizeram propostas de derivações, no entanto suas bases continuam sólidas para a realização das etapas que procedem as análises.

As revisões clássicas de literatura fazem alusão aos modelos inicialmente propostos, em relação às etapas ainda atuais de análise, organizacional, de tarefa e individual.

Goldstein (1980) argumentou, em seu ensaio, que os autores do Modelo O-T-P influenciaram vários pesquisadores da área, a considerarem a operacionalização da ANT por 
meio das três fases. O mesmo autor descreve as três propostas: na fase da análise organizacional, a ideia era prover subsídio para especificar onde e quando o treinamento poderia ser realizado na organização; na análise de tarefas, a proposta era contribuir com informações para o delineamento do processo instrucional; conquanto que, na análise individual, relatou poucos estudos na área, e então a falta de produção de procedimentos prospectivos.

$\mathrm{Na}$ revisão de literatura posterior, Wexley (1984) cita o referido Modelo como a abordagem que responde às principais questões que a ANT propõe: onde o treinamento deve ser realizado, qual deve seu conteúdo, e quem deve ser treinado em termos de conhecimentos e habilidades.

Acerca da análise organizacional o mesmo autor argumentou que pesquisas deveriam ser conduzidas para promover um melhor entendimento sobre como determinar sobre o treinamento como solução efetiva. Relatou que poucas organizações desenvolviam essa análise, porém sem utilizar metodologia sistemática. Sobre a análise de tarefa, a metodologia se sofisticou no quadro desta análise. Apresentou-se a utilização da taxa de validade de conteúdo, com o objetivo de avaliar as tarefas para o processo de ANT, e o uso da metodologia de múltiplas fontes para selecionar as competências para o treinamento. No âmbito da análise individual, foram conduzidas pesquisas de níveis de desempenho e foco em comportamentos observáveis.

Lathan (1988) descreveu as três fases do Modelo em referência. Na primeira etapa análise organizacional - abordou a articulação entre o processo de ANT e a estratégia da organização; a análise de tarefas teve como foco as características das tarefas, com foco em habilidades conceituais; quanto ao prisma individual, o autor trouxe a utilização de pares nas avaliações.

Tannenbaun et al. (1992), em publicação sobre estudos da área no período de aproximadamente cinco anos depois, contextualizaram a análise organizacional com componente do Modelo O-T-P, com recomendação de incorporar variáveis contextuais. Quanto à análise de tarefas, identificou a utilização de técnicas de avaliação, levando em conta competências futuras. Na avaliação individual foi observada a ocorrência de grupos funcionais específicos para identificar dados para subsidiar pré-requisitos para os cursos.

Na sequência, Salas et al. (2001), em achados do Modelo sob o aspecto da Análise organizacional, relatou que variáveis conceituais relacionadas ao clima organizacional e ao 
suporte de transferência de treinamento foram incorporadas às práticas usuais. Descreveu, ainda, a intensificação da utilização da análise cognitiva para a análise de tarefas.

Aguinis et al. (2009) notaram a utilização de juízes para análise de conteúdo, na fase de análise de tarefas, e o surgimento do contexto motivacional no preparo dos treinandos para a fase anterior ao treinamento, para a análise individual.

Desta forma, os relatos apresentados nas revisões demonstram que a área de ANT obteve algum desenvolvimento, corroborado por estudos realizados por Iqbal et al. (2011), que destaca essa evolução relacionada principalmente à finalidade e abrangência do processo - que abarca o aspecto organizacional como essencial ao processo, além da proposição de técnicas de análises individuais.

Ainda com foco nos modelos metodológicos que conduzem o processo de ANT, revisões conduzidas por Ferreira, Abbad, Pagotto e Meneses (2009) e, posteriormente, Abbad et al. (2012) indicam que pesquisas internacionais na temática de ANT pouco avançaram desde o período de proposição do primeiro modelo proposto por McGehee na década de 60, apesar de apresentarem importantes estudos, como ilustrado na Tabela 4.

Tabela 4. Modelos de ANT: estudos no contexto internacional.

\begin{tabular}{ll}
\hline Autor & Pesquisa \\
\hline Mac Gehee e Thayer (1961) & Publicaram o Modelo O-T-P. \\
Moore e Dutton (1978) & Identificam 34 métodos aplicáveis aos níveis O-T-P; \\
& sugeriram a inclusão da análise de contexto para determinar a \\
& necessidade de treinamento e recomendaram o alinhamento \\
& da ANT, estratégia organizacional e stakeholders. \\
Lathan (1988) & $\begin{array}{l}\text { Sugeriu que a ANT fosse feita com base em objetivos } \\
\text { estratégicos futuros; a inclusão da análise demográfica para } \\
\text { identificar necessidades de diferentes grupos. }\end{array}$ \\
Ostroff e Ford (1989) & $\begin{array}{l}\text { Sugeriram um modelo tridimensional multinível de ANT, que } \\
\text { abrange conceituação e mensuração de variáveis de } \\
\text { indivíduos, unidade e organização. }\end{array}$
\end{tabular}


Tabela 4. Modelos de ANT: estudos no contexto internacional (cont.).

\begin{tabular}{|c|c|}
\hline Autor & Pesquisa \\
\hline Taylor e O’ Driscoll (1988) & $\begin{array}{l}\text { Constataram que as práticas de ANT eram pouco } \\
\text { sistematizadas; propuseram modelo de ANT integrando } \\
\text { abordagens de McGehee e Thayer, e Mager e Pipe. }\end{array}$ \\
\hline Chiu, Thompson, Mak e Lo (1999) & $\begin{array}{l}\text { Observam que pesquisadores e consultores que promoviam a } \\
\text { ANT, mais focados no nível da organização e os } \\
\text { procedimentos de coleta eram genéricos e pouco } \\
\text { sistematizados. }\end{array}$ \\
\hline Salas, Cannon-Bowers (2001) & $\begin{array}{l}\text { Relatam as perspectivas da análise organizacional e de tarefas } \\
\text { em sua investigação. Destaca a ANT com foco tradicional no } \\
\text { modelo das competências, com atenção recente ao nível mais } \\
\text { abrangente, das organizações. }\end{array}$ \\
\hline Fan e Cheng (2006) & $\begin{array}{l}\text { Pesquisa para identificação de competências necessárias para } \\
\text { treinamento de corretores de seguros em Taiwan, com a } \\
\text { utilização da técnica Delphi. }\end{array}$ \\
\hline Tao, Yeh e Sun (2006) & Estudo para desenvolver ANT para organização e indivíduos. \\
\hline Markaki, AntonaKis, Hicks e Lionis (2007) & $\begin{array}{l}\text { Desenvolveram uma medida para avaliar necessidades de } \\
\text { treinamento para enfermeiras na Grécia. }\end{array}$ \\
\hline Bowman e Wilson (2008) & $\begin{array}{l}\text { Fizeram uma análise da literatura, concluindo que a ANT } \\
\text { deve ser sistemática, alinhada aos objetivos individuais e } \\
\text { organizacionais. }\end{array}$ \\
\hline Aguinis e Kraiger (2009) & $\begin{array}{l}\text { Enfatizaram a ANT como uma das etapas mais importantes } \\
\text { do sistema instrucional, e a análise a nível individual. } \\
\text { Sugeriram a relevância de conhecer e avaliar as características } \\
\text { individuais dos treinandos. }\end{array}$ \\
\hline
\end{tabular}

Fonte: Adaptado de Ferreira, Abbad, Pagotto e Meneses (2009); Abbad et al. (2012).

As pesquisas realizadas nas últimas décadas demonstram que as primeiras pesquisas se constituíram de propostas derivativas dos Modelos O-T-P, predominantemente, e o de Mager et al. (1983), com variações e aprofundamentos. Até 1999, houve poucas tentativas de realização de investigações sistemáticas para identificar necessidades organizacionais ou estudo com a utilização de diferentes modelos. 
No entanto, a partir de então já se notam esforços e algum progresso metodológico, com utilização de novas técnicas e desenvolvimento de medidas, ao passo que enfatizam a importância da análise organizacional. No contexto nacional podem ser identificados alguns avanços teóricos e, principalmente, metodológicos, observados na Tabela 5.

Tabela 5. Modelos de ANT - estudos no contexto nacional.

\begin{tabular}{ll}
\hline Autor & Pesquisa \\
\hline Borges-Andrade e Abbad (1996) & Concluíram em suas revisões de literatura que os três níveis \\
Abbad (1999) & de ANT não são igualmente focados pelos estudiosos e \\
& pesquisadores. \\
Borges-Andrade e Lima (1983) & Desenvolveram o método de análise do papel ocupacional - \\
& investigação dos ocupantes do cargo sobre o desenvolvimento \\
& dos CHAs - avaliados na escala em importância e domínio, \\
& possibilitando a composição do índice de prioridade para \\
treinamento. & \\
Ambos os trabalhos abordaram a aplicação do mesmo & método, tratando da manipulação das fontes de avaliação auto \\
Castro e Borges-Andrade (2004) & e heteroavaliação no processo de ANT para cargos. \\
Agut e Grau (2002)
\end{tabular}

Considerando as pesquisas no contexto nacional, conclui-se que houve progressos no conhecimento na área, em termos metodológicos, os quais se constituem na adoção e operacionalização do conceito de competência para identificar necessidades ligadas a processos estratégicos e metodológicos; diversificação de técnicas de coleta de dados (grupos focais, a técnica de Delphi e incidentes críticos); diversificação de fontes de avaliação - auto e heteroavaliação no processo de ANT para cargos; a integração no processo de ANT e estratégia organizacional, bem como reflexões metodológicas.

Estudos recentes foram analisados por Cesnik (2014), com o objetivo de atualizar o campo de pesquisa nacional e internacional, no tema de ANT no período de 2010 a 2012. Para proceder a revisão dos estudos na área, o presente trabalho orientou-se pelo modelo proposto 
pela autora, com abordagem dos objetivos das pesquisas e descrição da metodologia utilizada. Para a atualização e sistematização de resultados de pesquisa, foram realizadas revisões bibliográficas em bases de dados eletrônicas, abrangendo o período de 2013 a 2016 . Foram pesquisadas produções científicas nacionais e internacionais nas bibliotecas eletrônicas da Capes e Scielo, base de dados Web of Science e Proquest, além dos bancos de dissertações e teses da Universidade de São Paulo (USP) e da Universidade de Brasília (UnB). Foram utilizados para pesquisa os termos-chave em português "avaliação de necessidades de treinamento", "análise de necessidades de treinamento", "levantamento de necessidades de treinamento", "diagnóstico de treinamento" e "prognóstico de treinamento"; e em inglês "training needs assessment”, "training needs analysis", “diagnosis of training needs", "prognosis of training needs". Foram encontrados 806 artigos, dos quais foram selecionados para leitura, 32. A seleção dos estudos para encontra-se representada na Tabela 6.

\begin{tabular}{lcc}
\hline \multicolumn{1}{c}{ Base de dados } & Encontrados & Lidos \\
\hline Capes & 275 & 11 \\
Scielo & 156 & 7 \\
Web of Science & 337 & 5 \\
Proquest & 38 & 9 \\
\hline Total & 806 & 32 \\
\hline
\end{tabular}

Tabela 6. Estudos selecionados para a revisão de literatura em ANT.

\begin{tabular}{|c|c|c|}
\hline Autor & Ano & Título \\
\hline Anastasiou, Valkanos \& Brinia & 2012 & $\begin{array}{l}\text { Professional Development of the Administrative Staff of } \\
\text { Vocational Training Institutes (IEKs): An empirical study } \\
\text { concerning the training needs of headmasters and vice- } \\
\text { headmasters in Greece }\end{array}$ \\
\hline Araújo, Luana Cristina Rodrigues & 2013 & $\begin{array}{l}\text { Avaliação de Necessidades de Treinamento baseada em } \\
\text { Competências em uma Empresa Pública Federal }\end{array}$ \\
\hline Bubner, Laurence \& Tirimacco & 2012 & $\begin{array}{l}\text { Assessing pathology training needs-results from a survey of } \\
\text { general practice registrars }\end{array}$ \\
\hline Campos, Elziane Bouzada Dias & 2012 & $\begin{array}{l}\text { Avaliação de necessidades de treinamento de empresários } \\
\text { juniores brasileiros }\end{array}$ \\
\hline Carvalho \& Mourão & 2014 & Análise de Necessidades de Treinamento em Call Center \\
\hline Chen \& Hung & 2012 & The Utility of OTP Model in Taiwan Coast Guard \\
\hline $\begin{array}{l}\text { Cunha, Mesquita, Rosado, Sousa } \\
\text { \& Pereira }\end{array}$ & 2010 & $\begin{array}{l}\text { Necessidades de formação para o exercício profissional na } \\
\text { perspectiva do treinador de Futebol em função da sua } \\
\text { experiência e nível de formação }\end{array}$ \\
\hline Ferraz, Clarissa & 2014 & $\begin{array}{l}\text { Avaliação de Necessidades de Treinamento: aplicação de um } \\
\text { método prospectivo de organização não governamental }\end{array}$ \\
\hline Ferreira, Rodrigo & 2014 & $\begin{array}{l}\text { Avaliação de Necessidades de Aprendizagem do trabalho: } \\
\text { Proposição de um Modelo }\end{array}$ \\
\hline
\end{tabular}


Tabela 6. Estudos selecionados para a revisão de literatura em ANT (cont.).

\begin{tabular}{|c|c|c|}
\hline Autor & Ano & Título \\
\hline Ferreira \& Abbad & 2014 & $\begin{array}{l}\text { Avaliação de Necessidades de Treinamento no Trabalho: Ensaio } \\
\text { de um Método Prospectivo }\end{array}$ \\
\hline $\begin{array}{l}\text { Hoffman-Câmara, } \\
\text { Meneses \& Ferreira }\end{array}$ & 2010 & $\begin{array}{l}\text { Necessidades educacionais complementares do bacharel em } \\
\text { turismo: aplicação do método da análise do papel ocupacional }\end{array}$ \\
\hline $\begin{array}{l}\text { Mourão, Gondim, Macedo \& } \\
\text { Luna }\end{array}$ & 2013 & $\begin{array}{l}\text { Avaliação de Necessidades de Treinamento como Preditora do } \\
\text { Impacto do Treinamento no Trabalho }\end{array}$ \\
\hline Silva et al. & 2012 & $\begin{array}{l}\text { Necessidades de treinamento organizacional e motivação para } \\
\text { trabalhar }\end{array}$ \\
\hline $\begin{array}{l}\text { Gallagher, Cass, Black } \\
\text { Norridge }\end{array}$ & 2012 & $\begin{array}{l}\text { A training needs analysis of neonatal and pediatric health-care } \\
\text { staff in a tertiary children's hospital }\end{array}$ \\
\hline $\begin{array}{l}\text { Grason, Kavanagh,Dooley, } \\
\text { Partelow, Sharkey, Bradley \& } \\
\text { Handler }\end{array}$ & 2012 & $\begin{array}{l}\text { Findings from an Assessment of State Title } V \text { Workforce } \\
\text { Development Needs }\end{array}$ \\
\hline Huerta, Audet \& Sabata & 2012 & $\begin{array}{l}\text { The GDOR model. A new methodology for the analysis of } \\
\text { training needs: The case of Andorra }\end{array}$ \\
\hline Pennington & 2011 & $\begin{array}{l}\text { Using a training needs analysis framework in career } \\
\text { development }\end{array}$ \\
\hline Rodrigues & 2012 & $\begin{array}{l}\text { Avaliação de necessidades de treinamento: validação de um } \\
\text { instrumento e estudo descritivo dos aspectos considerados por } \\
\text { organizações públicas federais brasileiras na realização da ANT }\end{array}$ \\
\hline Skica \& Rodzinka & 2012 & $\begin{array}{l}\text { The analysis of training needs in public institutions operating in } \\
\text { health care sector in the Podkarpacie Province }\end{array}$ \\
\hline Sutton \& Booth & 2012 & $\begin{array}{l}\text { What type of leader am I?: a training needs analysis of health } \\
\text { library and information managers }\end{array}$ \\
\hline
\end{tabular}

Fonte: Adaptado de Cesnik (2014).

A seguir, na Tabela 7, esses estudos são descritos, conforme objetivos e procedimentos metodológicos utilizados nas pesquisas. São apresentados população, forma de coleta de dados da pesquisa, bem como instrumentos de medida utilizados pelo autor no estudo. 
Tabela 7. Aspectos metodológicos de estudos recentes em ANT (adaptado de Cesnik, 2014).

\begin{tabular}{lllll}
\hline Autor e ano & Objetivo & População & Coleta de dados & Instrumentos de medida \\
\hline & & & & Na entrevista foi utilizado um questionário específico com \\
perguntas sobre os dados sociodemográficos, funcionais, \\
objetivos dos participantes para o ano letivo, percepção de
\end{tabular}

\begin{tabular}{|c|c|c|c|c|}
\hline Araújo, 2013 & 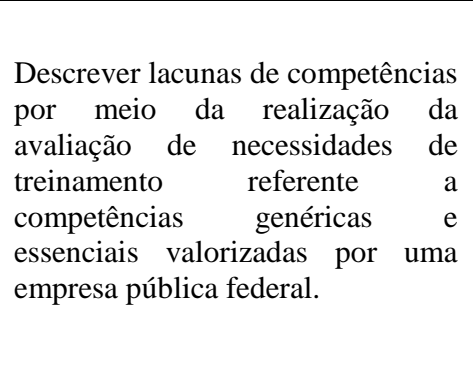 & $\begin{array}{l}\text { Todo o corpo funcional da } \\
\text { organização - } 895 \text { empregados } \\
\text { distribuídos na matriz e em } 22 \\
\text { estados do país. }\end{array}$ & $\begin{array}{l}\text { Na primeira etapa foi realizada análise } \\
\text { documental e entrevistas para compor } \\
\text { a análise organizacional; na segunda } \\
\text { etapa foram realizados grupos focais } \\
\text { com funcionários para extrair as } \\
\text { competências valorizadas pela } \\
\text { organização e não ligadas a nenhum } \\
\text { cargo ou função específica; e } \\
\text { posteriormente aplicado o questionário } \\
\text { para coleta das informações. }\end{array}$ & $\begin{array}{l}\text { Foi construído um instrumento baseado em competências } \\
\text { contendo itens associados a duas escalas (importância e } \\
\text { domínio) do tipo Likert de } 4 \text { pontos }(0 \text { a } 3) \text { e uma escala de } \\
\text { suporte composta por } 17 \text { itens associados a uma escala de } \\
\text { concordância de } 4 \text { pontos ( } 0 \text { a } 3 \text { ), além de uma questão } \\
\text { aberta. Após a sua construção, foi submetido a três etapas } \\
\text { de validação semântica e a realização de um estudo piloto, } \\
\text { além das análises estatísticas pós-coleta. }\end{array}$ \\
\hline $\begin{array}{l}\text { Bubner et al., } \\
2012\end{array}$ & $\begin{array}{l}\text { Identificar as necessidades de } \\
\text { treinamento de agentes de registo } \\
\text { de patologia de clínica geral em } \\
\text { relação à solicitação de exames e } \\
\text { interpretação de condições comuns } \\
\text { encontrados na prática geral. }\end{array}$ & $\begin{array}{l}\text { Questionários enviados a } 82 \\
\text { registradores de clínica geral. } 45 \\
\text { registradores devolveram } \\
\text { preenchidos, dando uma taxa de } \\
\text { resposta de } 55 \% \text {. }\end{array}$ & $\begin{array}{l}\text { Os questionários foram enviados via e- } \\
\text { mail para serem auto-administrados. } \\
\text { Para maximizar a taxa de resposta foi } \\
\text { aplicado o método apresentado por } \\
\text { Dillman (2007), o qual inclui a } \\
\text { recomendação de enviar dois } \\
\text { lembretes da pesquisa após o envio } \\
\text { inicial. }\end{array}$ & $\begin{array}{l}\text { Questionário de ANT que foi desenvolvido para este estudo } \\
\text { baseado na literatura, em um grupo focal com registradores } \\
\text { de clínica geral e em entrevistas com prestadores de } \\
\text { patologia. Informações sobre demografia dos respondentes; } \\
\text { treinamento de patologia recebido; usam patologia de } \\
\text { exames de sangue e urina de microscopia / cultura / } \\
\text { sensibilidade, incluindo níveis de dificuldade em relação à } \\
\text { atuação com testes: dificuldades de ordenação (por } \\
\text { exemplo, selecionar o teste apropriado), interpretação (ex. } \\
\text { resultados duvidosos), ambas dificuldades ou nenhuma } \\
\text { delas. }\end{array}$ \\
\hline
\end{tabular}


Amostra de 121 empresários entrevistas coletivas com 34 versão do questionário para a realização da ANT ficou com

Campos,

Realizar uma avaliação das necessidades de treinamento do
empresários juniores brasileiros

juniores para avaliação de empresários juniores e 22 entrevistas 67 itens, divididos em quatro categorias: individuo, equipe,

Empresas Juniores (organizações individuais com ex-empresários macroprocessos e contexto. Esses itens foram avaliados

que objetivam contribuir para a juniores, docentes e profissionais através de uma escala Likert de 11 pontos $(0$ a 10) por formação profissional de seus atrelados ao fome integrantes). organizações. APO (Análise do paps ocupacional).

indicadores de domínio e importância. Avaliação do funcionais por meio de um questionário online.

Identificar a percepção de Carvalho et necessidades de treinamento de al., 2014 supervisores de call centers e como suas varíveis pessoais center. influenciam essa percepção. A coleta de dados foi realizada por sobre o trabalho em call center e sobre as oportunidades de quantitativa) e roteiro semiestruturado percepção de necessidades de capacitação e a motivação (etapa qualitativa). para aprender; e questionário de ANT, com escalas de importância e domínio, do tipo Likert de 4 pontos (0 a 3).

A primeira secção do questionário era relacionada a dados sociodemográficos e a segunda seção voltada para os objetivos do curso e competências. Uma escala do tipo
(1) obter dados empíricos para o processo de ANT em uma organização do governo; (2) comparar as necessidades de treinamento entre a polícia militar

Chen et al., e marítima em TCG (Taiwan Coast

2012 gerencial para TCG em aplicação gerencial para TCG em aplicação
dos resultados do estudo, (4) demonstrar como os resultados deste estudo podem ser aplicados a trabalhos semelhantes em outras organizações. Os membros da força tarefa realizaram Likert de cinco pontos foi utilizada para que os análise organizacional e entrevistados classificassem as suas percepcões das TCG (Taiwan Coast Guard). A desenvolveram um questionário de habilidades a partir dos seguintes indicadores: 1) amostragem foi randomizada e autoavaliação para ser auto ministrado frequência: indica quantas vezes os funcionários aplicam de níveis diferentes de pessoal de baseado no conjunto de habilidades suas competências em seus trabalhos. Implica a linha de frente do TCG. Este superiores, divididas entre habilidades oportunidade para que os funcionários transferir as estudo analisou os questionários operacionais, administrativas e habilidades aprendidas para os seus empregos; 2) dos 1422 militares e 577 gerenciais, listadas a partir de importância: revela a relevância do desempenho de tabalho policiais. $\quad$ entrevistas e observações realizadas bem-sucedido e é algo relacionado ao aprendizado durante o expediente. motivação; 3) competência (domínio): representa necessidades discrepantes no nível de desempenho; 4) urgência: mostra a pressão que devesse aprender. O paradigma de urgência revela a prioridade de ação.

O questionário foi dividido em duas partes: a primeira referente a dados sociodemográficos e a segunda relativa a

Realizar a identificação das A pesquisa contou com 81 necessidades treinadores portugueses. Os treinadores portugues.

Cunha et al., treinadores de futebol em função 2010 dos anos de experiência treinadores participantes da A coleta de dados foi realizada atravé pesquisa possuem em maioria da aplicação de um questioná
$(60,4 \%)$ o curso de nível I da construído e validado neste estudo. profissional e da formação Federação Portuguesa de federativa. Futebol. itens de competências mapeadas. As competências foram categorizadas através do domínio: (a) Competências relacionadas com o Treino; (b) Competências relacionadas com a Competição; (c) Competências relacionadas com a 


\begin{tabular}{|c|c|c|c|c|}
\hline & & & & $\begin{array}{l}\text { Gestão Desportiva; (d) Competências relacionadas com o } \\
\text { Papel de Formador; (e) Competências Pessoais. }\end{array}$ \\
\hline Ferraz, 2014 & $\begin{array}{l}\text { Avaliar a percepção das } \\
\text { necessidades de treinamento dos } \\
\text { funcionários de uma organização } \\
\text { não-governamental. }\end{array}$ & $\begin{array}{l}\text { Colaboradores da instituição } \\
\text { não-governamental. }\end{array}$ & $\begin{array}{l}\text { Grupo focal e coleta por aplicação de } \\
\text { instrumento }\end{array}$ & $\begin{array}{l}\text { Roteiro de entrevista e instrumento de ANT, com } 32 \\
\text { competências, com escalas de importância e domínio, com } \\
\text { escala Likert de } 11 \text { pontos, variando de } 0 \text { a } 10 \text { pontos, } \\
\text { validado semanticamente e por juízes. }\end{array}$ \\
\hline $\begin{array}{l}\text { Ferreira, } \\
2014\end{array}$ & $\begin{array}{l}\text { Propor e explorar um modelo de } \\
\text { avaliação de necessidades de } \\
\text { aprendizagem. }\end{array}$ & Servidores públicos & $\begin{array}{l}\text { Grupos focais e entrevistas } \\
\text { semiestruturadas no estudo 1, e } \\
\text { aplicação de questionários no estudo } 2 .\end{array}$ & $\begin{array}{l}\text { No estudo 1, foi utilizado roteiro, e no estudo } 2 \text {, } \\
\text { instrumento de AVA, com escala Likert de } 11 \text { pontos. }\end{array}$ \\
\hline $\begin{array}{l}\text { Ferreira et } \\
\text { al., } 2014\end{array}$ & $\begin{array}{l}\text { Propor método prospectivo para } \\
\text { identificar } \\
\text { treinamento } \\
\text { organizacional. }\end{array}$ & Auditores de obras públicas & $\begin{array}{l}\text { Análise documental, entrevistas } \\
\text { coletivas e individuais, e aplicação de } \\
\text { instrumento de ANT. }\end{array}$ & $\begin{array}{l}\text { O questionário continha } 47 \text { itens de competências } \\
\text { associados a duas escalas tipo Likert de } 11 \text { pontos }(0 \text { a } 10) \text {. } \\
\text { Os dados foram analisados por meio de estatísticas } \\
\text { descritivas }\end{array}$ \\
\hline $\begin{array}{l}\text { Hoffman- } \\
\text { Câmara et al., } \\
2010\end{array}$ & $\begin{array}{l}\text { Analisar as necessidades de } \\
\text { treinamento de competências de } \\
\text { formandos de cursos de Turismo } \\
\text { de nove instituições do Distrito } \\
\text { Federal. }\end{array}$ & $\begin{array}{l}\text { A amostra de participantes desta } \\
\text { pesquisa foi } 165 \text { estudantes, } \\
\text { sendo que a maioria }(58,8 \%) \text { era } \\
\text { do sexo feminino, com idade } \\
\text { entre } 20 \text { e } 24 \text { anos }(43,6 \%) \text {. }\end{array}$ & $\begin{array}{l}\text { Método de análise do papel } \\
\text { ocupacional. }\end{array}$ & $\begin{array}{l}\text { Para este estudo, foi elaborado um instrumento de ANT } \\
\text { com } 23 \text { competências (conhecimentos, habilidades e } \\
\text { atitudes) tomando como base as diretrizes curriculares do } \\
\text { Ministério da Educação e Cultura para a formação de } \\
\text { turismólogos. Foram associadas a este instrumento duas } \\
\text { escalas de julgamento do tipo Likert (importância e } \\
\text { domínio), variando de } 0 \text { a } 3 \text {. }\end{array}$ \\
\hline $\begin{array}{l}\text { Mourão, } \\
\text { Gondim, } \\
\text { Macedo \& } \\
\text { Luna, } 2013\end{array}$ & $\begin{array}{l}\text { Testar a predição da análise de } \\
\text { necessidades de treinamento sobre } \\
\text { as mudanças no aprendiz (impacto } \\
\text { do treinamento no trabalho). }\end{array}$ & 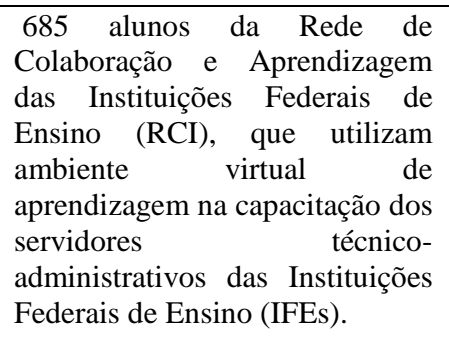 & $\begin{array}{l}\text { A coleta de dados ocorreu em dois } \\
\text { momentos: antes e depois do curso, } \\
\text { por meio de questionários, na } \\
\text { Plataforma Moodle. }\end{array}$ & $\begin{array}{l}\text { Os instrumentos compunham } 4 \text { escalas: uma de } \\
\text { expectativas pré e pós-curso; uma de características do } \\
\text { curso, uma de importância e outra de domínio - as duas } \\
\text { últimas para mensurar a ANT. }\end{array}$ \\
\hline $\begin{array}{l}\text { Silva et al., } \\
2012\end{array}$ & $\begin{array}{l}\text { Investigar a relação entre } \\
\text { motivação para o trabalho e } \\
\text { complexidade de necessidades de } \\
\text { treinamento. }\end{array}$ & $\begin{array}{l}\text { O estudo foi conduzido no } \\
\text { Fundo Nacional de } \\
\text { Desenvolvimento da Educação } \\
\text { (FNDE), uma autarquia federal } \\
\text { vinculada ao MEC. }\end{array}$ & $\begin{array}{l}\text { A coleta de dados por meio desses dois } \\
\text { instrumentos foi realizada via Internet. } \\
\text { No mesmo dia em que os questionários } \\
\text { foram enviados para o e-mail } \\
\text { institucional de todos os servidores, o } \\
\text { Presidente da Autarquia enviou uma } \\
\text { mensagem de apoio à pesquisa, na qual }\end{array}$ & $\begin{array}{l}\text { Construíram e validaram teórica e empiricamente um } \\
\text { instrumento para ANT (baseado na Análise do Papel } \\
\text { Ocupacional) bem como adaptaram e validaram teórica e } \\
\text { empiricamente um instrumento para avaliar a motivação } \\
\text { para o trabalho. }\end{array}$ \\
\hline
\end{tabular}



treinamento dos profissionais que trabalham com famílias e pacientes em cuidados paliativos. Os Participaram do estudo 111 profissionais de cuidados Os paliativos, dentre eles $61 \%$ de Gallagher et resultados deste estudo serão enfermeiros, 25\% médicos e o l., 2012 utilizados para desenvolver um restante distribuído em utilizados para desenvolver um fisioterapeutas, nutricionistas, módulo de atendimento
multidisciplinar para cuidados paliativos pediátricos em parceria com a escola de enfermagem da universidade local.
Questionário online

terapeutas ocupacionais, farmacêuticos, cientistas clínicos, psicólogos
Descrever os resultados de uma Foram enviados pedidos para Os participantes da avaliação foram avaliação de 2008 de competências 112 líderes do programa para solicitados a responder sobre as "Título V da força de trabalho" e ajudar com a pesquisa, de modo perspectivas dos funcionários sobre

Grason et al., necessidades de formação a nível que destes programas, $49 \mathrm{MCH}$ - áreas programáticas, ao pessoal de 2012 estadual, e analisar as preferências Saúde Materno-Infantil - (96\%) e linha e os níveis de gestão. Avisos em e as barreiras relacionadas com a $44 \mathrm{CYSHCN}$ - Crianças e Jovens correspondência e contatos pessoais educação disponível e com Necessidades Especiais de para aqueles que não respondem oportunidades de formação. $\quad$ Saúde - $(86 \%)$ responderam. dentro de um mês.
Para realização da pesquisa, foi construído um questionário baseado em itens de percepção de conhecimento, confiança e suporte dos profissionais de saúde neonatal e pediátrica para serem julgados através de uma escala Likert.
Demonstrar uma metodologia para determinar as necessidades de Foi feito um levantamento de 90 indicadores de gestão e organiza-os em treinamento contínuas em uma empresas de Andorra para value drivers (que pode ser visto como

Huerta et al., região de Andorra, visando analisar o potencial impacto da blocos de construção significativos) e

2012 oferecer uma solução para os formação sobre as principais áreas de resultado. Foram realizadas oferecer uma solução para os formação sobre as principais áreas de resultado. Foram realizadas
processos de ANT no Principado questôes operacionais, e para o cinco sessões de grupos focais e de Andorra para o período 2007- futuro das empresas. entrevistas em profundidade com 2009. membros das empresas participantes.
Itens de avaliação foram baseados em conceitos incorporados em cinco modelos de competências desenvolvidas por ATMCH, MCHB, a Associação das Escolas de Saúde Pública (ASPH), o Conselho sobre as ligações entre Academia e Prática de Saúde Pública, e pela Avaliação AMCHP da Capacitação para Programas Estaduais Título V (ELENCO-5). Vários itens de avaliação foram elaborados a partir dos estudos de 1992 e 2000, a fim de documentar as tendências temporais.

Para a concepção do questionário, os autores desenvolveram sua própria metodologia conhecida como Outcome Driven Development Management (GDOR ()). 
O processo de ANT foi

Descrever como um departamento concebido para o setor de tem usado a ferramenta de ANT radioterapia de uma organização para identificar e tratar a formação radioterapia de uma organização de pessoal e as necessidades de hospitalar. Participaram da

Pennington, CPD Profissional Contínuo), e como isso ajudou a cumprir os objetivos individuais, departamentais sioterapeuta, um nutricionista um cientista clínico, um cientista clínico, facilitados pelos professores da

Universidade de Salford.

organizacionais.

Para a investigação foi desenvolvido um questionário dividido em duas secções: A primeira parte foi projetada para obter as informações sobre formação continuada, tempo gasto com essa atividade, quando o respondente considera o melhor momento para EAD. A segunda parte Foram distribuídos 70 questionários, sobre treinamentos específicos referentes ao trabalho, como dentre os quais $65(93 \%)$ foram por exemplo: se os entrevistados reconhecem que tiveram respondidos. ugestões para melhorar o percurso de formação, como competentes, além de uma pergunta aberta pedindo sugestões sobre como melhorar a prestação de CPD e treinamento, com espaço para comentários adicionais.

\section{Investigar os aspectos} considerados por organizações

Rodrigues, públicas federais na realização de 2012 ANT, baseado na percepção dos profissionais de $\mathrm{RH}$ dessas instituiç̃̃es.
Participaram desta pesquisa 213 profissionais de 81 organizações úblicas de todo o Brasil.
Estudo foi dividido em três partes: 1)

elaboração e validação teórica e empírica do instrumento; 2) descrição

dos aspectos considerados por tais Foi construído e validado instrumento para identificar os organizações; 3) testagem das relações aspectos apreciados por organizações públicas federais entre os aspectos evidenciados e as brasileiras na ANT. O questionário apresentou bons índices características organizacionais e das psicométricos de validação e confiabilidade. unidades responsáveis pelo processo de TD\&E. APO (Análise do papel ocupacional).
Diagnosticar as necessidades de Skica et al treinamento dos funcionários de 2012
Os participantes foram questionados sobre treinamento externo recebido anteriormente assim como o tempo decorrido desde essa ação educacional, estudo foi feito em 50 centros área de interesse para receber algum e saúde de 22 cidades treinamento externo, que tipo de diferentes. fundos seu centro de saúde utiliza para fundos seu centro de saúde utilza as atividades educacionais, bem como se ele considera que treinamentos externos são motivadores para os funcionários. centros de saúde de uma província centros de
na Polônia.
Questionário com perguntas sobre treinamentos externos e financiamento recebido para esse fim.

Realizar uma análise das 153 bibliotecários de saúde e A coleta de dados foi feita a partir de

Sutton et al., necessidades de treinamento 153 bibliotecários de saúde e cinco seções: 1) questões demográficas

$\begin{array}{llll}2012 & \text { (ANT) de habilidades de liderança } & \begin{array}{l}\text { gestores de informação da } \\ \text { de bibliotecários de saúde e Inglaterra. }\end{array} & \begin{array}{l}\text { sobre perfil de trabalho, setor e área } \\ \text { geográfica. As seções seguintes (2 a 5) }\end{array}\end{array}$ gestores de informação da
Influencing Skills Style Profile (ISSP) foram adaptadas a partir do 


\begin{tabular}{|c|c|c|}
\hline Autor e ano & População & Instrumentos de medida \\
\hline & $\begin{array}{l}\text { Inglaterra, incluindo competências } \\
\text { atuais e de planejamentos futuros. }\end{array}$ & $\begin{array}{l}\text { instrumento Influencing Skills Style } \\
\text { Profile (ISSP). 2) A segunda seção } \\
\text { utilizou a técnica dos incidentes } \\
\text { críticos, a terceira seção perguntou aos } \\
\text { entrevistados sobre suas respostas } \\
\text { gerais a situações desafiadoras } \\
\text { rotineiras. A quarta seção examinou } \\
\text { como os entrevistados se sentem sobre } \\
\text { suas atuais competências e habilidades, } \\
\text { e a quinta seção questionou os } \\
\text { participantes em como eles gostariam } \\
\text { de desenvolver as habilidades } \\
\text { interpessoais, tratando-se de um } \\
\text { desenvolvimento futuro segundo os } \\
\text { autores. }\end{array}$ \\
\hline
\end{tabular}


Hoffman-Câmara et al. (2010) aplicaram o modelo APO em cenário profissional, ampliando o uso para contexto organizacional. Silva et al. (2012) também aplicaram o mesmo modelo em sua pesquisa, que estudou que indivíduos mais motivados para o trabalho teriam a tendência a indicar necessidades de treinamento mais complexas, baseadas na taxonomia de Bloom et al. (1972). O estudo trouxe contribuições, pois resultou em mais um tipo de uso possível do IPG e do método da APO de modo geral, possibilitando uma avaliação de variáveis preditoras das necessidades de treinamento. De acordo com Cesnik (2014), os autores relatam que a motivação para o trabalho não é considerada como preditora direta de necessidades de treinamento em modelos de investigação da natureza estudada; refletem que de acordo com as teorias motivacionais de processo, a motivação por trabalhar é produto ambiental e são relacionadas à maneira como as condições de trabalho são gerenciadas. Outro achado da pesquisa indica diferenças estatisticamente significativas entre tempo de serviço e necessidades de treinamento, confirmando os resultados encontrados por Magalhães et al. (2001).

No estudo sobre necessidades de treinamento para garantir a efetividade de empresas juniores, Campos (2012) relata altos índices de prioridade para competências genéricas indicando sua relevância nas grades curriculares da graduação ou em disciplinas elaboradas para atender demandas de aprendizagem de empresários juniores.

Rodrigues (2012) argumenta sobre as diferenças estatisticamente significativas entre os escores de organizações que possuem processos sistemáticos e formais de ANT e os de empresas que não operacionalizam esse método ou que realizam abordagens ad hoc, o que indica que as organizações com processos sistemáticos de ANT consideram um maior conjunto de aspectos na avaliação das necessidades que as outras organizações.

Sutton et al. (2012), estudou uma maneira de operacionalizar a ANT mais integradora, envolvendo diversos métodos de identificação, como o método de incidentes críticos de experiência na área e como o participante gostaria de desenvolver suas habilidades.

Skica et al. (2012) pesquisou os gestores públicos em centros de saúde, que percebem treinamento como fator de motivação importante ou muito importante para os trabalhadores. Os estudos investigaram em que área é necessário receber um treinamento externo, concluindo que não há diferenças na estrutura de indicações, e que não há critérios para hierarquia de importância dos programas de formação oferecidos às instituições. No entanto, 
este tipo de metodologia ainda deixa dúvidas em relação a uma adequada avaliação de necessidades de treinamento.

Segundo Grason et al. (2012), a maioria dos programas analisados (74\%) avaliam as necessidades de treinamento do seu pessoal em períodos anuais. A ANT é realizada para ajudar a melhorar as competências e desempenho dos funcionários, para o desenvolvimento do programa de capacitação geral, para promover a melhoria, e também para atender exigências de formação do programa. Embora os programas coletem informações sobre as necessidades de treinamento de pessoal, a sua capacidade de atender a essas necessidades é limitada. Esses resultados confirmam a pesquisa realizada por Abbad et al. (2012) que relata que avaliações de necessidades de treinamento por meio de listas de temas, que ainda parece ser uma das formas mais utilizadas pelas organizações e pesquisadores, que utilizam a metodologia no caso de capacitação concomitante a processo de descrição de competência.

Pennington (2011) indicou nos resultados de sua pesquisa que $20 \%$ dos entrevistados não têm formação adequada para realizar suas tarefas com competência. A avaliação de necessidades de treinamento foi realizada a partir de levantamento de áreas com os funcionários e não apresenta relacionamento de predição das variáveis relacionadas à ANT. O autor menciona que nesta organização qualquer percepção de falta de treinamento dos entrevistados significou que não poderiam realizar seu trabalho com competência e foram planejadas ações educacionais para os empregados.

Em estudo realizado em uma empresa pública federal, Araújo (2013) comparou grupos quanto às necessidades de treinamento e investigou a correlação entre as necessidades de treinamento desses grupos e as medidas de suporte. Estudou as variáveis: região de trabalho, tempo de serviço, escolaridade, faixa etária, setor de trabalho e sexo, sendo possível identificar variáveis antecedentes para lacunas de competências. Os reultados apontaram que o tempo de serviço é um bom preditor de necessidades de treinamento, corroborando achados anteriores, na pesquisa de Magalhães et al. (2001).

No trabalho desenvolvido por Cunha et al. (2010), os treinadores com formação federativa mais elevada percebem menores necessidades de treinamento que os treinadores sem a formação. Na análise das competências profissionais em função dos anos de experiência na função, notou-se que quanto maior a experiência menor a percepção de necessidade de capacitação em áreas específicas, se comparados aos menos experientes. Estes 
achados sugerem a importância de serem utilizadas variáveis funcionais de tempo de trabalho e formação profissional na avaliação de necessidades de treinamento.

Nos estudos de Chen et al. (2012), foram utilizados indicadores para analisar cada competência. Os resultados demonstram que os participantes percebem as habilidades mais importantes como aquelas que eram freqüentemente aplicadas.

Mourão et al. (2013) trazem a reflexão acerca da análise individual na dimensão da ANT à luz dos resultados de sua pesquisa, uma vez que devem ser complementadas por outros tipos de medida que levem em conta aspectos relativos à tarefa, ao desempenho no trabalho e a indicadores organizacionais. Seus achados indicaram predição inversa da percepção de necessidade de treinamento para o impacto do curso, ou seja, quanto menos a pessoa avaliava que precisava do curso, mais positivamente ela avaliou como positivo seu impacto.

Carvalho (2014), com o objetivo de identificar a percepção das necessidades de treinamento dos supervisores de call center e sua influência sobre as variáveis pessoais, desenvolveu um estudo qualitativo, pois utilizou como forma de coleta de dados entrevistas em profundidade. Esta estratégia de coleta de informações consiste em um desafio para o pesquisador, devido a análise de conteúdo de amostra numerosa. A pesquisa trabalhou com a análise de tarefa relacionando suas necessidades às características individuais, um aspecto do processo de ANT identificado recentemente, no entanto sem muitas experiências relatadas.

Analogamente, Ferraz (2014) realizou uma pesquisa com o mesmo objetivo, com a população-alvo de funcionários de organizações não governamentais. No entanto, sua coleta foi realizada por meio de questionários de ANT, desta forma, caracterizando-se como quantitativo.

Houve uma contribuição de cunho metodológico nesse período, com a proposição de uma metodologia prospectiva por Ferreira et al. (2014). A operacionalização da metodologia, integrou a análise documental, entrevistas e aplicação de questionário. A maioria dos estudos destacados aborda a utilização do modelo de papeis ocupacionais. Ferreira et al (2014), exceção dentre os estudos, procedeu a análise organizacional.

De forma geral, os estudos apresentados, desenvolvidos no contexto nacional e internacional, apresentam práticas de ANT em diferentes contextos, com utilização de metodologias diversas, adequadas a cada objetivo de pesquisa. Os estudos conduzidos têm como foco, em sua maioria, a análise individual. Nota-se, ainda, a propulsão de um reforço no 
campo teórico-metodológico na área por parte de autores no contexto nacional. No entanto, ainda se observa lacunas de estudos na área, seja pela falta de campo encontrado pelos pesquisadores, ou ausência de interesse das empresas em desenvolver ou investir recursos nesta etapa de TD\&E.

O presente estudo utilizou o Modelo do Papel Ocupacional (Borges-Andrade et al., 1983) para proceder à ANT dos líderes de projeto. As competências foram mapeadas e mensuradas para o cálculo do IPG. O processo de mapeamento e mensuração dos CHAs integra a próxima seção, características metodológicas da pesquisa. 


\section{CAPÍTULO 4. CARACTERÍSTICAS METODOLÓGICAS DA PESQUISA}

\section{Objetivo do capítulo 4}

Este capítulo se propõe a descrever a delimitação do problema, a justificativa e os objetivos da pesquisa; retratar o modelo de investigação; apresentar as características da instituição-alvo da pesquisa; descrever a população e a amostra; o instrumento de medida; e ilustrar os procedimentos de coleta e análise estatística dos dados.

\subsection{Delimitação do problema, objetivos de pesquisa e modelo de investigação}

O problema de pesquisa deste estudo foi delimitado a partir da apreciação das questões empíricas que tangem o domínio da literatura da área de treinamento, desenvolvimento e educação, com foco no subsistema de avaliação de necessidades de treinamento, e estudos anteriores voltados para o tema. Considerando a análise da literatura percebe-se que, apesar dos avanços na área, poucos estudos se dedicaram a propor modelos eficazes de predição sobre fatores que influenciam a necessidade de treinamento do indivíduo (Magalhães et al., 2001; Silva et al., 2012). Informações como essas podem auxiliar a tornar métodos de ANT mais criteriosos e efetivos, tornando investimentos na área TD\&E melhor aproveitados, outra agenda de pesquisa neste campo. Reflete-se, ainda, sobre a importância de utilizar instrumentos de ANT que reproduzam a realidade da empresa. No contexto desta pesquisa, foram encontrados, ainda, estudos voltados à identificação de competências de líderes de projeto, bem como de eventos de capacitação para essa clientela, evidenciando a relação do desempenho de sua gestão com o sucesso do projeto (Oliveira et al., 2016; Russo et al., 2005; Santana et al., 2016).

Esses componentes se relacionam no contexto deste estudo, e identifica-se que sua articulação venha a produzir resultados, a ponto de contribuir com lacunas de estudos sobre a influência de variáveis na ANT, validar a importância da utilização de instrumentos de ANT voltados à realidade da empresa, em atenção à clientela de líderes de projeto. Nesse sentido, o presente estudo pretende fornecer elementos que auxiliem na compreensão da relação das variáveis que integram as características da clientela (características sociodemográficas e funcionais) às necessidades de treinamento de líderes de projeto da instituição-alvo da 
pesquisa, identificadas por meio de instrumento construído especificamente para a clientela. $\mathrm{O}$ Modelo mostra a Figura 7.

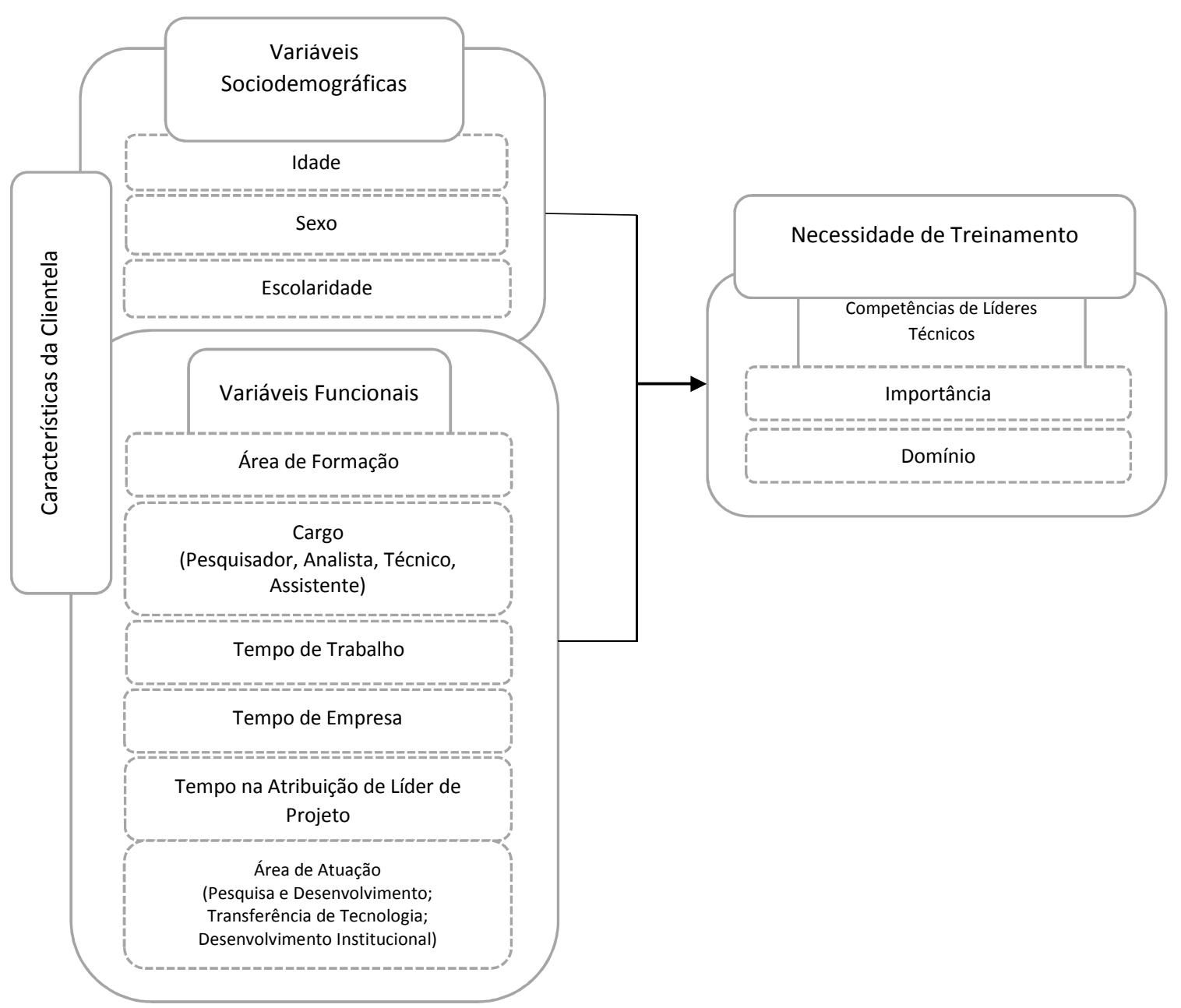

Figura 7 - Modelo de Investigação.

Em decorrência do modelo apresentado, são propostos os seguintes problemas de pesquisa:

1. Qual o perfil dos líderes de projeto das empresas que atuam com Pesquisa, Desenvolvimento e Inovação - PD\&I?

2. Qual o perfil dos líderes de projeto da Embrapa?

3. Há demanda de capacitação entre os líderes de projeto que atuam na Embrapa? 
4. O que pode causar uma eventual lacuna de competências entre os líderes de projeto que atuam na Embrapa?

Com a finalidade de responder às questões relacionadas, foram traçados os objetivos de pesquisa, apresentados a seguir.

- Objetivo Geral

Propor e testar um modelo de identificação de lacunas de competências de líderes de projeto, objetivando identificar suas variáveis preditoras relacionadas às características da clientela (características sociodemográficas e funcionais) no contexto de instituições de PD\&I.

- Objetivos Específicos

1. Construir o instrumento de Competências de Líderes de Projeto (CompLP).

2. Verificar evidências de validade do instrumento CompLP.

3. Identificar as lacunas de competências dos líderes de projeto da Embrapa.

4. Analisar o perfil da clientela de líderes de projeto da Embrapa.

5. Identificar as variáveis que influenciam a aquisição de CHAs.

\subsection{Características da Instituição}

A pesquisa foi desenvolvida tendo a Empresa Brasileira de Pesquisa Agropecuária Embrapa como instituição-alvo. A proposta de trabalhar com essa instituição teve origem desta pesquisadora, por integrar seu quadro de empregados e possuir, assim, a disponibilidade da referida instituição em constituir-se campo de investigação. Além disso, a Embrapa é uma empresa de fomento à pesquisa, voltada à geração de conhecimento, o que facilita a parceria e a condução do estudo pela proponente. Desta forma, foi emitida pela Empresa autorização (Anexo II) para proceder à coleta de dados, cujas etapas foram então iniciadas.

A Embrapa é uma empresa pública, vinculada ao Ministério da Agricultura, Pecuária e Abastecimento - MAPA. Criada em 1973, desde sua origem é dedicada a soluções aplicáveis à modernização agrícola. 
Trata-se de uma empresa de inovação tecnológica, e operacionaliza sua atuação por meio dos macroprocessos da Pesquisa e Desenvolvimento - P\&D, Transferência e Tecnologia e Desenvolvimento Institucional.

Considerando como produto final da Empresa a geração de conhecimento e tecnologia, possui em seu percurso a etapa da pesquisa. A programação de pesquisa tem como foco temas estratégicos da agropecuária brasileira, e é organizada em torno de projetos. Os projetos respondem a desafios de pesquisa, e são agrupados em carteiras, denominados macroprogramas (figuras programáticas de organização de projetos em temas), arranjos (projetos organizados por unidades e articulação com parceiros) e portifólios (projetos induzidos a partir de temas estratégicos, definidos pela direção da Empresa).

As carteiras de projetos - macroprogramas, arranjos e portifólios fazem parte do Sistema Embrapa de Gestão - SEG, que organiza a produção da Empresa. Contempla a definição das pesquisas, sua prioridade, e a avaliação do impacto das ações na Empresa.

A instituição é descrita mais detalhadamente, em seus aspectos estruturais, de funcionamento, estratégicos, de negócios, bem como dos processos de gestão de pessoas a partir da análise organizacional, uma das etapas as quais integram a ANT, descritas a posteriori.

\section{Análise organizacional}

Realizada para promover o alinhamento das necessidades das ações de treinamento às estratégias organizacionais, a análise organizacional descreve a organização, compreendendo assim a apreciação e o diagnóstico de aspectos relevantes a serem considerados para esse processo de articulação.

Para proceder à análise do contexto da organização, foram feitas análise documental e bibliográfica de registros e publicações disponibilizados pela Empresa (Plano Diretor da Embrapa; Cartilha de Estruturação e Organização dos Processos da área de Gestão de Pessoas; Embrapa em Números; Visão 2014-2034). Todos os documentos para a análise foram acessados por esta pesquisadora por meio de pesquisa em site corporativo da Empresa.

A partir dos referidos documentos considerou-se como aspectos relevantes para compreender o cenário da organização, bem como seus objetivos e estratégias: a origem da empresa; sua estrutura organizacional; seu funcionamento e planejamento estratégico. No 
intuito de entender o funcionamento dos processos no âmbito da gestão de pessoas, mais especificamente os de treinamento e desenvolvimento, investigou-se acerca desses aspectos.

\section{Estrutura organizacional}

A composição administrativa da Empresa abrange a Sede, em Brasília, responsável por planejar, supervisionar, coordenar e controlar as atividades relacionadas à execução de pesquisa agropecuária, transferência de tecnologias e desenvolvimento institucional. Composta por 17 unidades administrativas, denominadas Unidades Centrais - Ucs, as quais fornecem suporte à Diretoria-Executiva da Empresa. Ademais, a Empresa possui 46 Unidades Descentralizadas - UDs, presentes em todas as regiões do país, além da atuação internacional, por meio de parcerias com algumas das principais instituições e redes de pesquisa do mundo.

De acordo com estatuto da Empresa de 2017, sua composição administrativa abrange, em ordem hierárquica: 1) Assembleia Geral, 2) Conselho de Administração, 3) Auditoria, 4) Conselho fiscal, 5) Ouvidoria, 6) Diretoria Executiva - Presidência, Pesquisa e Desenvolvimento, Transferência e Tecnologia e Administração e Finanças; 7) Unidades Centrais e 8) Unidades Descentralizadas.

Com relação ao quadro de pessoal da Empresa, é composto, atualmente, por 9.713 empregados, distribuídos nas unidades centrais e descentralizadas. Ocupam cargos de pesquisador, analista, técnico, assistente e cargos em comissão. A maioria é representada pelo sexo masculino (70\%), que também predomina entre o grupo de gestores $(68,6 \%)$. A maior faixa está entre 46 e 55 anos (31,36\%), e 64,38\% encontram-se acima de 36 anos. Predominam os empregados com pós-graduação, totalizando 48,32\%, entre especialistas, mestres, doutores e pós-doutores. Os empregados com mais de 25 anos de empresa apresentam a faixa com maior índice, de $44,52 \%$. Esse perfil é ilustrado na Tabela 8. 
Tabela 8 - Perfil dos empregados da Embrapa

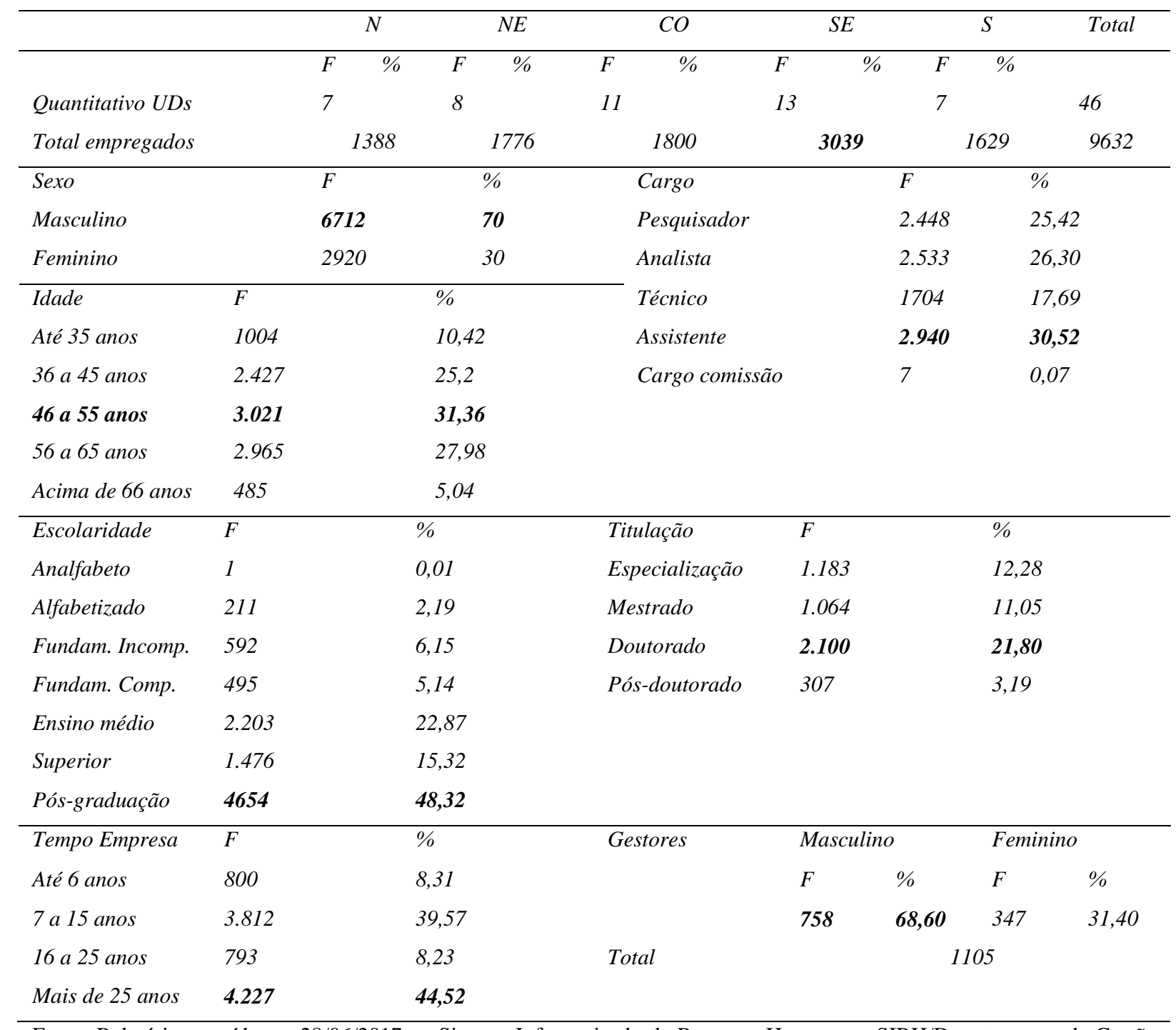

Fonte: Relatório extraído em 28/06/2017 no Sistema Informatizado de Recursos Humanos - SIRH/Departamento de Gestão de Pessoas - DGP/ Embrapa

Com o intuito de compreender as estratégias da Empresa para estabelecer prioridades, políticas e metas e conduzir seus componentes à atuação em sinergia com seus objetivos, foram consultados documentos de diagnóstico e planejamento estratégico da Embrapa.

\section{Planejamento Estratégico}

A Empresa desenvolve estudos de cenários, sistematicamente, e elabora planos diretores para orientar os rumos de sua evolução institucional, e assim estudar quais aspectos e recursos são necessários ao desenvolvimento da agropecuária nacional. A Empresa instituiu um sistema de inteligência estratégica, denominado Agropensa, e iniciou um processo de 
construção, aferição, modulação e atualização de cenários, necessários ao planejamento da Empresa.

No intuito de vincular as estratégias de atuação da empresa às necessidades das cadeias produtivas, foram definidos macrotemas, identificados para prospectar e monitorar tendências e identificar panoramas futuros relevantes para a pesquisa e para a inovação na agropecuária. A gestão de Pesquisa \& Desenvolvimento, de Transferência de Tecnologias, de Negócios e de Desenvolvimento Institucional devem ser desenvolvidas com foco nos macrotemas.

A partir desses pilares, a Empresa espera concretizar sua missão e visão institucionais. Os objetivos e as diretrizes estratégicas são derivados dos macrotemas, os quais devem ser considerados pelas Unidades da Embrapa no planejamento de suas atividades, e subsidiam o processo de planejamento global da Embrapa.

Como missão, a Empresa busca viabilizar soluções de pesquisa, desenvolvimento e inovação para a sustentabilidade da agricultura, em benefício da sociedade brasileira. Tem como visão consolidar-se como referência mundial na geração e oferta de informações, conhecimentos e tecnologias, contribuindo para a inovação e a sustentabilidade da agricultura. Como valores, possui o Comprometimento; a Cooperação; a Equidade; a Ética; a Excelência; a Responsabilidade socioambiental; a Flexibilidade; e a Transparência.

No intuito de promover uma visão geral do processo de gestão de pessoas e suscitar o entendimento do contexto das ações de treinamento na Empresa são explicitados em seguida seus aspectos mais relevantes.

\section{Gestão de Pessoas}

A área de Gestão de Pessoas na Embrapa é estruturada em um Departamento/ Unidade Central na Sede - Departamento de Gestão de Pessoas (DGP), responsável por promover a gestão estratégica de pessoas, coordenando as políticas, diretrizes e procedimentos relacionados à área; e em Setores de Gestão de Pessoas (SGPs), os quais estão localizados nas Unidades Descentralizadas. As ações desenvolvidas na Unidade Central têm reflexo nas atividades realizadas pelos SGPs, que atuam em parceria na área de gestão de pessoas.

Os macroprocessos que integram a área compreendem: 1) Bem-estar - com foco em Benefícios, Saúde, Clima Organizacional e Qualidade de Vida, Pró-equidade de Gênero, Raça e Diversidade, e Segurança no Trabalho; 2) Atração e Seleção Profissional - foco em 
Recrutamento e Seleção de Pessoas, Gestão da Informação de Pessoal e Gestão da Vida Funcional; 3) Estudos e Desempenho - Gestão de Desempenho; Reconhecimento e Recompensa, e Carreira e Indicadores; 4) Remuneração - Folha de Pagamento, Gestão do Sistema de Recursos Humanos da Embrapa, Acompanhamento das Obrigações Trabalhistas, Previdenciárias, Tributárias e Fiscais, Contribuição Sindical; e 5) Educação Corporativa treinamento e desenvolvimento, educação profissional dos empregados; e formação e qualificação dos estagiários, estudantes e bolsistas. Para que a área de gestão de pessoas contribua para a elevação do desempenho global da Embrapa, suas práticas devem estar alinhadas às estratégias organizacionais.

Cada macroprocesso corresponde a uma coordenadoria administrativa no DGP / Unidade Central - Sede, e todos são conduzidos por um SGP, que fica em cada uma das unidades descentralizadas. Atualmente a área de gestão de pessoas conta com 305 empregados, distribuídos entre o DGP (24,6\% dos empregados) e em cada um dos 46 SGPs (230 empregados).

\section{Treinamento}

As ações de treinamento são, na Empresa, aquelas voltadas à atualização e ao aprofundamento de competências relevantes à atuação profissional do empregado, resultando no aprimoramento do desempenho no trabalho. Tem como objetivo aprimorar competências relacionadas à atuação profissional atual e/ ou futura, por meio de ações de aprendizagem diversificadas, coerentes com as diretrizes da Embrapa, visando a melhoria do desempenho e o crescimento profissional do empregado.

O treinamento é desenvolvido a partir de ações de capacitação técnica e gerencial. As capacitações técnicas são realizadas por meio de estratégias formais e informais de aprendizagem contínua que estimulam os empregados a serem corresponsáveis pelo seu desenvolvimento profissional.

As necessidades de capacitação técnica individual são identificadas pelo chefe imediato, em conjunto com o empregado, no processo de gestão do desempenho, considerando o que deve ser aprimorado ou desenvolvido em termos de conhecimento ou habilidades técnicas. 
Acerca das capacitações gerenciais, estas possuem como público alvo os empregados ocupantes de função/cargo de confiança, e são relacionadas ao Programa de Desenvolvimento Gerencial da Embrapa, em fase de implantação.

Tal como a pesquisa se propõe a avaliar as necessidades de treinamento dos líderes de projeto, apresenta-se a seguir o como se dá o referido processo na Empresa.

\section{Avaliação de necessidades de treinamento}

Na Embrapa a ANT é denominada INC - identificação de necessidades de capacitação. A área responsável pelo processo realiza periodicamente o diagnóstico de necessidades de capacitação junto às Unidades Centrais (UCs) e Unidades Descentralizadas (UDs). Para isso, adota metodologia específica com objetivo de identificar necessidades de capacitação coletiva, tanto de natureza local quanto corporativa. Necessidade de capacitação é vista como a discrepância de desempenho, em termos de necessidades atuais e futuras da organização (Abbad, Freitas e Pilati, 2006). O diagnóstico de necessidades é relevante para orientar a construção de programas e ações de treinamento e desenvolvimento (T\&D) e a mensuração de seus resultados. Assim, a INC orienta a preparação dos Projetos de Capacitação Técnica Coletiva, quer sejam direcionados a empregados de uma Unidade ou à Embrapa de forma corporativa.

Para subsidiar o planejamento de ações de educação continuada, as quais possibilitam o desenvolvimento profissional dos empregados, a identificação de necessidades avalia a condição real de desempenho em função do que é esperado. E, como foi citado anteriormente, as necessidades de capacitação técnica individual são identificadas no processo de gestão do desempenho.

A seção a seguir descreve a população a qual esta pesquisa foi destinada, bem como a amostra estratificada de seus respondentes.

\subsection{População e amostra}

A população identificada para a pesquisa é composta por empregados de empresas cujo produto é PD\&I. Como mencionado anteriormente, na Embrapa, são identificados como líderes de projeto. O líder de projeto na Embrapa exerce papel relevante na tramitação de um projeto no ciclo de planejamento, execução, acompanhamento e avaliação da produção em 
Pesquisa e Desenvolvimento, Transferência e Tecnologia e Desenvolvimento Institucional: de forma geral, dá origem aos projetos, seja para ampliar o conhecimento de uma área, ou para resolver um problema específico.

Os líderes de projeto compõem um grupo de 886 empregados (dados de relatórios internos do departamento de pesquisa da Embrapa), podendo estar associados, na Empresa, a mais de um projeto. Com relação à amostra, o estudo é censitário, pois a aplicação do questionário foi realizada a todos os empregados com atribuição de líder de projeto da Instituição-alvo.

Do total de 886 líderes de projeto para os quais foram enviados os e-mails-convite para participação na pesquisa, obteve-se um índice de retorno de 43,11\%. A caracterização da amostra considerou os dados sociodemográficos e funcionais coletados na ocasião da pesquisa, referente aos 300 questionários válidos, após análises realizadas. Os dados do perfil da amostra estão apresentados na Tabela 9.

Tabela 9 - Caracterização da amostra

\begin{tabular}{|c|c|c|c|c|c|}
\hline Variável & $\mathrm{F}$ & $\%$ & Variável & $\mathrm{F}$ & $\%$ \\
\hline Sexo & & & Cargo & & \\
\hline Masculino & 180 & 60 & Pesquisador & 291 & 97 \\
\hline Feminino & 120 & 40 & Analista & 9 & 3 \\
\hline \multicolumn{6}{|l|}{ Idade } \\
\hline Até 40 anos & 83 & 27,7 & Média & 47 & \\
\hline 41 a 50 anos & 109 & 36,3 & Desvio padrão & 9,37 & \\
\hline 51 a 60 anos & 76 & 25,3 & Moda & 44 & \\
\hline \multirow[t]{2}{*}{ Acima de 60 anos } & 31 & 10,3 & Mínimo & 31 & \\
\hline & & & Máximo & 80 & \\
\hline \multicolumn{3}{|c|}{ Eixo de atuação na Empresa } & Titulação & & \\
\hline Com. desenv instit & 3 & 1 & Mestrado & 21 & 7 \\
\hline Pesq desenv \& inov & 289 & 96,3 & Doutorado & 207 & 69 \\
\hline Tranf tecnol & 8 & 2,7 & Pós-doutorado & 72 & 24 \\
\hline \multicolumn{6}{|l|}{ Tempo de Empresa } \\
\hline Até 10 anos & 138 & 46 & Média & 15,25 & \\
\hline 11 a 20 anos & 79 & 26,3 & Desvio padrão & 10,51 & \\
\hline 21 a 30 anos & 54 & 18 & Moda & 6 & \\
\hline \multirow[t]{2}{*}{ Acima 30 anos } & 29 & 9,7 & Mínimo & 2 & \\
\hline & & & Máximo & 53 & \\
\hline
\end{tabular}


Tabela 9 - Caracterização da amostra (cont.).

\begin{tabular}{|c|c|c|c|c|c|}
\hline Variável & $\mathrm{F}$ & $\%$ & Variável & F & $\%$ \\
\hline \multicolumn{6}{|l|}{ Tempo de trabalho } \\
\hline Até 10 anos & 75 & 25 & Média & 20,58 & \\
\hline 11 a 20 anos & 91 & $\mathbf{3 0 , 3}$ & Desvio padrão & 11,23 & \\
\hline 21 a 30 anos & 75 & 25 & Moda & 10 & \\
\hline \multirow[t]{2}{*}{ Acima 30 anos } & 58 & 19,3 & Mínimo & 0 & \\
\hline & & & Máximo & 54 & \\
\hline \multicolumn{6}{|c|}{ Exp Líder Proj Empresa } \\
\hline Até 5 anos & 118 & 39,3 & Média & 9,58 & \\
\hline 6 a 10 anos & 88 & 29,3 & Desvio padrão & 8,15 & \\
\hline 11 a 15 anos & 33 & 11 & Moda & 5 & \\
\hline \multirow[t]{2}{*}{ Acima de 15 anos } & 61 & 20,3 & Mínimo & 0 & \\
\hline & & & Máximo & 40 & \\
\hline \multicolumn{6}{|l|}{ Exp Líder Proj } \\
\hline Até 5 anos & 75 & 25 & Média & 12 & \\
\hline 6 a 10 anos & 84 & 28 & Desvio padrão & 8,76 & \\
\hline 11 a 15 anos & 51 & 17 & Moda & 16 & \\
\hline \multirow[t]{2}{*}{ Acima de 15 anos } & 86 & 28,7 & Mínimo & 0 & \\
\hline & & & Máximo & 45 & \\
\hline
\end{tabular}

Fonte: Elaborado pela autora com base nos dados coletados nesta pesquisa.

Dentre os líderes de projeto respondentes desta pesquisa predominam pesquisadores, com a quase totalidade de $97 \%$ da amostra. A maioria são homens $-60 \%$, e prevalecem os que estão na idade de 41 a 50 anos. Observa-se, ainda com relação à faixa etária, que há uma grande variação, pois há respondentes com 31 bem como com 80 anos (DP =9,37). Um índice de $69 \%$ da amostra são doutores, caracterizando-se principalmente pela atuação na área de pesquisa, desenvolvimento e inovação.

Os líderes de projeto com até 10 anos de empresa representam a faixa mais frequente entre os participantes (46\%), e nota-se que há empregados na função contratados há pouco tempo - tempo mínimo de 2 anos, e mais frequente de 6 anos, observando-se que pertencem a esta faixa. Os dados coletados demonstram que o tempo de experiência de trabalho predomina na faixa de 11 a 20 anos (30,3\%), com tempo médio de experiência de 20,58 anos, mas grande diferença entre as respostas $(\mathrm{DP}=11,23)$

Com relação à experiência como líder de projeto na Empresa, a faixa que apresentou maior frequência foi a com menor experiência (até 5 anos $=39,3 \%$ ). Há registros de empregados na função de líderes de projeto há mais tempo (máx = 40), bem como com menos 
de um ano (mín =0). Muitos declararam, no entanto, ter mais de 15 anos de experiência na função de líder de projeto desde o início de sua trajetória profissional na Empresa (28,7\%), sendo que a média foi de 12 anos de experiência.

\subsection{Instrumento de medida}

$\mathrm{O}$ instrumento empregado na pesquisa (CompLP), no intuito de avaliar as necessidades de treinamento dos líderes de projeto da Embrapa, foi construído e validado ao longo deste estudo. Os procedimentos metodológicos de construção e validação de tal instrumento serão detalhados a seguir.

\section{Metodologia de Construção do Instrumento}

A metodologia de construção do instrumento abarcou as etapas de coleta de dados com profissionais de empresas de PD\&I para identificar as competências inerentes ao papel ocupacional do líder de projeto para construção dos itens do instrumento a partir dessas competências; e submissão do questionário à validação semântica e por juízes.

\section{Coleta de dados: análise documental e entrevistas}

Os procedimentos que viabilizaram o levantamento de informações para construção do instrumento foram a análise documental e a condução de entrevistas.

A análise documental envolveu a apreciação de documentos internos da instituição, tais como: Documento orientador - Processo padrão de gestão de projetos; Documento orientador - Dicas para a preparação de Projetos para fundos competitivos e outros mecanismos de seleção; Documento orientador - Instruções para preenchimento de orçamento dos projetos; Documento orientador - tutorial de acompanhamento de atividades pelo líder e responsável de planos de ação no SISGP; Documento orientador - Instruções para líderes realizarem a distribuição orçamentária no Ideare; e Norma - Características e gestão do projeto. A análise documental foi realizada por meio de consulta a documentos eletrônicos hospedados em sítio da página virtual na intranet da instituição-alvo da pesquisa.

As entrevistas foram realizadas no mês de novembro de 2015. Participaram das entrevistas profissionais-chave de instituições de PD\&I, com conhecimento empírico do papel ocupacional estudado: nove especialistas, sendo seis da Instituição-alvo - profissionais que 
supervisionam a programação e organização dos projetos da Embrapa; e três especialistas de empresas de PD\&I de mercado: dois em pesquisa no campo de inovação e um em pesquisa na área de tecnologia de alimentos. Todos os profissionais especialistas foram sugeridos pelo chefe de $\mathrm{P} \& \mathrm{D}$ da instituição-alvo, ao ser consultado por esta pesquisadora.

Todos os entrevistados foram contatados por e-mail, em mensagem explicitando os objetivos e relevância da pesquisa, e solicitando apoio e parceria para esta etapa. Depois de agendadas as entrevistas, foram feitos os devidos arranjos e contatos telefônicos necessários com as Empresas para confirmação das reuniões.

As entrevistas com os profissionais da Embrapa foram conduzidas pessoalmente, enquanto aquelas realizadas com as empresas de mercado se deram a distância, via telefone. O roteiro semiestruturado (Anexo III), foi previamente elaborado, composto por questões abertas, e encaminhado para conhecimento aos especialistas participantes das entrevistas. As entrevistas tiveram duração de aproximadamente duas horas, sendo todas as informações registradas e transcritas por esta pesquisadora, de acordo com Flick (2002); Jovechlovitch e Bauer (2002); Manzini (2004); e Bardin (2008).

O roteiro das entrevistas orientava aos participantes a descrever características por meio de comportamentos observáveis dos líderes de projeto. Conforme descrito anteriormente, o construto que permeia a identificação do perfil da clientela versa sobre competência.

O conceito de competência utilizado nesta pesquisa, de acordo com o que foi abordado, constitui o conjunto de conhecimentos (corpo organizado de informações requerido para o desempenho da atividade); habilidades (atividades de natureza psicomotoras ou cognitivas) e atitudes (conjunto de crenças, normas, valores e regras que orientam o comportamento individual), necessárias ao desempenho esperado no trabalho (Meneses et al., 2010).

O conceito ou constructo (conceito com um significado construído, ao qual de atribui símbolos ou valores) de competência, para sua mensuração, possui duas dimensões - uma constitutiva e outra operacional, como observa Kerlinger (1980). A dimensão constitutiva se dá pelos conhecimentos, habilidades e atitudes, e a dimensão operacional atribui significado a um constructo, especificando as atividades ou operações para mensurá-la. Neste caso, acontece por meio dos métodos de ANT: a autoavaliação de lacunas de competências, nas 
escalas de importância e domínio, que constituem em critérios para mensurar os níveis do constructo.

Os conteúdos sobre os CHAs coletados nas entrevistas (observados na Tabela 10) fundamentaram as descrições de comportamento esperadas dos líderes de projeto, bem como a análise de conteúdo para proceder a sua categorização e agrupamento de conteúdos afins. 


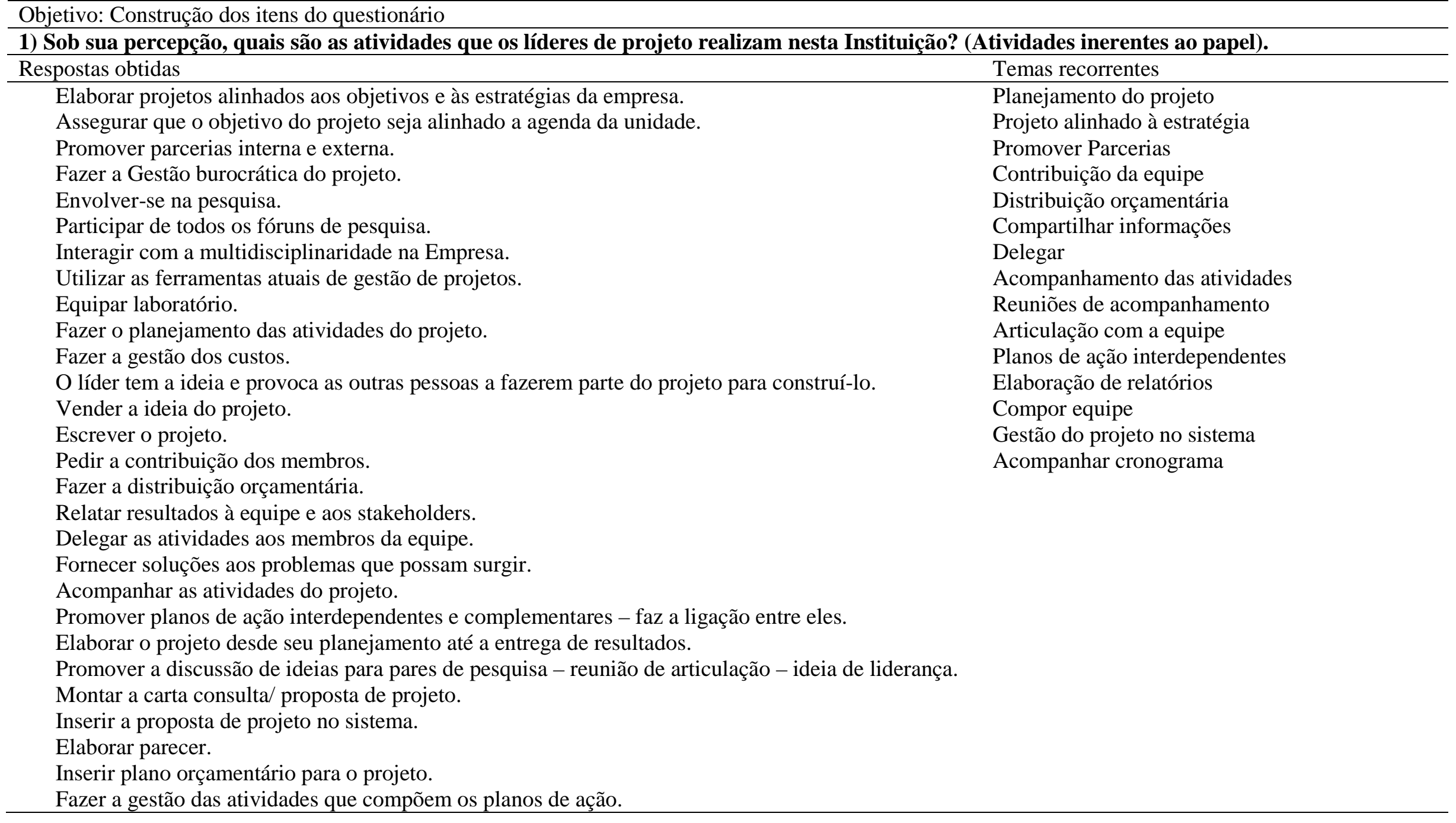


Tabela 10 - Informações obtidas nas entrevistas de coleta de dados e análise de conteúdo (cont.)

Objetivo: Construção dos itens do questionário

1) Sob sua percepção, quais são as atividades que os líderes de projeto realizam nesta Instituição? (Atividades inerentes ao papel).

Respostas obtidas

Elaborar os planos de ação em conjunto com a equipe.

Fazer a gestão junto aos líderes de atividades.

Motivar as entregas de resultados.

Fazer o lançamento e o relato de atividades.

Elaborar os relatórios anuais de resultados de projetos.

Atuar em diversas dimensões, como executor de atividades e como gestor de equipe e do processo

dentro do projeto.

Fazer o acompanhamento das atividades.

Promover a articulação com a equipe.

Fazer o acompanhamento das atividades do projeto pelo sistema.

Elaborar o relato de atividades.

Fazer a distribuição orçamentária das atividades.

Fazer o acompanhamento dos resultados.

Elabora relatórios, preservando a qualidade das informações.

Relatar o que ele está trabalhando.

Escrever proposta de projeto a partir de demanda.

Montar proposta de projeto com ações que atendam a demanda.

Montar equipe com a qual ele consiga trabalhar.

Relatar resultados do projeto.

Relatar o andamento das atividades do projeto.

Manter uma relação de confiança com os membros da equipe.

Promover um trabalho de motivação na equipe do projeto.

Fazer a distribuição de recurso.

Promover a articulação de parcerias.

Promover reuniões de acompanhamento.

Cobrar resultados da equipe.

Delega atividades.

Monitora o andamento do projeto.

Motiva a equipe.

Difusor de tecnologia. 
Tabela 10 - Informações obtidas nas entrevistas de coleta de dados e análise de conteúdo (cont.).

Objetivo: Construção dos itens do questionário

1) Sob sua percepção, quais são as atividades que os líderes de projeto realizam nesta Instituição? (Atividades inerentes ao papel).

Respostas obtidas

Integrar resulados.

Fazer liderança compartilhada.

Promove a colaboração.

Negociar com os stakeholders.

Acompanhar o cronograma.

Acompanhar as atividades do projeto.

Fazer o planejamento do projeto.

Promover reuniões com a equipe.

Fazer a gestão orçamentária das atividades que integram o projeto.

Compor equipe do projeto.

Preparar relatórios.

Monitorar as o andamento do projeto.

Fazer reuniões de acompanhamento com a equipe.

Fazer o planejamento de custos do projeto.

Assegurar o cumprimento dos objetivos do projeto dentro do orçamento e prazo planejados.

Compartilhar informações.

Avaliar se o projeto está alinhado a estratégia da empresa.

Avaliar se sua execução será a curto, médio ou longo prazo.

Avaliar custo e retorno do projeto.

Avaliar quem estará envolvido no projeto - equipe.

Avaliar como a tecnologia promovida pelos resultados do projeto vai alavancar a empresa.

Fazer o Planejamento do projeto.

Convencer seus parceiros sobre a importância do projeto.

Elaborar o Cronograma das atividades, bem como atentar-se para seu cumprimento.

Promover reuniões de acompanhamento das atividades do projeto.

Participar de comitês de inovação.

Divulgar os resultados do projeto.

Captar recursos para o projeto.

Identificar antecipadamente recursos necessários ao projeto.

Identificar ameaças ao projeto para solucioná-las. 
Tabela 10 - Informações obtidas nas entrevistas de coleta de dados e análise de conteúdo (cont.).

Objetivo: Construção dos itens do questionário

\section{2) Para realizarem essas atividades, o que esses profissionais devem saber fazer? Quais conhecimentos devem ter?}

Respostas obtidas

Capacidade de Iniciativa

Certo grau de autonomia e manejo

Capacidade de articulação

Dominar o conhecimento técnico da área do projeto

Conhecer os procedimentos para preenchimento do Ideare

Visão sistêmica

Capacidade de agregar a equipe

Capacidade de motivar a equipe

Capacidade de perceber problemas

Conhecimento do sistema

Temas recorrentes

Gestão de pessoas

Comunicação

Capacidade de articulação

Visão sistêmica

Conhecimento técnico

Organização

Conhecimento de orçamento, compras e finanças

Gestão de projetos

Conhecimento do Sistema

Trânsito para resolução de problemas e alternativas

Capacidade de elaboração de projetos

Organização

Comunicação

Proatividade

Bom relacionamento

Empatia

Comprometido

Capacidade de dar feedback

Promove a integração dos resultados para incitar a curiosidade dos integrantes

Orçamento

Finanças

Compras

Gestão de processos e projetos

Gestão de Pessoas

Conhecimento técnico

Gestão de projetos

Relação interpessoal - flexibilidade, pulso, tomada de decisão na gestão da equipe, equilíbrio emocional.

Saber ouvir e entender o que está sendo proposto para ele, assimilar e entende o problema.

Conhecimento na área para propor soluções 
Tabela 10 - Informações obtidas nas entrevistas de coleta de dados e análise de conteúdo (cont.).

Objetivo: Construção dos itens do questionário

\section{2) Para realizarem essas atividades, o que esses profissionais devem saber fazer? Quais conhecimentos devem ter?}

Respostas obtidas

Temas recorrentes

Saber ouvir propostas, construção coletiva.

Comunicação

Capacidade de fazer parcerias e redes de relacionamentos.

Organização

Reconhecer suas fragilidades, a falta de conhecimento e as habilidades.

Conhecimento e habilidades com o sistema Ideare e Sigepe.

Habilidade com planilhas.

Conhecimento de Orçamento/ compras.

Atualização em sua área para propor soluções.

Saber se expressar.

Trabalho em equipe.

Equilíbrio

Capacidade de Lidar com pessoas.

Elaboração de projeto.

Articulação com pessoas as funções.

Distribuição orçamentária.

Capacidade de Comunicação com os pares.

Habilidade para compor a equipe.

Ter Clareza dos objetivos.

Capacidade de comunicação.

Saber defender o projeto.

Ter boa rede de relacionamento.

Ter conhecimento técnico.

Atualização

Lidar com as adversidades.

Ser flexível.

Ter o conhecimento técnico na área, a visão específica como, por exemplo, ter apresentado sucesso

em projetos anteriores. Para isso, é interessante que tenhamos indicadores que demonstrem esses

resultados.

Visão sistêmica, abrangente - como ele estabelece interligações entre as áreas e processos. 
Tabela 10 - Informações obtidas nas entrevistas de coleta de dados e análise de conteúdo (cont.).

Objetivo: Construção dos itens do questionário

\section{2) Para realizarem essas atividades, o que esses profissionais devem saber fazer? Quais conhecimentos devem ter?}

Respostas obtidas

Temas recorrentes

Conhecimento da organização e de seus processos como um todo - pode ser reconhecido por meio

das propostas aderentes aos objetivos e desafios institucionais.

Capacidade de Planejamento - clareza nos objetivos, metodologia, gerir recursos, adequação do

tempo, e equipe.

Gestão de recursos - planejar real e executar conforme o planejado.

Capacidade de buscar parcerias - identificar e mapear grupos internos e externos bem

estabelecidos na área de atuação.

Gestão de equipe - facilidade de comunicação, atender sugestões, dividir tarefas.

Assegurar objetivos institucionais.

Assegurar a propriedade intelectual dos resultados da pesquisa.

Flexibilidade - capacidade de se adaptar e encontrar soluções frente a mudanças e/ou adversidades

que possam acontecer.

Gestão de pessoas - capacidade de lidar com a equipe de trabalho, provendo integração e

colaboração entre seus membros.

Visão sistêmica - capacidade de integrar atividades dos planos de ação; resultados do projeto aos

objetivos macro.

Gestão orçamentária - capacidade de acompanhar e monitorar os gastos ao longo do projeto.

Comunicação - capacidade de se comunicar com a equipe e com os parceiros de negócio, de forma

a deixar claras as informações, entender e se fazer entender.

Capacidade de fazer parcerias - capacidade de promover uma rede de contatos internos e externos,

promovendo parcerias e colaboração.

Organização - capacidade de organizar o tempo e as atividades tanto burocráticas quanto de

planejamento da operacionalização do projeto.

Conhecer o planejamento estratégico.

Visão global.

Conhecimento técnico ou conhecimento de saber buscar quem conhece.

Capacidade de articulação.

Saber aonde a empresa quer ir e conduzir o projeto na mesma direção.

Atuação transversal.

Organização 
Tabela 10 - Informações obtidas nas entrevistas de coleta de dados e análise de conteúdo (cont.).

Objetivo: Construção dos itens do questionário

2) Para realizarem essas atividades, o que esses profissionais devem saber fazer? Quais conhecimentos devem ter?

Respostas obtidas

Temas recorrentes

Saber liderar a equipe.

Foco na entrega.

Conhecimento de pay back.

Comunicação

Rede de contatos interna e externa.

Proatividade, facilidade de cumprir prazo, horário e qualidade.

Saber convencer a equipe, empatia, disponibilidade.

Avaliar custo e retorno financeiro do projeto.

Comunicação clara e objetiva com a equipe, ser claro e convincente.

3) Existe alguma outra competência ou capacidade que considera importante?

Respostas obtidas

Aquele que consegue formar uma equipe que consiga se manter organizada e independente.

Temas recorrentes

Formar equipe que se mantenha organizada $e$

independente.

\section{4) O que considera mais importante nesse profissional para executar seu papel de forma exemplar? Cite um exemplo de desempenho que possa ser} observável, sob essa perspectiva.

Respostas obtidas

Espera-se do pesquisador que ele contribua com a liderança da empresa.

Temas recorrentes

O líder de projeto tem autonomia.

Que esteja preparado nos conceitos básicos que tenha os fundamentos básicos para a função.

Gestão de pessoas e da equipe, em termos de composição da equipe.

Reconhecer a importância de cada um na equipe.

Promover a colaboração e o compartilhamento da informação entre os membros da equipe.

Capacidade de compartilhar a informação com a equipe.

Negociação - prazo, recurso, afastamento de membro importante do projeto.

Ser flexível e acessível.

Gostar do tema técnico que ele lida.

Promover um ambiente de criatividade.

Acompanhamento presencial é essencial ao projeto, dependendo da complexidade e tamanho da rede -

Fazer o acompanhamento do projeto.

utilização de instrumentos de gestão.

Saber monitorar o conhecimento da área técnica onde atua.

Ser transparente.

Saber lidar com pessoas.

Ter responsabilidade. 
Tabela 10 - Informações obtidas nas entrevistas de coleta de dados e análise de conteúdo (cont.).

Objetivo: Construção dos itens do questionário

4) $O$ que considera mais importante nesse profissional para executar seu papel de forma exemplar? Cite um exemplo de desempenho que possa ser observável, sob essa perspectiva.

\begin{tabular}{lr}
\hline Respostas obtidas & Temas recorrentes \\
\hline Ser acessível &
\end{tabular}

Ser acessível.

Ter equilíbrio psicológico.

Ser organizado.

Saber delegar.

Entender a demanda.

Conversar com a equipe.

Buscar pessoas que possam contribuir e construir coletivamente para consolidar uma proposta de

projeto coerente e bem montada para apresentar, com levantamento de custos.

Ser proativo.

Acompanhar o andamento das atividades.

Acompanhar no sistema os relatos.

Se antecipar, juntar os resultados, se organizar.

Bom comunicador.

Interessado em compartilhar a liderança.

Reconhecer o papel e a importância das pessoas no projeto.

Ter honestidade, humanidade, flexibilidade.

Promover um ambiente de criatividade.

Fonte: Elaborado pela autora a partir da coleta de dados em entrevistas realizadas nesta pesquisa. 
Desta forma, observados os critérios psicométricos, os quais ser elencados na Tabela 11, foram construídos os itens do questionário.

Tabela 11 - Critérios psicométricos para construção de itens do questionário.

\begin{tabular}{ll}
\hline Critério & Observação \\
\hline Comportamental & Expressa comportamento concreto \\
Simplicidade & Expressa uma única ideia \\
Clareza & O item deve ser compreendido pelo participante \\
Relevância & O item deve ser consistente com o que se pretende medir \\
Precisão & Os itens devem ser distintos entre si \\
Variedade & Os itens devem ter a linguagem diversificada \\
Tipicidade & As frases formuladas devem ser adequadamente avaliadas conforme a escala \\
& disposta \\
Credibilidade & Os itens devem ser adequados, os quais despertem credibilidade no participante. \\
Amplitude & O conjunto de itens deve cobrir a do mesmo critério de avaliação \\
Modalidade & Os itens devem compreende expressões modais, sem termos extremados. \\
\hline Fonte: Adaptado de Pasquali (1998) e Meneses et al. (2010).
\end{tabular}

Nesta fase de construção, o questionário obteve 22 itens elaborados. De acordo com apontamentos de Castro e Borges-Andrade (2004) a despeito da possível interferência do pesquisador no processo de construção dos itens do instrumento, parte dos critérios componentes é adquirida no processo de validação do instrumento, que conferem incremento à qualidade dos itens. A etapa de validação do instrumento abrange o processo de análise semântica e análise de juízes, apresentadas na seção subsequente.

\section{Validação do instrumento}

Considerando a definição de validade de um teste, diz-se que este é válido se de fato mede o que se supõe medir. Esta definição preconiza que, ao se medirem os comportamentos (itens), aos quais representam a dimensão do construto, mede-se o próprio construto. Essa suposição é justificada se a representação comportamental for legítima (Pasquali, 1996).

Para validação do instrumento, nesta fase da pesquisa foram realizadas duas etapas: a validação semântica e a validação por juízes. De acordo com Pasquali (1999), a validação semântica afere se os conteúdos são compreensíveis à população-alvo a que se destina a pesquisa. Procura-se saber, ainda, se os itens estão adequados quanto à precisão, clareza e objetividade, bem como sua congruência às instruções contidas no questionário e à escala correspondente.

Para validação semântica do questionário foram enviados 26 convites por e-mail. Ao grupo de alunos de doutorado, mestrado e graduação, envolvidos com pesquisa na área e pertencentes ao Laboratório de Psicologia Organizacional e do Trabalho da Universidade de 
São Paulo - USP/ RP (LabPOT), foram conduzidas 23 mensagens, e a analistas de gestão de pessoas da Embrapa, foram encaminhados três e-mails. A mensagem compreendia orientações de como proceder na apreciação do instrumento e, como anexo, o questionário. Foram obtidos seis questionários como retorno. O processo de validação semântica foi realizado em março de 2016.

Os participantes da validação semântica analisaram o questionário, indicando a substituição de algumas palavras ou acréscimo de expressões que complementassem o sentido dos itens que representavam as competências expressas; além disso, indicaram se a escala estava adequada ao julgamento dos itens. As sugestões foram compiladas e analisadas por meio de comparação e, quando consideradas adequadas para o aperfeiçoamento da escala, os itens foram alterados.

Posteriormente, o resultado dessa etapa foi submetido à análise por juízes. A análise por juízes, ou análise de construto, tem o intuito de conferir representatividade da linguagem, clareza e precisão dos itens, bem como das instruções e da escala (Pasquali, 1999).

$\mathrm{Na}$ validação por juízes foram necessárias duas etapas. A primeira etapa de validação por juízes contemplou o envio de seis mensagens de solicitação para colaborar com a pesquisa - e-mail composto por orientações de procedimento e pelo questionário. Os juízes selecionados constituíram três dos seis especialistas que haviam participado das entrevistas de coleta de dados para mapeamento de competências no processo de construção do instrumento; um professor na Universidade de Brasília com atuação na área de estudo; uma doutoranda do LabPOT, que participou da fase da validação semântica, com experiência na construção de instrumentos; e um supervisor de projetos da Embrapa, ao qual não havia sido consultado anteriormente. Dos seis envios, foram obtidos cinco retornos.

Após exame de Qualificação desta pesquisadora, um dos membros da Banca sugeriu que os itens do questionário abordassem caráter mais estratégico. Optou-se, desta forma, que o instrumento fosse analisado novamente por outro grupo de juízes.

Foi realizada a segunda etapa da análise de juízes. Foram propostos dez profissionais para participar da validação, por sugestão do membro da banca da Qualificação, que é também pesquisadora da Instituição-alvo. São profissionais com atuação em âmbito estratégico superior da Empresa, com o intuito de conferir aos itens do instrumento uma dimensão mais ampla acerca do papel ocupacional do líder de projeto. Dos dez instrumentos 
encaminhados - anexados em mensagens de convite de colaboração com a pesquisa, obteve-se um retorno de sete respostas.

Após a construção e processo final de validação dos itens do instrumento, para mensurar o nível de desempenho ou o grau com que o atributo está presente no comportamento os itens foram associados a escalas do tipo Likert de cinco pontos, compondo duas escalas: Importância ( 1 = nada importante para o cumprimento do bom desempenho do trabalho; e 5 = muito importante para o cumprimento do bom desempenho do trabalho) e Domínio $(1$ = não domino a competência; e $5=$ domino completamente a competência), a serem analisadas simultaneamente. A análise de resultados deu-se pelo índice de prioridade de treinamento, calculado de forma geral, por participante da pesquisa e também por item do questionário. Quanto maior a prioridade, maior a necessidade de treinamento.

O instrumento final continha dois campos: a primeira parte incluía informações gerais como sexo; idade; titulação, área de formação, área de especialização; cargo, tempo de empresa; tempo de trabalho; eixo de atuação na empresa; tempo de experiência como líder de projeto na empresa; tempo de experiência como líder de projeto desde o início da atuação profissional; participação em grupos e comitês na empresa; e abrangência de atuação do projeto. A segunda parte era destinada ao questionário de avaliação de necessidades de treinamento, com instruções de preenchimento, as duas escalas - importância e domínio, e 25 itens relativos às competências de líderes de projeto.

\subsection{Considerações éticas}

O projeto foi submetido ao Comitê de Ética em Pesquisa da Faculdade de Filosofia, Ciências e Letras de Ribeirão Preto - FFCLRP-USP. Após aprovação (Anexo I), a instituiçãoalvo foi contatada, sendo seus gestores informados acerca dos objetivos da pesquisa e os procedimentos necessários para sua realização.

Mediante autorização da chefia da área de gestão de pessoas da Empresa, foi possível a realização da pesquisa. Previamente à aplicação dos questionários (realizada online por meio do software Limesurvey), os participantes optaram, por meio do Termo de Consentimento Livre e Esclarecido (previamente aprovado pelo Comitê de Ética citado), por participar ou não da pesquisa. O Termo era apresentado em tela, e garantia sigilo e anonimato 
de identidade, caráter de sua participação voluntária, bem como solicitava a autorização do uso de suas informações no estudo.

\subsection{Procedimentos de coleta de dados}

Com o intuito de cumprir os objetivos da pesquisa, foram aplicados questionários a uma amostra de 886 profissionais pertencentes a atribuição de líderes de projeto, os quais integram o corpo de empregados da instituição participante. Os questionários pretendiam levantar o perfil sociodemográfico e funcional da clientela, bem como as necessidades de treinamento da amostra, a partir de informações sobre o dia-a-dia no trabalho, por meio da autoavaliação da importância e do domínio das competências (conhecimentos, habilidades e atitudes).

A pesquisa foi realizada no período de 16 a 27 de janeiro de 2017 e, devido ao baixo índice de retorno, fez-se necessário um segundo momento para a coleta de dados, que foi realizada de $1^{\circ}$ a 10 de fevereiro. A aplicação dos questionários foi feita à distância, online, por meio do software livre Limesurvey.

Tanto para o primeiro quanto para o segundo momento de coleta, o convite para participação na pesquisa foi encaminhado para o e-mail corporativo da amostra. No segundo momento o convite foi reiterado. No corpo da mensagem foi disponibilizado o link de acesso ao questionário, que direcionava ao software Limesurvey, onde as respostas eram salvas. Ao final do período da aplicação da pesquisa, todos os dados foram exportados para o software de análise de dados Statistical Package for the Social Sciences 23.0 (SPSS).

O índice de retorno geral foi de $43,11 \%$, desde que foram enviados convites para 886 participantes.

\subsection{Procedimentos de análises de dados}

Os procedimentos de análises de dados foram realizados em duas etapas: inicialmente, foram feitas análises descritivas (média, desvio-padrão, moda, mínimo e máximo) e exploratórias para verificar a exatidão da entrada dos dados, a presença de casos extremos, a distribuição de casos omissos, a distribuição de frequência das variáveis e o tamanho das amostras. 
$\mathrm{Na}$ segunda etapa, foram realizadas análises diretamente relacionadas ao cumprimento dos objetivos desta pesquisa: análises fatoriais exploratórias - AFE e de consistência interna para a verificação de evidências de validade do instrumento de medida construído e utilizado, a ANT para verificar as necessidades de treinamento da clientela, bem como análises de regressão para estudar a relação entre as variáveis. Todas as análises foram realizadas no SPSS versão 23.0, e serão apresentadas a seguir.

\subsubsection{Procedimentos de análises exploratórias e fatoriais da estrutura empírica do questionário}

A utilização de análises exploratórias se refere, segundo aponta Tabachnick e Fidell (2007), à verificação da exatidão de entrada dos dados, identificação de casos omissos, casos extremos univariados e multivariados, normalidade, linearidade, singularidade e multicolinearidade, considerando a distribuição das variáveis e o tamanho da amostra.

Os testes para investigação de normalidade não foram realizados uma vez que, segundo Pasquali (2004), a identificação da normalidade para análise fatorial exploratória não causaria dificuldades, pois a análise fatorial é robusta à violação desse pressuposto, suportando desvios de normalidade.

Com relação à identificação de casos omissos, orienta-se, pelos mesmos autores citados acima, que pode ser feita de três formas: substituí-los pela média; eliminá-los em uma ou duas variáveis, quando são tomados aos pares (pairwise); ou considerar apenas os casos que contenham dados válidos em todos os indicadores/variáveis (listwise).

Para eleger um desses procedimentos para tratamento dos casos omissos, deve-se considerar a quantidade e a aleatoriedade dos dados ausentes, em função da possível identificação de subgrupos amostrais. No entanto, proceder a essa análise é necessário apenas caso o percentual de casos omissos supere 5\% dos casos. Para esta pesquisa, optou-se pela utilização do método pairwise, pois nenhuma variável apresentava mais que 5\% de casos omissos.

Para a identificação dos casos extremos univariados, todas as variáveis foram transformadas em escores $\mathrm{Z}$, e excluídas aquelas respostas cujos escores padronizados eram iguais ou superiores a 3,29 ( $\mathrm{p}<0,001$, two-tailed $)$. Casos extremos univariados são definidos por Tabachnick et al. (2007) como respostas que destoam dentre um conjunto de respostas em uma única variável. 
Os casos extremos multivariados são valores resultantes de uma combinação anormal de escores em duas ou mais variáveis. Para identifica-los, verificou-se a distância Mahalanobis - distância de um caso do centro do restante dos casos, quando o centro é o ponto criado pelas médias de todas as variáveis. Considerando o número de graus de liberdade (referente ao número de variáveis envolvidas) e o nível de significância de $99 \%(\alpha=0,01)$, foi possível obter um valor de referência (consulta à tabela de distribuição qui-quadrado). Os valores acima desta referência são considerados extremos (Tabachnick et al., 2007). Foram identificados 31 casos; no entanto foram mantidos, pois não afetam a AFE.

Para proceder às análises fatoriais do instrumento, Pasquali (2004) orienta a coleta de informações por meio de pesquisa empírica; elaboração de matriz de covariância; análise da matriz de covariância, considerando a fatorabilidade e o número de fatores; realização da extração inicial dos fatores e da rotação dos fatores para uma estrutura final; interpretação dos fatores; e a construção de escores fatoriais para uso em análises futuras. A coleta de dados foi explicitada anteriormente. Com relação à matriz de covariância, foram observadas as seguintes indicações do referido autor:

1) tipos de coeficientes de correlação: utilizou-se as correlações bivariadas paramétricas de Pearson, devido a adequabilidade do método à análise fatorial;

2) tamanho da amostra: observou-se o critério que indica cerca de 10 casos para cada variável observável;

3) normalidade e linearidade: não foram feitos testes de normalidade, pois a análise fatorial exploratória é robusta à violação desse pressuposto e suporta desvios da normalidade. No que diz respeito ao critério de linearidade, este afeta a análise fatorial, visto que as correlações consistem em medidas de relações lineares. Foram realizadas correlações bivariadas para este critério, tendo como parâmetro o coeficiente de correlação produtomomento de Pearson, onde valores diferentes de 0 (zero) e significativos indicam a presença de uma relação linear, considerada forte quanto mais próxima de 1 (um) for o coeficiente obtido;

4) Multicolinearidade e Singularidade: quando o critério de multicolinearidade se aplica às variáveis, entende-se que são como sinônimos, com alta correlação, devendo-se assim eliminar uma delas da análise. A singularidade confere às variáveis um caráter redundante, ou seja, uma variável é a combinação de duas ou mais variáveis. Para verificar os 
dois critérios - multicolinearidade e singularidade - foram analisadas as correlações superiores a 0,90 , tal como orientado por Pasquali (2004).

Para proceder à análise da matriz de covariância, considerando sua fatorabilidade, e à análise do número de fatores, foram cumpridas as seguintes etapas: análise do tamanho das correlações, tendo sido estimadas como relevantes aquelas com valores acima de 0,30 (positivo ou negativo). Quando esse número de correlações superava 50\%, a matriz foi considerada fatorável; e o teste de adequação da amostra de Kaiser-Meyer-Olkin (KMO) este teste analisa as correlações parciais das variáveis. Quanto mais próximo do valor 1 (um) for esta estatística, mais a matriz é fatorável, pois indica que as variáveis têm muita variância em comum.

A análise dos componentes principais (Principal Components - PC) foi feita para obter a extração inicial dos fatores. O objetivo dessa análise é reduzir o número de variáveis em um conjunto de componentes, que explique a maior parte da variância original das variáveis. Analisa os componentes mais importantes e define o número mínimo de fatores para extração, constituindo-se em uma técnica de simplificação. Para proceder com a PC e definir o número de componentes, foram observados alguns critérios:

1) Critérios convencionais: foram considerados valores próprios (eigenvalues) superiores a 1 (um) e foi analisada a distribuição visual dos valores próprios no gráfico scree plot (onde o número máximo de fatores a serem extraídos é indicado a partir da mudança da inclinação dos pontos que representam os componentes);

2) Critérios estatísticos (testes de significância): foi realizada, por meio do software RanEigen, a análise paralela de Horn, que compara valores próprios empíricos, obtidos na PC, com valores próprios aleatórios, de acordo com o número de variáveis e tamanho da amostra (os fatores são retirados da estrutura quando apresentam valor próprio empírico igual ou menor que os valores aleatórios). Segundo aponta Laros (2005) essa análise apresenta índice de precisão de $92 \%$ de indicação correta do número de fatores, constituindo-se assim no método adequado para definição do número de fatores de uma matriz de respostas a questionários.

3) Critérios de relevância do fator: foram feitas análises de interpretabilidade, importância e consistência dos fatores após a rotação dos fatores. A importância do fator é definida pela variância que consegue explicar após a rotação da matriz fatorial - o critério de Harman considera um fator irrelevante aquele que explica menos do que $3 \%$ da variância total 
das variáveis. A validade do fator é expressa pelo tamanho das cargas fatoriais, ou seja, quanto maiores elas forem, mais a variável é representativa do fator. No entanto, um fator pode ser válido, e não ser consistente. Desta forma, foram feitas análises de consistência dos fatores, por meio da análise de Alfa de Cronbach.

Foram feitas análise fatoriais e a utilização do método de fatoração dos eixos principais (Principal Axis Factoring - PAF) para confirmar a estrutura fatorial obtida. $\mathrm{O}$ método, apesar de utilizar os mesmos procedimentos da PC, substitui o valor 1 da PC por uma estimativa das comunalidades na diagonal da matriz, uma vez que a variabilidade que interessa na PAF é a variabilidade que as variáveis têm em comum, ou seja, a covariância entre elas (modelo causal). A vantagem de realizar a PC antes da PAF é definir os números mínimos de fatores a serem inicialmente extraídos. Nesta análise utilizou-se

Na PAF foi utilizado o método de rotação oblíqua (direct oblimin), o qual permite que apareçam fatores ortogonais quando estes existem, e não força a dependência entre os fatores, ao passo que a rotação ortogonal só permite fatores independentes.

Após a extração dos fatores foram verificadas a estabilidade e a interpretabilidade dos mesmos, bem como, foram produzidos escores fatoriais. Para analisar a estabilidade, verificou-se a carga fatorial, significando o quanto os itens representavam o fator - o tamanho da carga representa a correlação entre o item com o conjunto dos outros itens do fator (quanto mais próxima de 1 for esta carga, melhor representa o fator). Os escores fatoriais foram produzidos pela média dos escores das variáveis originais que pertencem ao fator ${ }^{1}$.

\subsubsection{Procedimentos de análises dos testes de regressão múltipla}

Com o objetivo de identificar e investigar os principais preditores da variável "Necessidades de Treinamento de Líderes de Projeto" - medidos pela autopercepção nas escalas de importância e domínio das competências de líder de projeto foram realizadas análises de regressão múltipla padrão.

Para essa etapa de análise foi utilizado o arquivo de dados em sua totalidade - 322 casos, após a exclusão de 25 casos sem nenhuma resposta às questões e 26 casos com respostas incompletas, e utilizadas as seguintes variáveis sociodemográficas e funcionais do modelo: sexo, idade, titulação, cargo, tempo de empresa, tempo de trabalho (desde o início da

\footnotetext{
${ }^{1}$ Informações descritas nesta seção foram consultadas em Zerbini (2007), que expõe as orientações de Pasquali (2004) para nortear cada etapa do processo de análise de dados, conferindo rigor aos procedimentos adotados.
} 
atuação profissional), área de atuação, tempo como líder de projeto na Empresa, tempo como líder de projeto (desde o início da atuação profissional).

De acordo com o que foi explicitado na seção instrumento de medida, não foram utilizadas nas análises de regressão as variáveis "área de formação" e "área de atuação" integrantes do modelo, por constituírem informações necessárias ao planejamento da capacitação dos líderes de projeto, a serem concedidas à instituição alvo como contribuição da pesquisa.

Segundo orientações de Tabachnick et al. (2007) e Hair, Anderson, Tatham e Black (2005) foram realizadas análises exploratórias para identificação de casos omissos e casos extremos (univariados e multivariados) e verificação da presença de normalidade univariada, linearidade, multicolinearidade e singularidade. Os critérios relativos à normalidade univariada e cálculos utilizados para definição do tamanho da amostra diferem daqueles usados nas análises fatoriais exploratórias, pois as análises multivariadas são influenciadas pelo pressuposto da normalidade, que deve ser avaliada por meio de índices estatísticos ou métodos gráficos (frequências com histogramas e curva normal), sendo os dois componentes de análise, a assimetria (skewness) e a curtose (kurtosis). No entanto, não foram realizadas transformações dessas variáveis, considerando que pesquisas anteriores não apresentaram diferenças nas análises com e sem transformação das variáveis com assimetria/curtose (Carvalho \& Abbad, 2006; Lacerda \& Abbad, 2003; Meneses \& Abbad, 2003; Sant'anna, 2002; Tamayo, 2002; Zerbini \& Abbad, 2005).

De acordo com os mesmos critérios descritos na seção anterior, os dados omissos foram tratados pelo método listwise, os casos extremos univariados e multivariados foram desconsiderados.

Os critérios de tamanho amostral em relação a variáveis antecedentes (amostra maior ou igual a 50 casos mais oito vezes o número de variáveis antecedentes $-\mathrm{N} \geq 50+8 \mathrm{~m}$ ) para testar correlações múltiplas e para testar preditores individuais $(\mathrm{N} \geq 104+\mathrm{m})$, conforme recomendam Tabachnick et al. (2007), foram cumpridos.

No próximo capítulo serão apresentados os resultados obtidos nas etapas de construção do instrumento - coleta de dados, validação semântica e validação por juízes; nas análises descritivas, análises exploratórias e fatoriais, ANT e análise de regressão. 


\section{CAPÍTULO 5. RESULTADOS}

\section{Objetivos do capítulo 5}

Este capítulo dispõe sobre os resultados da presente pesquisa, advindos dos procedimentos e das análises realizadas acerca do instrumento de avaliação de necessidades de treinamento de líderes de projeto: resultados obtidos nos procedimentos de construção do instrumento - coleta de dados, validação semântica, validação por juízes e versão final do instrumento; e resultados obtidos das análises descritivas, análises exploratórias fatoriais, cálculo do índice de IPG de treinamento e análise de regressão.

\subsection{Procedimentos de construção do instrumento}

Esta seção apresenta os resultados obtidos por meio de coleta de dados e validação como parte dos procedimentos de construção do instrumento de avaliação de necessidades de treinamento de líderes de projeto CompLP. Além disso, ilustra sua versão final.

\subsubsection{Coleta de dados}

Com o propósito de reunir informações necessárias ao mapeamento de competências da clientela e posterior construção dos itens do instrumento, realizou-se a coleta de dados por meio de entrevistas semiestruturadas.

Os itens foram construídos por meio dos comportamentos observáveis na expressão da competência. São 21 itens que representam a primeira versão do questionário. A Tabela 12 exibe os itens elaborados a partir das entrevistas realizadas.

Tabela 12 - Construção dos itens do instrumento: resultado da coleta de dados.

\begin{tabular}{l}
\hline Itens do questionário construídos a partir das entrevistas \\
\hline 1.Redigir projetos de pesquisa de acordo com os objetivos e desafios institucionais. \\
2.Monitorar os resultados do projeto segundo o cronograma inicialmente proposto. \\
3.Exemplificar à equipe suas propostas sobre o projeto. \\
4.Associar as atividades previstas no projeto a processos de trabalho correlacionados, desenvolvidos por \\
unidades da Empresa. \\
5.Organizar os planos de ação na composição de um projeto, considerando a interdependência entre eles. \\
6.Estimular os colegas de equipe de projeto a darem sugestões sobre o trabalho desenvolvido. \\
7.Solucionar problemas no andamento do projeto em colaboração com a equipe. \\
\hline
\end{tabular}


Tabela 12 - Construção dos itens do instrumento: resultado da coleta de dados (contin.).

Itens do questionário construídos a partir das entrevistas

8.Promover reuniões periódicas para acompanhamento das atividades do projeto.

9.Compor equipes de trabalho por meio de parcerias internas e externas reconhecidas na área de atuação.

10.Dividir tarefas na equipe com que trabalha.

11.Planejar recursos do projeto de acordo com as atividades previstas no plano de ação.

12.Executar recursos do projeto segundo o orçamento proposto.

13.Esclarecer seus parceiros sobre a importância do projeto.

14.Descrever no projeto detalhes sobre investimentos em produtos e serviços necessários para a sua execução.

15.Antever situações de risco para evitar problemas no andamento do projeto.

16.Identificar os principais resultados comprometidos e entregues pela Empresa, por meio do SISGP.

17.Elaborar relatórios de resultados do projeto em conformidade aos prazos estabelecidos pela Empresa.

18.Elaborar relatórios de resultados do projeto com clareza e precisão.

19.Compartilhar informações relevantes do projeto com sua equipe de trabalho.

20.Utilizar ferramentas de gestão de projeto disponíveis na Empresa.

21.Utilizar o software que permite a gestão da programação da Empresa (Ideare), em conformidade aos procedimentos estabelecidos no sistema.

22.Coordenar profissionais de natureza multidisciplinar para sua equipe de trabalho.

Fonte: Elaborado pela autora com base na coleta de dados realizada nesta pesquisa.

Os itens resultantes da coleta de dados demonstram a presença de temas recorrentes identificados nas entrevistas, tais como Planejamento do projeto; Projeto alinhado à estratégia; Promoção de parcerias; Promover a contribuição da equipe; Distribuição orçamentária; Compartilhamento de informações; Delegar; Acompanhamento das atividades; Reuniões de acompanhamento; Articulação com a equipe; Planos de ação interdependentes; Elaboração de relatórios; Compor equipe; Gestão do projeto no sistema; Acompanhamento do cronograma; Gestão de pessoas; Comunicação; Capacidade de articulação; Visão sistêmica; Conhecimento técnico; Organização; Conhecimento de orçamento, compras e finanças; Gestão de projetos; Conhecimento do Sistema; Capacidade de elaboração de projetos; Formar equipe que se mantenha organizada e independente; Reconhecer a importância de cada um na equipe; Ser flexível e acessível; Promover um ambiente de criatividade. A Tabela 13 demonstra a correspondência dos resultados da coleta de dados - temas recorrentes - com alguns dos itens construídos. Aqueles itens que não se associam a nenhum dos temas recorrentes apontados abordam outros conteúdos sugeridos pelos participantes das entrevistas, como pode ser observado na Tabela a seguir. 
Tabela 13 - Relação Itens do questionário e temas recorrentes identificados na coleta de dados da entrevista.

\begin{tabular}{ll}
\hline Itens do questionário & Temas identificados na entrevista \\
\hline $\begin{array}{l}\text { 1.Redigir projetos de pesquisa de acordo com os objetivos e } \\
\text { desafios institucionais. }\end{array}$ & $\begin{array}{l}\text { Planejamento do projeto } \\
\text { Projeto alinhado à estratégia }\end{array}$ \\
$\begin{array}{l}\text { 2.Monitorar os resultados do projeto segundo o cronograma } \\
\text { inicialmente proposto. }\end{array}$ & Acompanhamento do cronograma \\
3.Exemplificar à equipe suas propostas sobre o projeto. & Comunicação \\
& $\begin{array}{l}\text { Promover a colaboração e o compartilhamento } \\
\text { da informação entre os membros da equipe. } \\
\text { Gestão de pessoas }\end{array}$
\end{tabular}

4.Associar as atividades previstas no projeto a processos de trabalho correlacionados, desenvolvidos por unidades da Empresa.

5.Organizar os planos de ação na composição de um projeto, considerando a interdependência entre eles.

6.Estimular os colegas de equipe de projeto a darem sugestões sobre o trabalho desenvolvido.

Visão sistêmica

Planos de ação interdependentes

Promover a contribuição da equipe

Promover a colaboração e o compartilhamento da informação entre os membros da equipe.

Gestão de pessoas

7.Solucionar problemas no andamento do projeto em colaboração com a equipe.

Articulação com a equipe

Promover a colaboração e o compartilhamento da informação entre os membros da equipe.

Gestão de pessoas

8.Promover reuniões periódicas para acompanhamento das atividades do projeto.

Reuniões de acompanhamento

Acompanhamento das atividades

9.Compor equipes de trabalho por meio de parcerias internas e externas reconhecidas na área de atuação.

10.Dividir tarefas na equipe com que trabalha.

\section{Compor equipes}

Parcerias

Promover a colaboração e o compartilhamento da informação entre os membros da equipe.

11.Planejar recursos do projeto de acordo com as atividades previstas no plano de ação.

Conhecimento do orçamento, compras e finanças.

12.Executar recursos do projeto segundo o orçamento proposto.

Recursos, Planejamento 
Tabela 13 - Relação Itens do questionário e temas recorrentes identificados na coleta de dados da entrevista (cont.).

\begin{tabular}{|c|c|}
\hline Itens do questionário & Temas identificados na entrevista \\
\hline 13.Esclarecer seus parceiros sobre a importância do projeto. & $\begin{array}{l}\text { Item inserido associado a outros conteúdos } \\
\text { das entrevistas. }\end{array}$ \\
\hline $\begin{array}{l}\text { 14.Descrever no projeto detalhes sobre investimentos em } \\
\text { produtos e serviços necessários para a sua execução. }\end{array}$ & $\begin{array}{l}\text { Conhecimento do orçamento, compras e } \\
\text { finanças. } \\
\text { Recursos, Planejamento }\end{array}$ \\
\hline $\begin{array}{l}\text { 15.Antever situações de risco para evitar problemas no } \\
\text { andamento do projeto. } \\
\text { 16.Identificar os principais resultados comprometidos e } \\
\text { entregues pela Empresa, por meio do SISGP. }\end{array}$ & $\begin{array}{l}\text { Itens inseridos associados a outros conteúdos } \\
\text { das entrevistas. }\end{array}$ \\
\hline $\begin{array}{l}\text { 17.Elaborar relatórios de resultados do projeto em } \\
\text { conformidade aos prazos estabelecidos pela Empresa. }\end{array}$ & Elaboração de relatórios \\
\hline $\begin{array}{l}\text { 18.Elaborar relatórios de resultados do projeto com clareza e } \\
\text { precisão. }\end{array}$ & Elaboração de relatórios \\
\hline $\begin{array}{l}\text { 19.Compartilhar informações relevantes do projeto com sua } \\
\text { equipe de trabalho. }\end{array}$ & Compartilhamento de informações \\
\hline $\begin{array}{l}\text { 20.Utilizar ferramentas de gestão de projeto disponíveis na } \\
\text { Empresa. }\end{array}$ & Gestão de projeto \\
\hline $\begin{array}{l}\text { 21.Utilizar o software que permite a gestão da programação } \\
\text { da Empresa (Ideare), em conformidade aos procedimentos } \\
\text { estabelecidos no sistema. }\end{array}$ & $\begin{array}{l}\text { Gestão do Projeto no sistema } \\
\text { Conhecimento do Sistema }\end{array}$ \\
\hline $\begin{array}{l}\text { 22.Coordenar profissionais de natureza multidisciplinar para } \\
\text { sua equipe de trabalho. }\end{array}$ & $\begin{array}{l}\text { Reconhecer a importância de cada um na } \\
\text { equipe. }\end{array}$ \\
\hline
\end{tabular}

Fonte: Elaborado pela autora com base na coleta de dados realizada nesta pesquisa.

Os resultados das etapas de validação do instrumento serão apresentados na seção seguinte.

\subsubsection{Validação do instrumento}

A apreciação do instrumento por meio da análise semântica, que tomou como base a correção de termos, nomenclatura, considerando a clareza das frases e a percepção dos profissionais quanto à cultura da instituição-alvo e dos respondentes, produziu algumas mudanças nos itens. A Tabela 14 evidencia essas modificações. 
A validação por juízes promoveu modificações mais contundentes, referenciando a análise dos juízes, no contexto da pesquisa, a representatividade do conteúdo das frases em relação às competências que efetivamente representam o papel ocupacional dos líderes de projeto, para que fazem suas atividades, e a necessidade de incluir ou excluir itens. Adicionalmente, revisaram os itens e sua adequação à escala de mensuração. As mudanças realizadas nas etapas 1 e 2 da análise por juízes estão apresentadas na Tabela 15 e Tabela 16, respectivamente. 
Tabela 14. Versão dos itens do instrumento após validação semântica.

\begin{tabular}{|c|c|}
\hline Versão para validação semântica & Versão final após sugestões \\
\hline 1.Redigir projetos de pesquisa de acordo com os objetivos e desafios institucionais. & 1.Redigir projetos de pesquisa de acordo com os objetivos e desafios institucionais. \\
\hline 2.Monitorar os resultados do projeto segundo o cronograma inicialmente proposto. & 2.Monitorar os resultados do projeto segundo o cronograma inicialmente proposto. \\
\hline 3.Exemplificar à equipe suas propostas sobre o projeto. & 3.Exemplificar à equipe suas propostas sobre o projeto. \\
\hline $\begin{array}{l}\text { 4.Associar as atividades previstas no projeto a processos de trabalho correlacionados, desenvolvidos } \\
\text { por unidades da Empresa. }\end{array}$ & $\begin{array}{l}\text { 4.Associar as atividades previstas no projeto a processos de trabalho correlacionados, desenvolvidos } \\
\text { por unidades da Empresa. }\end{array}$ \\
\hline $\begin{array}{l}\text { 5. Organizar os planos de ação na composição de um projeto, considerando a interdependência entre } \\
\text { eles. }\end{array}$ & $\begin{array}{l}\text { 5.Organizar os planos de ação na composição de um projeto, considerando a interdependência entre } \\
\text { eles. }\end{array}$ \\
\hline 6.Estimular os colegas de equipe de projeto a darem sugestões sobre o trabalho desenvolvido. & 6.Estimular os colegas de equipe de projeto a darem sugestões sobre o trabalho desenvolvido. \\
\hline 7.Solucionar problemas no andamento do projeto em colaboração com a equipe. & 7.Solucionar problemas no andamento do projeto em colaboração com a equipe. \\
\hline 8.Promover reuniões periódicas para acompanhamento das atividades do projeto. & 8.Promover reuniões periódicas para acompanhamento das atividades do projeto. \\
\hline $\begin{array}{l}\text { 9.Compor equipes de trabalho por meio de parcerias internas e externas reconhecidas na área de } \\
\text { atuação. }\end{array}$ & $\begin{array}{l}\text { 9.Compor equipes de trabalho por meio de parcerias internas e externas reconhecidas na área de } \\
\text { atuação. }\end{array}$ \\
\hline 10.Dividir tarefas na equipe com que trabalha. & 10.Dividir tarefas na equipe com que trabalha. \\
\hline 11.Planejar recursos do projeto de acordo com as atividades previstas no plano de ação. & 11.Planejar recursos do projeto de acordo com as atividades previstas no plano de ação. \\
\hline 12.Executar recursos do projeto segundo o orçamento proposto. & 12.Executar recursos do projeto segundo o orçamento proposto. \\
\hline 13.Esclarecer seus parceiros sobre a importância do projeto. & 13.Esclarecer seus parceiros sobre a importância do projeto. \\
\hline $\begin{array}{l}\text { 14.Descrever no projeto detalhes sobre investimentos em produtos e serviços necessários para a sua } \\
\text { execução. }\end{array}$ & $\begin{array}{l}\text { 14.Descrever no projeto detalhes sobre investimentos em produtos e serviços necessários para a sua } \\
\text { execução. }\end{array}$ \\
\hline 15.Antever situações de risco para evitar problemas no andamento do projeto. & 15.Analisar situações de risco de forma antecipada, para evitar problemas no andamento do projeto. \\
\hline $\begin{array}{l}\text { 16.Identificar os principais resultados comprometidos e entregues pela Empresa, por meio do } \\
\text { SISGP. }\end{array}$ & 16. Retirado \\
\hline $\begin{array}{l}\text { 17.Elaborar relatórios de resultados do projeto em conformidade aos prazos estabelecidos pela } \\
\text { Empresa. }\end{array}$ & $\begin{array}{l}\text { 17.Elaborar relatórios de resultados do projeto em conformidade aos prazos estabelecidos pela } \\
\text { Empresa }\end{array}$ \\
\hline 18.Elaborar relatórios de resultados do projeto com clareza e precisão. & 18.Elaborar relatórios de resultados do projeto com clareza e precisão. \\
\hline 19.Compartilhar informações relevantes do projeto com sua equipe de trabalho. & 19. Compartilhar informações relevantes do projeto com sua equipe de trabalho. \\
\hline 20.Utilizar ferramentas de gestão de projeto disponíveis na Empresa. & 20. Utilizar ferramentas de gestão de projetos disponíveis na Empresas. \\
\hline $\begin{array}{l}\text { 21.Utilizar o software que permite a gestão da programação da Empresa (Ideare), em conformidade } \\
\text { aos procedimentos estabelecidos no sistema. }\end{array}$ & $\begin{array}{l}\text { 21. Utilizar o software que permite a gestão da programação da Empresa (Ideare), em conformidade } \\
\text { aos procedimentos estabelecidos no sistema. }\end{array}$ \\
\hline \multirow[t]{2}{*}{ 22.Coordenar profissionais de natureza multidisciplinar para sua equipe de trabalho. } & 22. Coordenar profissionais de natureza multidisciplinar para sua equipe de trabalho. \\
\hline & $\begin{array}{l}\text { Acrescentado: Utilizar ferramentas de gestão de pessoas e processos disponíveis na organização } \\
\text { (tais como avaliar resultados no Integro). }\end{array}$ \\
\hline
\end{tabular}




\section{Versão enviada aos juízes}

1.Redigir projetos de pesquisa de acordo com os objetivos e desafios institucionais

2.Monitorar os resultados do projeto segundo o cronograma inicialmente proposto.

3.Exemplificar à equipe suas propostas sobre o projeto.

4.Associar as atividades previstas no projeto a processos de trabalho correlacionados, desenvolvidos por unidades da Empresa.

5.Organizar os planos de ação na composição de um projeto, considerando a interdependência entre eles.

6.Estimular os colegas de equipe de projeto a darem sugestões sobre o trabalho desenvolvido.

7.Solucionar problemas no andamento do projeto em colaboração com a equipe.

8.Promover reuniões periódicas para acompanhamento das atividades do projeto

9.Compor equipes de trabalho por meio de parcerias internas e externas reconhecidas na área de atuação.

10.Dividir tarefas na equipe com que trabalha.

11.Planejar recursos do projeto de acordo com as atividades previstas no plano de ação.

12.Executar recursos do projeto segundo o orçamento proposto.

13.Esclarecer seus parceiros sobre a importância do projeto.

14.Descrever no projeto detalhes sobre investimentos em produtos e serviços necessários para a sua execução.

15.Analisar situações de risco de forma antecipada, para evitar problemas no andamento do projeto.

16.Utilizar o software que permite a gestão da programação da Empresa (Ideare), em conformidade aos procedimentos estabelecidos no sistema.

17.Elaborar relatórios de resultados do projeto com clareza e precisão.

18.Compartilhar informações relevantes do projeto com sua equipe de trabalho.

19.Utilizar ferramentas de gestão de projetos disponíveis na Empresas.

20.Elaborar relatórios de resultados do projeto em conformidade aos prazos estabelecidos.

21.Coordenar profissionais de natureza multidisciplinar para sua equipe de trabalho.

22.Utilizar ferramentas de gestão de pessoas e processos disponíveis na organização (tais como avaliar resultados no Integro).

Acrescentado

Acrescentado

Acrescentado
Versão final após sugestões

Formular projetos de pesquisa de acordo com os objetivos e desafios institucionais.

Monitorar os resultados do projeto segundo o cronograma inicialmente proposto.

Exemplificar à equipe suas propostas sobre o projeto.

Correlacionar as atividades previstas no projeto a processos de trabalho desenvolvidos por unidades da Empresa.

Organizar os planos de ação na composição de um projeto, considerando a interdependência entre eles.

Estimular os colegas de equipe de projeto a darem sugestões sobre o trabalho desenvolvido.

Solucionar problemas no andamento do projeto em colaboração com a equipe

Promover reuniões periódicas para acompanhamento das atividades do projeto.

Compor equipes de trabalho por meio de parcerias internas e externas reconhecidas na área de atuação.

Item retirado

Planejar as atividades que compõem os planos de ação de acordo com os recursos previstos para o Projeto.

Executar recursos do projeto segundo o orçamento proposto.

Esclarecer seus parceiros sobre a importância do projeto.

Descrever no projeto detalhes sobre investimentos em produtos e serviços necessários à execução.

Propor soluções em situações de riscos e ameaças internas e externas, para evitar problemas no andamento do projeto.

Item retirado

Elaborar relatórios de resultados do projeto com clareza e precisão.

Compartilhar informações relevantes do projeto com sua equipe de trabalho.

Utilizar ferramentas de gestão disponíveis na Empresa.

Item retirado

Organizar projetos em rede, considerando a natureza multidisciplinar de seus componentes. Item retirado

Identificar os principais resultados obtidos pelo projeto a serem entregues à sociedade.

Divulgar os resultados do projeto e seus impactos para públicos diversos.

Promover a
competitivos

Fonte: Elaborado pela autora a partir da coleta de dados realizada em entrevistas nesta pesquisa. 
Tabela 16. Versão dos itens do instrumento após validação por juízes - etapa 2.

\begin{tabular}{|c|c|c|}
\hline Versão enviada aos juízes & Versão final após sugestões & Versão Final \\
\hline $\begin{array}{l}\text { 1.Formular projetos de pesquisa de acordo com os objetivos e } \\
\text { desafios institucionais. }\end{array}$ & $\begin{array}{l}\text { Elaborar projetos de pesquisa que utilizem as melhores abordagens } \\
\text { disponíveis para atender às demandas tecnológicas previamente } \\
\text { identificadas. } \\
\text { Redigir projetos de pesquisa, desenvolvimento e inovação de acordo com } \\
\text { os objetivos e desafios institucionais. } \\
\text { Redigir propostas (planos de projetos) e projetos de pesquisa de acordo } \\
\text { com os objetivos e desafios institucionais. } \\
\text { Estruturar e redigir projetos de PD\&I, considerando temas, orientações e } \\
\text { desafios institucionais. } \\
\text { Considero importante os projetos de pesquisa que apresentam o } \\
\text { componente inovação muito forte, e às vezes estão além dos desafios } \\
\text { institucionais, apresentando soluções nacionais/internacionais com o seu } \\
\text { resultado. }\end{array}$ & $\begin{array}{l}\text { Formular projetos de pesquisa, desenvolvimento e } \\
\text { inovação de acordo com os objetivos e desafios } \\
\text { institucionais. }\end{array}$ \\
\hline $\begin{array}{l}\text { 2.Monitorar os resultados do projeto segundo o cronograma } \\
\text { inicialmente proposto. }\end{array}$ & $\begin{array}{l}\text { Monitorar os resultados do projeto (intermediários e finalísticos) segundo } \\
\text { o cronograma inicialmente proposto. } \\
\text { Orientar a composição de equipes de trabalho promovendo parcerias } \\
\text { internas e externas com profissionais de reconhecida competência na área } \\
\text { de atuação do projeto. }\end{array}$ & $\begin{array}{l}\text { Monitorar os resultados do projeto segundo o } \\
\text { cronograma inicialmente proposto. }\end{array}$ \\
\hline 3.Exemplificar à equipe suas propostas sobre o projeto. & $\begin{array}{l}\text { Apresentar à equipe do projeto, a relevância das propostas definidas para } \\
\text { cada plano de ação. } \\
\text { Apresentar à equipe, suas ideias e propostas sobre o projeto. }\end{array}$ & $\begin{array}{l}\text { Exemplificar à equipe suas propostas sobre o } \\
\text { projeto. }\end{array}$ \\
\hline $\begin{array}{l}\text { 4.Correlacionar as atividades previstas no projeto a processos } \\
\text { de trabalho desenvolvidos por unidades da Empresa. }\end{array}$ & $\begin{array}{l}\text { Associar as atividades previstas no projeto a processos de trabalho } \\
\text { correlacionados, desenvolvidos por unidades da Empresa. } \\
\text { Obs.: retirar este item. Ficou confuso e sem clareza quanto ao que ele } \\
\text { propõe. }\end{array}$ & $\begin{array}{l}\text { Correlacionar as atividades a serem } \\
\text { desenvolvidas no projeto a processos promovidos } \\
\text { comparcerias externas. }\end{array}$ \\
\hline $\begin{array}{l}\text { 5. Organizar os planos de ação na composição de um projeto, } \\
\text { considerando a interdependência entre eles. }\end{array}$ & $\begin{array}{l}\text { Organizar os planos de ação e atividades na composição de um projeto, } \\
\text { considerando as dependências entre eles de forma a obter o caminho } \\
\text { crítico (atividades que impactam na duração no projeto). } \\
\text { Este item já está considerado na estruturação e redação do projeto (item } 1 \\
\text { do instrumento). }\end{array}$ & $\begin{array}{l}\text { Organizar os planos de ação na composição de um } \\
\text { projeto, considerando a interdependência entre } \\
\text { eles. }\end{array}$ \\
\hline $\begin{array}{l}\text { 6.Estimular os colegas de equipe do projeto a darem sugestões } \\
\text { sobre o trabalho desenvolvido. }\end{array}$ & $\begin{array}{l}\text { Estimular os membros da equipe, no desenvolvimento das ações } \\
\text { previstas no projeto. }\end{array}$ & $\begin{array}{l}\text { Estimular os colegas de equipe do projeto a darem } \\
\text { sugestões sobre o trabalho desenvolvido }\end{array}$ \\
\hline $\begin{array}{l}\text { 7.Solucionar problemas no andamento do projeto em } \\
\text { colaboração com a equipe. }\end{array}$ & $\begin{array}{l}\text { Solucionar problemas no andamento do projeto em colaboração com a } \\
\text { equipe e registrá-la como lições aprendidas em base de conhecimento. } \\
\text { Envolver os membros da equipe na solução de problemas decorrentes da } \\
\text { execução do projeto. }\end{array}$ & $\begin{array}{l}\text { Solucionar problemas no andamento do projeto em } \\
\text { colaboração com a equipe. }\end{array}$ \\
\hline
\end{tabular}


Tabela 16. Versão dos itens do instrumento após validação por juízes - etapa 2. (cont.).

\begin{tabular}{|c|c|c|}
\hline Versão enviada aos juízes & Versão final após sugestões & Versão Final \\
\hline $\begin{array}{l}\text { 8.Promover reuniões periódicas para acompanhamento das } \\
\text { atividades do projeto. }\end{array}$ & $\begin{array}{l}\text { Promover a reunião de kick-off e também reuniões periódicas para } \\
\text { acompanhamento das atividades do projeto. } \\
\text { Promover reuniões periódicas para monitorar, acompanhar e registrar } \\
\text { as atividades e os resultados do projeto. } \\
\text { Este item faz parte da gestão do projeto - poderia ser eliminado }\end{array}$ & $\begin{array}{l}\text { Promover reuniões periódicas para acompanhamento } \\
\text { das atividades do projeto. }\end{array}$ \\
\hline $\begin{array}{l}\text { 9.Compor equipes de trabalho por meio de parcerias internas e } \\
\text { externas reconhecidas na área de atuação. }\end{array}$ & Este item já está contemplado, pode ser eliminado. & $\begin{array}{l}\text { Compor equipes de trabalho por meio de parcerias } \\
\text { internas e externas reconhecidas na área de atuação. }\end{array}$ \\
\hline $\begin{array}{l}\text { 10.Planejar as atividades que compõem os planos de ação de } \\
\text { acordo com os recursos previstos para o Projeto. }\end{array}$ & $\begin{array}{l}\text { Planejar recursos do projeto de acordo com as atividades previstas no } \\
\text { plano de ação e restrições do projeto (escopo, prazo, custo e qualidade). } \\
\text { Planejar e executar a aplicação de recursos financeiros do projeto de } \\
\text { acordo com as atividades previstas nos planos de ação e do orçamento } \\
\text { aprovado. } \\
\text { Pode ser que a resposta dada não venha a contribuir com a pesquisa, } \\
\text { pois para elaboração dos orçamentos (entenda planejamento) existem } \\
\text { metodologias e regras definidas na Embrapa, mas quando da execução } \\
\text { da pesquisa - por estar vinculado ao orçamento da empresa - as vezes } \\
\text { o previsto torna-se muito diferente do realizado }\end{array}$ & $\begin{array}{l}\text { Planejar as atividades que compõem os planos de } \\
\text { ação de acordo com os recursos previstos para c } \\
\text { Projeto. }\end{array}$ \\
\hline $\begin{array}{l}\text { 11.Executar recursos do projeto segundo o orçamento } \\
\text { proposto. }\end{array}$ & $\begin{array}{l}\text { Planejar a distribuição de recursos do projeto de acordo com as } \\
\text { atividades previstas no plano de ação } \\
\text { Envolver equipe e instituições parceiras na captação de recursos para o } \\
\text { desenvolvimento do projeto. }\end{array}$ & $\begin{array}{l}\text { Executar recursos do projeto segundo o orçamentc } \\
\text { proposto. }\end{array}$ \\
\hline 12.Esclarecer seus parceiros sobre a importância do projeto. & $\begin{array}{l}\text { Esclarecer seus parceiros sobre a importância do projeto (gerenciar os } \\
\text { stakeholders do projeto, conforme as práticas de Gestão de Mudanças } \\
\text { Organizacionais, incluindo definição e gestão do mapa de } \\
\text { stakeholders). Ver HCMBOK ou outra prática como a APCM. } \\
\text { Retirar o item - seu conteúdo já está atendido pela proposta de texto } \\
\text { para o item } 2 \text { do instrumento. }\end{array}$ & $\begin{array}{l}\text { Esclarecer seus parceiros sobre a importância do } \\
\text { projeto. }\end{array}$ \\
\hline $\begin{array}{l}\text { 13.Descrever no projeto detalhes sobre investimentos em } \\
\text { produtos e serviços necessários à execução. }\end{array}$ & $\begin{array}{l}\text { Retirar o item. Seu conteúdo já está atendido pela proposta de redação } \\
\text { dos itens } 1\end{array}$ & $\begin{array}{l}\text { Descrever no projeto detalhes sobre investimentos } \\
\text { em produtos e serviços necessários à execução. }\end{array}$ \\
\hline $\begin{array}{l}\text { 14.Propor soluções em situações de riscos e de ameaças } \\
\text { internas e externas, a fim de evitar problemas no andamento do } \\
\text { projeto. }\end{array}$ & $\begin{array}{l}\text { Analisar situações de risco de forma antecipada, para evitar problemas } \\
\text { no andamento do projeto. } \\
\text { Realizar Planejamento de Riscos e Estratégia de Respostas para evitar } \\
\text { problemas no andamento e na entrega de resultados. } \\
\text { Retirar este item, pois está fora de alcance dos líderes de projetos } \\
\text { (ausência de ferramentas e preparo da instituição como um todo). }\end{array}$ & $\begin{array}{l}\text { Propor soluções em situações de riscos e de ameaças } \\
\text { internas e externas, a fim de evitar problemas nc } \\
\text { andamento do projeto. }\end{array}$ \\
\hline
\end{tabular}


Tabela 16. Versão dos itens do instrumento após validação por juízes - etapa 2. (cont.).

\begin{tabular}{|c|c|c|}
\hline Versão enviada aos juízes & Versão final após sugestões & Versão Final \\
\hline $\begin{array}{l}\text { 15. Elaborar relatórios de resultados de projetos com clareza e } \\
\text { precisão. }\end{array}$ & $\begin{array}{l}\text { Elaborar relatórios de resultados do projeto com clareza e precisão e na } \\
\text { periodicidade adequada para tomada de decisão (continuar, } \\
\text { redirecionar ou parar o projeto). } \\
\text { Elaborar relatórios de resultados do projeto em atendimento aos } \\
\text { requisitos e prazos estabelecidos pela Empresa. } \\
\text { Elaborar relatórios de resultados dos projetos em conformidade aos } \\
\text { prazos estabelecidos pela Empresa, órgãos de fomento ou órgão } \\
\text { regulador (ex.: TCU). }\end{array}$ & $\begin{array}{l}\text { Elaborar relatórios de resultados do projeto com } \\
\text { precisão, em conformidade aos prazos estabelecidos } \\
\text { pela Empresa. }\end{array}$ \\
\hline $\begin{array}{l}\text { 16.Compartilhar informações relevantes ao projeto com sua } \\
\text { equipe de trabalho.. }\end{array}$ & $\begin{array}{l}\text { Compartilhar informações relevantes do projeto com sua equipe de } \\
\text { trabalho (compartilhar usando a comunicação, no sentido de } \\
\text { levar/trazer e não apenas divulgar) } \\
\text { Retirada deste item. Já está contemplado nos itens } 6 \text { e } 7 .\end{array}$ & $\begin{array}{l}\text { Compartilhar informações relevantes ao projeto com } \\
\text { sua equipe de trabalho. }\end{array}$ \\
\hline $\begin{array}{l}\text { 17.Utilizar ferramentas de gestão de projeto disponíveis na } \\
\text { Empresa. }\end{array}$ & $\begin{array}{l}\text { Utilizar a ferramenta de gestão da programação de projetos de PD\&I da } \\
\text { Empresa (Ideare) para acompanhar o seu projeto. }\end{array}$ & $\begin{array}{l}\text { Utilizar metodologias e ferramentas de gestão de } \\
\text { projetos disponíveis na Empresa }\end{array}$ \\
\hline $\begin{array}{l}\text { 18. Organizar projetos em rede, considerando a natureza } \\
\text { multidisciplinar de seus componentes. }\end{array}$ & $\begin{array}{l}\text { Coordenar profissionais de natureza multidisciplinar para sua equipe de } \\
\text { trabalho - critério ambíguo. }\end{array}$ & $\begin{array}{l}\text { Organizar projetos em rede, considerando a natureza } \\
\text { multidisciplinar de seus componentes. }\end{array}$ \\
\hline $\begin{array}{l}\text { 19.Identificar os principais resultados obtidos pelo projeto a } \\
\text { serem entregues à sociedade. }\end{array}$ & & $\begin{array}{l}\text { Identificar os principais resultados obtidos pelo } \\
\text { projeto a serem entregues à sociedade. }\end{array}$ \\
\hline $\begin{array}{l}\text { 20.Divulgar os resultados do projeto e seus impactos para } \\
\text { públicos diversos (Empresa e sociedade). }\end{array}$ & & $\begin{array}{l}\text { Divulgar os resultados do projeto e seus impactos } \\
\text { para públicos diversos (Empresa e sociedade). }\end{array}$ \\
\hline $\begin{array}{l}\text { 21.Promover a captação de recursos externos por meio de } \\
\text { participação efetiva em editais competitivos. }\end{array}$ & & $\begin{array}{l}\text { Promover a captação de recursos externos por meio } \\
\text { de participação efetiva em editais competitivos. }\end{array}$ \\
\hline $\begin{array}{l}\text { OBSERVAÇÕES } \\
\text { Inclusão de item } \\
\text { Sugestões/observações }\end{array}$ & $\begin{array}{l}\text { Descrição } \\
\text { Inclusão de item relacionado a: }\end{array}$ & \\
\hline & $\begin{array}{l}\text { a) Usar novas técnicas de comunicação com as equipes, que } \\
\text { incluem web conferencias, redes sociais etc. } \\
\text { Manter canal de comunicação aberto com a gestão da } \\
\text { Unidade de forma a assegurar o comprometimento dos } \\
\text { gestores com os resultados do projeto. } \\
\text { Preparar os resultados do projeto para a sua efetiva } \\
\text { transferência ao público-alvo. }\end{array}$ & $\begin{array}{l}\text { Utilizar novas técnicas de comunicação com a } \\
\text { equipe, como web conferências, redes sociais. } \\
\text { Preparar os resultados do projeto para a sua efetiva } \\
\text { transferência ao público-alvo. }\end{array}$ \\
\hline
\end{tabular}

Fonte: Elaborado pela autora a partir da coleta de dados realizada em entrevistas nesta pesquisa. 
Na validação semântica, um dos itens modificados denotou preocupação com a clareza da escrita - item 15. "Antever situações de risco para evitar problemas no andamento do projeto" modificado para "Analisar situações de risco de forma antecipada, para evitar problemas no andamento do projeto". O item 16 foi retirado, com a justificativa de não constituir competência relevante a atividade, e um item foi acrescentado "Utilizar ferramentas de gestão de pessoas e processos disponíveis na organização (tais como avaliar resultados no Integro)", com o objetivo de compor um elemento de gestão de pessoas ao rol de competências.

Com relação à validação por juízes, na etapa 1 , foram modificados os itens $1,4,11 \mathrm{e}$ 15 ; retirados os itens 10,16 e 20 e acrescentados 3 itens

$\mathrm{Na}$ etapa 2 da validação por juízes, foram modificados os itens 1, 4, 15, 17 e 22, e incluídos 2 itens.

Por fim, após as duas etapas de validação, totalizaram 25 itens, vislumbrados na próxima seção. Foram suprimidos cinco itens entre as duas validações - um na primeira e quatro na segunda, e incorporados quatro - um na primeira e três na segunda.

\subsubsection{Versão final do instrumento}

$\mathrm{Na}$ versão final do instrumento, destinado à aplicação, era composto de duas partes: a primeira parte consistia em 13 perguntas para informações gerais, dados sociodemográficos e funcionais.

A segunda parte era composta pelos vinte e cinco itens do questionário, a serem avaliados por duas escalas de cinco pontos cada uma: uma para domínio (variando de "não domino" a "domino completamente") e outra para importância ("nada importante" a "muito importante").

Precedia ao instrumento as instruções de preenchimento, contendo o objetivo da pesquisa, considerações de sigilo dos dados, bem como tratamento das informações de forma agregada, e agradecimento pela participação. 


\section{Avaliação de Necessidades de Treinamento para líderes de projeto}

Prezado (a) líder de projeto,

Este questionário tem como objetivo identificar as necessidades de treinamento no contexto de PD\&I, por meio da apreciação das principais atribuições de seu papel ocupacional (atribuição de líder de projeto).

A $1^{\text {a }}$ parte é composta por dados sociodemográficos e funcionais - itens como sexo, idade, escolaridade, área de formação, cargo, tempo de trabalho, tempo na Empresa, tempo na atribuição de líder de projeto, área de atuação e participação em comitês.

A $2^{\mathrm{a}}$ Parte possui 25 itens, acompanhados de duas escalas: uma para avaliar sua percepção sobre a Importância da atividade para a atribuição de líder de projeto, e outra o seu Domínio sobre a competência descrita.

Suas respostas serão tratadas de forma agrupada e sigilosa. Você não precisa se identificar, pois a intenção não é avaliar o seu desempenho, mas planejar ações educacionais adequadas a melhoria dos processos de trabalho da sua área. Desta forma, é importante que as respostas representem sua percepção da realidade de seu trabalho.

Sua participação é muito importante! Por favor, não deixe repostas em branco. 


\section{$1^{\text {a }}$ parte - Informações gerais}

1 Sexo:

( ) Masculino ( ) Feminino

2 Idade (anos):

3 Titulação

( ) Especialização

( ) Mestrado

( ) Doutorado

( ) Pós-doutorado

4 Área de formação (curso de graduação)

5 Área de especialização (área de conhecimento na qual se especializou)

6 Cargo:

( ) Analista

( ) Pesquisador

7 Tempo de Empresa (anos):

8 Tempo de trabalho (anos - desde o início de sua atuação profissional)

9 Eixo de atuação na Empresa

( ) Comunicação e Desenvolvimento Institucional

( ) Pesquisa e Desenvolvimento

( ) Transferência e Tecnologia

10 Tempo de experiência como líder de projeto na Embrapa (anos)

11 Tempo de experiência como líder de projeto (anos - desde o início de sua atuação profissional)

12 Participação em grupos e comitês da Empresa

( ) Comitê Gestor de Portifólio

( ) Grupo Gestor de Arranjo

( ) Comitê Técnico Interno

( ) Nenhum

Outros:

13 Abrangência de atuação do Projeto *

( ) Nacional ( ) Internacional ( ) Nacional e Internacional 


\section{QUESTIONÁRIO AVALIAÇÃO DE NECESSIDADES DE TREINAMENTO PARA LÍDERES DE PROJETO}

Os 25 itens que integram o questionário referem-se as atividades relacionadas ao trabalho do líder de projeto da Embrapa. Avalie as afirmativas a partir dos critérios de Importância e Domínio.

\section{Importante:}

Mesmo que exerça outras atividades na Empresa, a análise dos itens listados no questionário deve considerar seu contexto de trabalho na função de líder de projeto.

Para as afirmativas que se referem à equipe, a análise deve considerar a equipe de projeto nessa atribuição.

Para responder ao questionário, leia atentamente os itens relacionados e escolha, para cada um deles, o ponto da escala de Importância $(1,2,3,4,5)$ e o ponto da escala de Domínio $(1,2,3,4,5)$ que melhor represente a sua percepção.

Para importância, avalie a relevância da competência representada em cada atividade descrita para o cumprimento do bom desempenho do trabalho na atribuição de líder de projeto. A escala varia de 1 (nada importante) a 5(muito importante).

Escala de Importância:

\begin{tabular}{|l|l|l|l|l|}
\hline 1 & 2 & 3 & 4 & 5 \\
\hline Nada importante & & & & $\begin{array}{c}\text { Muito } \\
\text { importante }\end{array}$ \\
\hline
\end{tabular}

Para domínio, considere sua percepção em relação a quanto você domina a competência representada em cada atividade descrita nos itens do questionário que, em conjunto, na prática do trabalho, são essenciais a atribuição de líder de projeto. Para isso, utilize a escala que varia de 1 (Não domino) a 5 (Domino completamente).

Escala de Domínio

\begin{tabular}{|l|l|l|l|l|}
\hline 1 & 2 & 3 & 4 & 5 \\
\hline Não domino & & & & $\begin{array}{c}\text { Domino } \\
\text { completamente }\end{array}$ \\
\hline
\end{tabular}




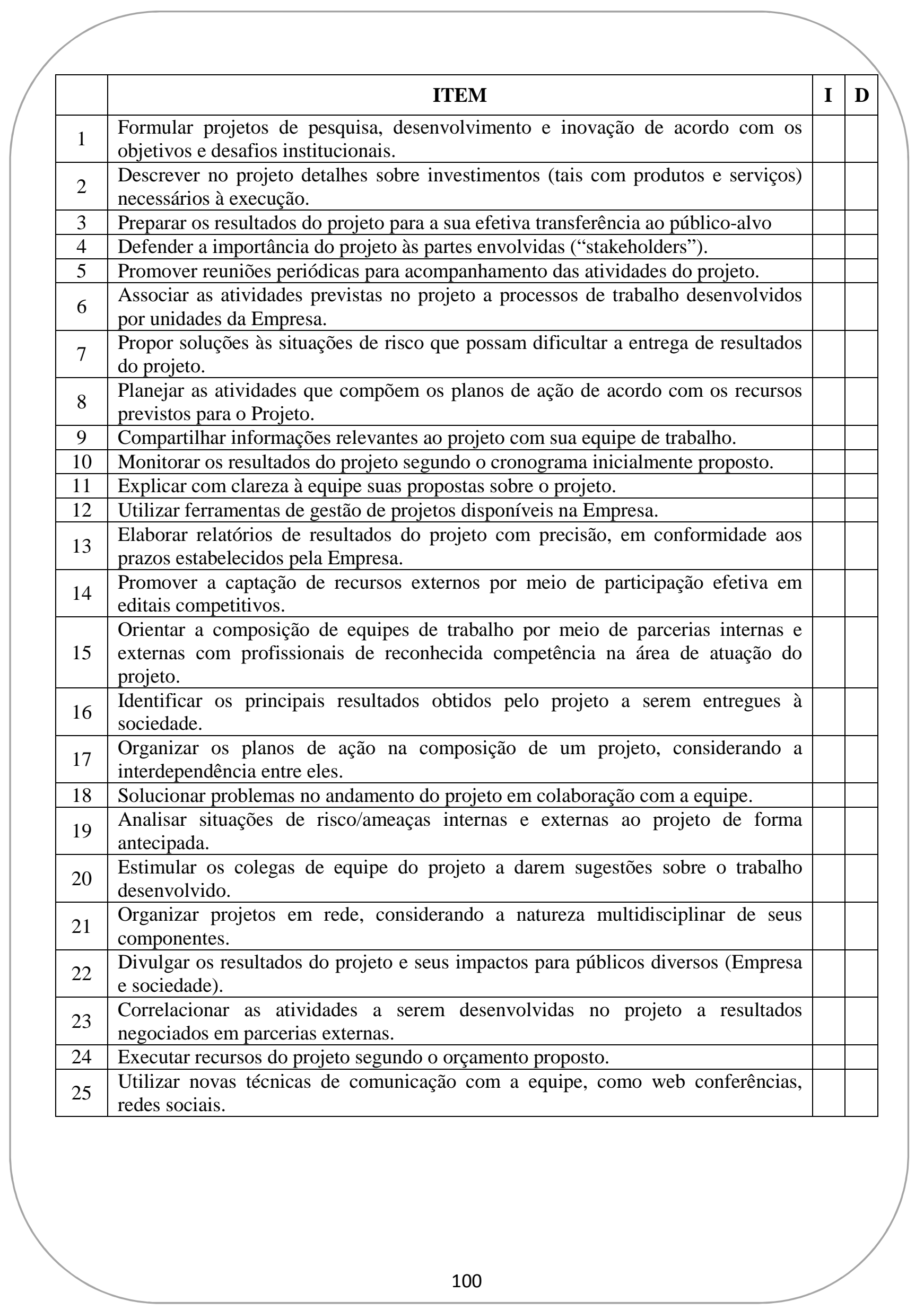




\subsection{Análises descritivas}

Essa seção apresenta os resultados descritivos dos instrumentos de avaliação de necessidades de treinamento de líderes de projeto, em termos de médias, moda, valores mínimo e máximo, desvio-padrão, além da concentração das respostas obtidas pela coleta de dados da pesquisa. Não houve casos omissos de respostas para nenhum dos itens.

São apresentados análises descritivas dos 25 itens do questionário CompLP, associados a duas escalas - importância e domínio.

Os dados descritivos da escala de importância são ilustrados na Tabela 17.

Tabela 17 - Dados descritivos dos itens relativos a escala de importância.

\begin{tabular}{|c|c|c|c|c|c|c|c|}
\hline \multirow[t]{2}{*}{ Itens } & \multirow[t]{2}{*}{ Média } & \multirow[t]{2}{*}{ Moda } & \multirow[t]{2}{*}{ Mín } & \multirow[t]{2}{*}{ Máx } & \multirow{2}{*}{$\begin{array}{l}\text { Desvio } \\
\text { padrão }\end{array}$} & \multicolumn{2}{|c|}{$\begin{array}{l}\text { Concentração } \\
\text { Resp }\end{array}$} \\
\hline & & & & & & $1-3$ & $4-5$ \\
\hline $\begin{array}{l}\text { 1. Formular projetos de pesquisa, } \\
\text { desenvolvimento e inovação de acordo com } \\
\text { os objetivos e desafios institucionais. }\end{array}$ & 4,81 & 5 & 2 & 5 & 496 & 2,8 & 97,2 \\
\hline $\begin{array}{l}\text { 16. Identificar os principais resultados } \\
\text { obtidos pelo projeto a serem entregues à } \\
\text { sociedade. }\end{array}$ & 4,74 & 5 & 2 & 5 & ,513 & 2,8 & 97,2 \\
\hline $\begin{array}{l}\text { 3. Preparar os resultados do projeto para a } \\
\text { sua efetiva transferência ao público-alvo. }\end{array}$ & 4,67 & 5 & 2 & 5 & 653, & 7,2 & 92,9 \\
\hline $\begin{array}{l}\text { 22. Divulgar os resultados do projeto e seus } \\
\text { impactos para públicos diversos (Empresa e } \\
\text { sociedade). }\end{array}$ & 4,67 & 5 & 2 & 5 & 628 & 6,8 & 93,2 \\
\hline $\begin{array}{l}\text { 9. Compartilhar informações relevantes ao } \\
\text { projeto com sua equipe de trabalho. }\end{array}$ & 4,66 & 5 & 2 & 5 & ,553 & 10,2 & 89,8 \\
\hline $\begin{array}{l}\text { 11. Explicar com clareza à equipe suas } \\
\text { propostas sobre o projeto. }\end{array}$ & 4,64 & 5 & 1 & 5 & ,623 & 40,1 & 59,9 \\
\hline $\begin{array}{l}\text { 8. Planejar as atividades que compõem os } \\
\text { planos de ação de acordo com os recursos } \\
\text { previstos para o projeto. }\end{array}$ & 4,59 & 5 & 1 & 5 & 683, & 2,8 & 97,2 \\
\hline $\begin{array}{l}\text { 18. Solucionar problemas no andamento do } \\
\text { projeto em colaboração com a equipe. }\end{array}$ & 4,57 & 5 & 2 & 5 & ,593 & 4,6 & 95,3 \\
\hline $\begin{array}{l}\text { 4. Defender a importância do projeto às } \\
\text { partes envolvidas ("stakeholders"). }\end{array}$ & 4,56 & 5 & 2 & 5 & 615, & 5,9 & 94,1 \\
\hline $\begin{array}{l}\text { 15. Orientar a composição de equipes de } \\
\text { trabalho por meio de parcerias internas e } \\
\text { externas com profissionais de reconhecida } \\
\text { competência na área de atuação do projeto. }\end{array}$ & 4,52 & 5 & 2 & 5 & ,689 & 6,2 & 91,3 \\
\hline $\begin{array}{l}\text { 24. Executar recursos do projeto segundo o } \\
\text { orçamento proposto. }\end{array}$ & 4,5 & 5 & 1 & 5 &, 750 & 9,9 & 90,1 \\
\hline 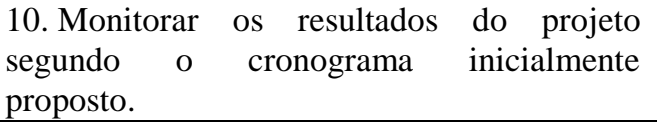 & 4,45 & 5 & 2 & 5 & ,692 & 26,4 & 96,5 \\
\hline
\end{tabular}


Tabela 17 - Dados descritivos dos itens relativos a escala de importância (cont.).

\begin{tabular}{|c|c|c|c|c|c|c|c|}
\hline Itens & Média & Moda & Mín & Máx & $\begin{array}{l}\text { Desvio } \\
\text { padrão }\end{array}$ & $\begin{array}{c}\text { Concentração } \\
\text { Resp }\end{array}$ & Itens \\
\hline & & & & & & $1-3$ & $4-5$ \\
\hline $\begin{array}{l}\text { 14. Promover a captação de recursos } \\
\text { externos por meio de participação } \\
\text { efetiva em editais competitivos. }\end{array}$ & 4,43 & 5 & 1 & 5 &, 822 & 11,8 & 88,2 \\
\hline $\begin{array}{l}\text { 20. Estimular os colegas de equipe do } \\
\text { projeto a darem sugestões sobre o } \\
\text { trabalho desenvolvido. }\end{array}$ & 4,4 & 5 & 2 & 5 & ,700 & 9,9 & 90 \\
\hline $\begin{array}{l}\text { 7. Propor soluções às situações de risco } \\
\text { que possam dificultar a entrega de } \\
\text { resultados do projeto. }\end{array}$ & 4,38 & 5 & 2 & 5 & ,753 & 13,9 & 86 \\
\hline $\begin{array}{l}\text { 19. Analisar situações de risco/ameaças } \\
\text { internas e externas ao projeto de forma } \\
\text { antecipada. }\end{array}$ & 4,32 & 5 & 2 & 5 & ,761 & 15 & 85 \\
\hline $\begin{array}{l}\text { 5. Promover reuniões periódicas para } \\
\text { acompanhamento das atividades do } \\
\text { projeto. }\end{array}$ & 4,31 & 5 & 1 & 5 & ,814 & 17,1 & 82,9 \\
\hline $\begin{array}{l}\text { 17. Organizar os planos de ação na } \\
\text { composição de um projeto, } \\
\text { considerando a interdependência entre } \\
\text { eles. }\end{array}$ & 4,27 & 5 & 1 & 5 &, 867 & 17,1 & 82,9 \\
\hline $\begin{array}{l}\text { 21. Organizar projetos em rede, } \\
\text { considerando a natureza multidisciplinar } \\
\text { de seus componentes. }\end{array}$ & 4,26 & 5 & 1 & 5 & ,900 & 19,4 & 80,4 \\
\hline $\begin{array}{l}\text { 13. Elaborar relatórios de resultados do } \\
\text { projeto com precisão, em conformidade } \\
\text { aos prazos estabelecidos pela Empresa. }\end{array}$ & 4,24 & 5 & 1 & 5 & ,915 & 17,6 & 82,3 \\
\hline $\begin{array}{l}\text { 2. Descrever no projeto detalhes sobre } \\
\text { investimentos (tais com produtos e } \\
\text { serviços) necessários à execução. }\end{array}$ & 4,19 & 5 & 1 & 5 & ,954 & 21,1 & 78,9 \\
\hline $\begin{array}{l}\text { 25. Utilizar novas técnicas de } \\
\text { comunicação com a equipe, como web } \\
\text { conferencias, redes sociais. }\end{array}$ & 4,17 & 5 & 1 & 5 & ,899 & 22 & 78 \\
\hline $\begin{array}{l}\text { 23. Correlacionar as atividades a serem } \\
\text { desenvolvidas no projeto a resultados } \\
\text { negociados em parcerias externas. }\end{array}$ & 4,04 & 4 & 1 & 5 & ,949 & 24,8 & 75,2 \\
\hline $\begin{array}{l}\text { 6. Associar as atividades previstas no } \\
\text { projeto a processos de trabalho } \\
\text { desenvolvidos por unidades da } \\
\text { Empresa. }\end{array}$ & 3,93 & 4 & 1 & 5 & ,999 & 28,8 & 71,1 \\
\hline $\begin{array}{l}\text { 12. Utilizar ferramentas de gestão de } \\
\text { projetos disponíveis na Empresa. }\end{array}$ & 3,69 & 5 & 1 & 5 & 1,164 & 40,1 & 59,9 \\
\hline
\end{tabular}

As estatísticas descritivas da Escala de Importância demonstram que, nessa amostra, a média de importância das competências descritas teve uma variação de 3,69 a 4,81. Todos os itens apresentam concentração de respostas nos pontos mais altos da escala, sendo que os itens que apresentaram índices mais baixos foram os itens 11 e 12 - com igual concentração de $59,9 \%$ de respostas nos pontos mais altos da escala. Os outros itens variaram de 71,1 a 
97,2\%. A moda também apresenta valores iguais, apontando para o valor máximo, com exceção dos itens 23 e 6, que apresentam igualmente valor superior na escala (4). Os desvios padrão apresentados são altos para a maioria das competências, o que indica divergência na opinião dos respondentes acerca da importância daquela competência para o trabalho. Os dados descritivos relativos à escala de domínio estão ilustrados na Tabela 18 a seguir.

Tabela 18 - Dados descritivos dos itens relativos a escala de domínio.

\begin{tabular}{|c|c|c|c|c|c|c|c|}
\hline \multirow[t]{2}{*}{ Itens } & \multirow[t]{2}{*}{ Média } & \multirow[t]{2}{*}{ Moda } & \multirow[t]{2}{*}{ Mín } & \multirow[t]{2}{*}{ Máx } & \multirow{2}{*}{$\begin{array}{l}\text { Desvio } \\
\text { padrão }\end{array}$} & \multicolumn{2}{|c|}{$\begin{array}{c}\text { Concentração } \\
\text { Resp }\end{array}$} \\
\hline & & & & & & $1-3$ & $4-5$ \\
\hline $\begin{array}{l}\text { 1.Formular projetos de pesquisa, } \\
\text { desenvolvimento e inovação de acordo com } \\
\text { os objetivos e desafios institucionais }\end{array}$ & 4,07 & 4 & 1 & 5 & ,756 & 20,8 & 79,2 \\
\hline $\begin{array}{l}\text { 2.Descrever no projeto detalhes sobre } \\
\text { investimentos (tais com produtos e serviços) } \\
\text { necessários à execução }\end{array}$ & 3,88 & 4 & 1 & 5 & ,815 & 29,5 & 70,5 \\
\hline $\begin{array}{l}\text { 3.Preparar os resultados do projeto para a } \\
\text { sua efetiva transferência ao público-alvo }\end{array}$ & 3,66 & 4 & 1 & 5 & ,884 & 42,2 & 57,8 \\
\hline $\begin{array}{l}\text { 4.Defender a importância do projeto às } \\
\text { partes envolvidas ("stakeholders") }\end{array}$ & 3,85 & 4 & 1 & 5 & ,860 & 34,8 & 65,2 \\
\hline $\begin{array}{l}\text { 5.Promover reuniões periódicas para } \\
\text { acompanhamento das atividades do projeto. }\end{array}$ & 3,93 & 4 & 1 & 5 & 890 & 29,5 & 70,5 \\
\hline $\begin{array}{l}\text { 6.Associar as atividades previstas no projeto } \\
\text { a processos de trabalho desenvolvidos por } \\
\text { unidades da Empresa. }\end{array}$ & 3,45 & 3 & 1 & 5 & ,903 & 52,8 & 47,2 \\
\hline $\begin{array}{l}\text { 7. Propor soluções às situações de risco que } \\
\text { possam dificultar a entrega de resultados do } \\
\text { projeto. }\end{array}$ & 3,69 & 4 & 1 & 5 & ,810 & 40,7 & 59,3 \\
\hline $\begin{array}{l}\text { 8.Planejar as atividades que compõem os } \\
\text { planos de ação de acordo com os recursos } \\
\text { previstos para o Projeto. }\end{array}$ & 4,13 & 4 & 1 & 5 & ,820 & 20,2 & 79,8 \\
\hline $\begin{array}{l}\text { 9.Compartilhar informações relevantes ao } \\
\text { projeto com sua equipe de trabalho. }\end{array}$ & 4,24 & 5 & 2 & 5 & ,789 & 18,9 & 81,1 \\
\hline $\begin{array}{l}\text { 10. Monitorar os resultados do projeto } \\
\text { segundo o cronograma inicialmente } \\
\text { proposto. }\end{array}$ & 3,87 & 4 & 1 & 5 & ,836 & 34,5 & 65,5 \\
\hline $\begin{array}{l}\text { 11.Explicar com clareza à equipe suas } \\
\text { propostas sobre o projeto. }\end{array}$ & 4,29 & 4 & 2 & 5 & ,719 & 13,0 & 87,0 \\
\hline $\begin{array}{l}\text { 12.Utilizar ferramentas de gestão de projetos } \\
\text { disponíveis na Empresa. }\end{array}$ & 3,12 & 3 & 1 & 5 & 1,036 & 62,7 & 37,3 \\
\hline $\begin{array}{l}\text { 13.Elaborar relatórios de resultados do } \\
\text { projeto com precisão, em conformidade aos } \\
\text { prazos estabelecidos pela Empresa. }\end{array}$ & 3,80 & 4 & 1 & 5 & ,920 & 36,3 & 63,7 \\
\hline $\begin{array}{l}\text { 14.Promover a captação de recursos externos } \\
\text { por meio de participação efetiva em editais } \\
\text { competitivos }\end{array}$ & 3,58 & 4 & 1 & 5 & 1,068 & 43,5 & 56,5 \\
\hline $\begin{array}{l}\text { 15.Orientar a composição de equipes de } \\
\text { trabalho por meio de parcerias internas e } \\
\text { externas com profissionais de reconhecida } \\
\text { competência na área de atuação do projeto. }\end{array}$ & 3,78 & 4 & 1 & 5 & ,930 & 36,6 & 63,4 \\
\hline
\end{tabular}


Tabela 18 - Dados descritivos dos itens relativos a escala de domínio (cont.).

\begin{tabular}{|c|c|c|c|c|c|c|c|}
\hline \multirow[t]{2}{*}{ Itens } & \multirow[t]{2}{*}{ Média } & \multirow[t]{2}{*}{ Moda } & \multirow[t]{2}{*}{ Mín } & \multirow[t]{2}{*}{ Máx } & \multirow{2}{*}{$\begin{array}{l}\text { Desvio } \\
\text { padrão }\end{array}$} & \multicolumn{2}{|c|}{$\begin{array}{c}\text { Concentração } \\
\text { Resp }\end{array}$} \\
\hline & & & & & & $1-3$ & $4-5$ \\
\hline $\begin{array}{l}\text { 16.Identificar os principais resultados } \\
\text { obtidos pelo projeto a serem entregues à } \\
\text { sociedade. }\end{array}$ & 4,04 & 4 & 2 & 5 & ,784 & 22,7 & 77,3 \\
\hline $\begin{array}{l}\text { 17.Organizar os planos de ação na } \\
\text { composição de um projeto, considerando a } \\
\text { interdependência entre eles. }\end{array}$ & 4,16 & 4 & 2 & 5 & ,781 & 18,6 & 81,4 \\
\hline $\begin{array}{l}\text { 18. Solucionar problemas no andamento do } \\
\text { projeto em colaboração com a equipe. }\end{array}$ & 3,97 & 4 & 2 & 5 & ,765 & 23,9 & 76,1 \\
\hline $\begin{array}{l}\text { 19.Analisar situações de risco/ameaças } \\
\text { internas e externas ao projeto de forma } \\
\text { antecipada. }\end{array}$ & 3,46 & 3 & 1 & 5 & ,879 & 51,9 & 48,1 \\
\hline $\begin{array}{l}\text { 20.Estimular os colegas de equipe do projeto } \\
\text { a darem sugestões sobre o trabalho } \\
\text { desenvolvido. }\end{array}$ & 3,85 & 4 & 1 & 5 & ,833 & 32,9 & 67,1 \\
\hline $\begin{array}{l}\text { 21.Organizar projetos em rede, considerando } \\
\text { a natureza multidisciplinar de seus } \\
\text { componentes. }\end{array}$ & 3,66 & 4 & 1 & 5 & ,971 & 40,7 & 59,3 \\
\hline $\begin{array}{l}\text { 22.Divulgar os resultados do projeto e seus } \\
\text { impactos para públicos diversos (Empresa e } \\
\text { sociedade). }\end{array}$ & 3,72 & 4 & 1 & 5 & ,902 & 41,3 & 58,7 \\
\hline $\begin{array}{l}\text { 23.Correlacionar as atividades a serem } \\
\text { desenvolvidas no projeto a resultados } \\
\text { negociados em parcerias externas. }\end{array}$ & 3,34 & 3 & 1 & 5 & ,999 & 57,5 & 42,5 \\
\hline $\begin{array}{l}\text { 24.Executar recursos do projeto segundo o } \\
\text { orçamento proposto. }\end{array}$ & 3,83 & 4 & 1 & 5 & 1,009 & 31,1 & 68,9 \\
\hline $\begin{array}{l}\text { 25.Utilizar novas técnicas de comunicação } \\
\text { com a equipe, como web conferencias, redes } \\
\text { sociais. }\end{array}$ & 3,52 & 4 & 1 & 5 & ,993 & 48,1 & 51,9 \\
\hline
\end{tabular}

Para a escala de domínio, as estatísticas descritivas demonstram que os respondentes da amostra percebem o domínio das competências descritas nos itens com uma variação de média de 3,12 a 4,29. Dentre os 25 itens presentes no questionário, a maioria dos itens apresentam concentração de respostas nos pontos mais altos da escala, sendo que os itens que apresentaram maior índice foram os itens $17,9,8$ e o item 1 - com respectivamente 81,4\%; $81,1 \% ; 79,8 \%$ e $79,2 \%$ de concentração de respostas nos pontos mais altos da escala. Os outros itens variaram de 37,3 a 77,3\%. Os itens 12, 23, 6 e 19 apresentaram concentração superior de resposta no par de valores 1-3 da escala, com índices respectivos de 62,7\%; 57,5; $52,8 \%$; e 51,9\%. Com exceção dos itens $19,6,23$, e 12 com valor de moda 3 , todos os outros itens apresentam valores 4 e 5 na escala. As modas ratificam os valores das médias, o que indica respostas com muita frequência em determinados aspectos e com baixa frequência em outros, demonstrando que algumas competências são percebidas como com mais domínio que 
outras, mas de um modo geral todas se encontram com média acima de 3 na escala. Os desvios padrão apresentados são bastante altos, indicando diferentes percepções de domínio nas competências descritas.

\subsection{Análises fatoriais exploratórias}

A presente seção demonstra os resultados das análises fatoriais exploratórias das estruturas empíricas das escalas de Importância e Domínio do questionário de avaliação de necessidades de treinamento de líderes de projeto - CompLP. Tais análises se relacionam ao alcance dos objetivos específicos dessa pesquisa, relacionados à verificação de evidências de validade do instrumento de medida.

\section{Escala de Importância}

Antes de iniciar a explanação acerca dos resultados das análises exploratórias para a escala de Importância, é necessário descrever o percurso que levou a esses resultados. Em um primeiro momento, foram realizadas todas as análises necessárias (linearidade, multicolinearidade, casos omissos, casos extremos e PC). Após realizar a análise paralela, obteve-se 2 fatores e realizou-se a PAF.

A escala de Importância apresentou 322 casos válidos, sem presença de casos omissos. Dadas as recomendações de Tabachnick et al. (2007), quando o total de casos omissos não ultrapassa 5\% dos dados, não é preciso realizar nenhuma análise ou alteração dos dados. As respostas não apresentaram casos extremos univariados. Foram identificados 31 casos extremos multivariados. Optou-se por mantê-los por não afetar a AFE.

A matriz de covariância foi elaborada e analisada, o que possibilitou a verificação de que não houve relacionamentos lineares entre as variáveis (linearidade), nem a presença de singularidade e multicolinearidade. Em relação a fatorabilidade, o tamanho das correlações e a adequação da amostra foram analisados. Foram encontrados valores de correlação superiores a 0,30 em mais de 50\% dos casos, indicando que uma matriz provavelmente fatorável. O teste de KMO também foi realizado e obteve-se um valor de 0,927 , considerado um bom índice de adequação da amostra. A extração inicial de fatores foi feita mediante análise dos componentes principais. Foi realizado o tratamento pairwise para os casos omissos. A análise dos componentes principais sugeriu uma estrutura empírica com até cinco 
componentes, que explicam, em conjunto, $41,55 \%$ da variância total das respostas dos participantes aos itens do questionário. Foi seguido o critério dos eigenvalues (valores próprios) dos fatores maiores ou iguais a 1 (um). Dessa maneira, chegou-se ao valor máximo de 5 fatores a serem extraídos. Ao realizar a análise do scree plot, foi verificada a existência de 1 a 2 fatores, como pode ser observado na Figura 8.

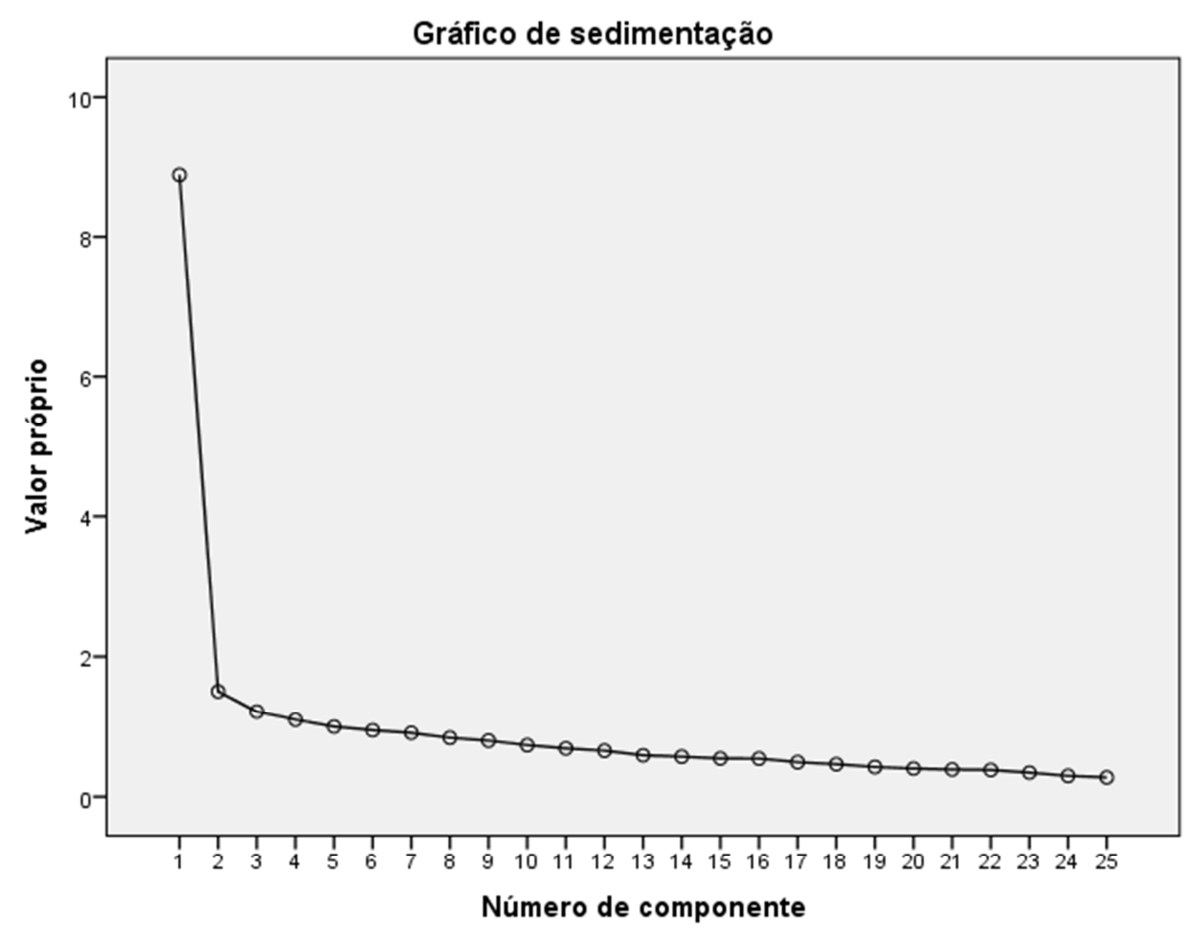

Figura 8: Distribuição dos valores próprios (scree plot) da escala de Importância do CompLP.

A análise paralela de Horn, por sua vez, apontou 2 fatores para esta escala. Como demonstrado na Tabela 19, apenas os fatores com valores empíricos maiores ou iguais aos valores aleatórios são mantidos na estrutura.

Tabela 19. Valores próprios empíricos e aleatórios dos primeiros cinco componentes da escala de importância do CompLP

\begin{tabular}{lrrrrrr}
\hline \multirow{2}{*}{ Valores próprios } & \multicolumn{3}{c}{ Componentes } & & & \\
\cline { 2 - 6 } & & 1 & 2 & 3 & 4 & 5 \\
\hline Empírico & 8,88 & 1,50 & 1,21 & 1,10 & 1,00 \\
Aleatório & 1,54 & 1,45 & 1,39 & 1,33 & 1,28 \\
\hline
\end{tabular}

Fonte: Elaborada pela autora a partir da análise dos dados. 
A Tabela 19 demonstra que os dois primeiros fatores explicam maior variância do que os fatores correspondentes nos dados aleatórios. Sendo assim, a partir da análise paralela, foi possível confirmar uma estrutura com 2 fatores.

Para confirmar de maneira definitiva a estrutura fatorial do instrumento, foi realizada a PAF, com método de rotação oblíqua e tratamento pairwise para casos omissos. Decidiu-se incluir na escala apenas os itens com cargas fatoriais iguais ou superiores a 0,30. Tal análise permitiu a extração de 2 fatores que explicam, respectivamente, 35,52\%, e 6,02\% da variância total das respostas aos itens do instrumento. Somados explicam, portanto, $41,55 \%$ da variância total. A Tabela 20 apresenta a estrutura empírica da escala, as cargas fatoriais, as comunalidades $\left(\mathrm{h}^{2}\right)$ dos itens, as médias e desvios-padrão, os índices de consistência interna, os valores próprios e percentuais de variância explicada de cada fator.

Tabela 20 - Estrutura empírica da escala de Importância.

\begin{tabular}{|c|c|c|c|c|c|}
\hline \multirow{2}{*}{ Descrição dos itens } & \multicolumn{2}{|c|}{ Cargas fatoriais } & \multirow{2}{*}{$\mathrm{h}^{2}$} & \multirow{2}{*}{$X$} & \multirow{2}{*}{ DP } \\
\hline & 1 & 2 & & & \\
\hline $\begin{array}{l}\text { 1.Formular projetos de pesquisa, } \\
\text { desenvolvimento e inovação de acordo com } \\
\text { os objetivos e desafios institucionais. }\end{array}$ & & & ,190 & 4,81 & ,496 \\
\hline $\begin{array}{l}\text { 2. Descrever no projeto detalhes sobre } \\
\text { investimentos (tais com produtos e serviços) } \\
\text { necessários à execução. }\end{array}$ & &, 572 & ,312 & 4,19 & ,954 \\
\hline $\begin{array}{l}\text { 3. Preparar os resultados do projeto para a sua } \\
\text { efetiva transferência ao público-alvo }\end{array}$ & & ,408 & ,313 & 4,67 & ,653 \\
\hline $\begin{array}{l}\text { 4. Defender a importância do projeto às partes } \\
\text { envolvidas ("stakeholders"). }\end{array}$ & & ,306 & ,310 & 4,56 & ,615 \\
\hline $\begin{array}{l}\text { 5.Promover reuniões periódicas para } \\
\text { acompanhamento das atividades do projeto. }\end{array}$ & ,334 & & ,281 & 4,31 &, 814 \\
\hline $\begin{array}{l}\text { 6. Associar as atividades previstas no projeto a } \\
\text { processos de trabalho desenvolvidos por } \\
\text { unidades da Empresa. }\end{array}$ & & ,682 & ,492 & 3,93 & ,999 \\
\hline $\begin{array}{l}\text { 7. Propor soluções às situações de risco que } \\
\text { possam dificultar a entrega de resultados do } \\
\text { projeto. }\end{array}$ & ,404 & ,307 & ,429 & 4,38 &, 753 \\
\hline $\begin{array}{l}\text { 8. Planejar as atividades que compõem os } \\
\text { planos de ação de acordo com os recursos } \\
\text { previstos para o Projeto. }\end{array}$ & & ,351 & ,299 & 4,59 & ,683 \\
\hline $\begin{array}{l}\text { 9. Compartilhar informações relevantes ao } \\
\text { projeto com sua equipe de trabalho. }\end{array}$ & ,587 & &, 334 & 4,66 &, 553 \\
\hline 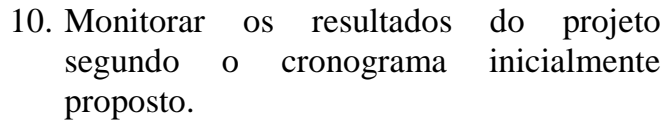 & & ,379 & ,400 & 4,45 & ,692 \\
\hline $\begin{array}{l}\text { 11. Explicar com clareza à equipe suas } \\
\text { propostas sobre o projeto. }\end{array}$ & ,657 & & ,398 & 4,64 & ,623 \\
\hline $\begin{array}{l}\text { 12. Utilizar ferramentas de gestão de projetos } \\
\text { disponíveis na Empresa. }\end{array}$ & &, 847 & ,515 & 3,69 & 1,164 \\
\hline
\end{tabular}


Tabela 20 - Estrutura empírica da escala de Importância (cont.).

\begin{tabular}{|c|c|c|c|c|c|}
\hline \multirow{2}{*}{ Descrição dos itens } & \multicolumn{2}{|c|}{ Cargas fatoriais } & \multirow{2}{*}{$h^{2}$} & \multirow{2}{*}{$X$} & \multirow{2}{*}{$\mathrm{DP}$} \\
\hline & 1 & 2 & & & \\
\hline $\begin{array}{l}\text { 13. Elaborar relatórios de resultados do } \\
\text { projeto com precisão, em conformidade } \\
\text { aos prazos estabelecidos pela Empresa. }\end{array}$ & & ,674 & ,441 & 4,24 & ,915 \\
\hline $\begin{array}{l}\text { 14. Promover a captação de recursos externos } \\
\text { por meio de participação efetiva em } \\
\text { editais competitivos. }\end{array}$ & ,501 & &, 225 & 4,43 & ,822 \\
\hline $\begin{array}{l}\text { 15. Orientar a composição de equipes de } \\
\text { trabalho por meio de parcerias internas e } \\
\text { externas com profissionais de reconhecida } \\
\text { competência na área de atuação do } \\
\text { projeto. }\end{array}$ & 673 & & ,426 & 4,52 & ,689 \\
\hline $\begin{array}{l}\text { 16. Identificar os principais resultados obtidos } \\
\text { pelo projeto a serem entregues à } \\
\text { sociedade. }\end{array}$ & ,582 & & ,462 & 4,74 &, 513 \\
\hline $\begin{array}{l}\text { 17. Organizar os planos de ação na } \\
\text { composição de um projeto, considerando a } \\
\text { interdependência entre eles. }\end{array}$ & &, 555 & ,346 & 4,27 &, 867 \\
\hline $\begin{array}{l}\text { 18. Solucionar problemas no andamento do } \\
\text { projeto em colaboração com a equipe. }\end{array}$ & ,656 & &, 378 & 4,57 &, 593 \\
\hline $\begin{array}{l}\text { 19. Analisar situações de risco/ameaças } \\
\text { internas e externas ao projeto de forma } \\
\text { antecipada. }\end{array}$ &, 500 & &, 427 & 4,32 &, 761 \\
\hline $\begin{array}{l}\text { 20. Estimular os colegas de equipe do projeto } \\
\text { a darem sugestões sobre o trabalho } \\
\text { desenvolvido. }\end{array}$ &, 586 & &, 381 & 4,40 &, 700 \\
\hline $\begin{array}{l}\text { 21. Organizar projetos em rede, considerando } \\
\text { a natureza multidisciplinar de seus } \\
\text { componentes. }\end{array}$ & & ,478 &, 346 & 4,26 & ,900 \\
\hline $\begin{array}{l}\text { 22. Divulgar os resultados do projeto e seus } \\
\text { impactos para públicos diversos (Empresa } \\
\text { e sociedade). }\end{array}$ & ,488 & &, 372 & 4,67 & ,628 \\
\hline $\begin{array}{l}\text { 23. Correlacionar as atividades a serem } \\
\text { desenvolvidas no projeto a resultados } \\
\text { negociados em parcerias externas. }\end{array}$ & &, 515 & ,459 & 4,04 & ,949 \\
\hline $\begin{array}{l}\text { 24. Executar recursos do projeto segundo o } \\
\text { orçamento proposto. }\end{array}$ & & ,462 & ,294 & 4,50 &, 750 \\
\hline $\begin{array}{l}\text { 25. Utilizar novas técnicas de comunicação } \\
\text { com a equipe, como web conferencias, } \\
\text { redes sociais. }\end{array}$ & ,319 & &, 341 & 4,17 & ,899 \\
\hline $\mathrm{N}$ & 322 & 322 & & & \\
\hline Eigenvalue (valor próprio) & 8,81 & 1,50 & & & \\
\hline \% da variância explicada & 35,52 & 6,02 & & & \\
\hline $\mathrm{N}^{\mathrm{o}}$ de itens & 12 & 12 & & & \\
\hline Alfa $(\alpha)$ & 0,864 & 0,868 & & & \\
\hline
\end{tabular}

Fonte: Elaborada pela autora a partir da análise dos dados.

A escala de Importância do instrumento CompLP é formada por 2 fatores que foram chamados de: Fator 1 "Capacidade de iniciativa e comunicação" e Fator 2 "Orientação para 
gestão de processos e projetos". O item 1 "Formular projetos de pesquisa, desenvolvimento e inovação de acordo com os objetivos e desafios institucionais" não permaneceu na estrutura por não possuir carga fatorial.

O Fator 1, "Capacidade de iniciativa e comunicação" apresenta um total de 12 itens e possui um bom índice de consistência interna $(\alpha=0,864)$, com cargas fatoriais variando entre 0,319 e 0,673 . Os itens pertencentes a esse fator tratam de questões relativas a comunicação e motivação da equipe, solução de problemas, compartilhamento de informações, e ações que envolvem iniciativa do líder de projeto em situações de desempenho.

O Fator 2, "Orientação para gestão de processos e projetos" apresenta um total de 12 itens e possui índice de consistência interna $(\alpha=0,868)$, com cargas fatoriais variando entre 0,306 e 0,847 . Os itens pertencentes a esse fator descrevem questões relativas à administração de atividades, processos e ferramentas afetas a estrutura que envolve a gestão técnica de projetos.

\section{Escala de Domínio}

Da mesma forma que foi procedida para a obtenção dos resultados com as análises realizadas com a escala de Importância, foram efetuadas análises exploratórias (linearidade, multicolinearidade, casos omissos, casos extremos e PC) para a escala de Domínio. Após realizar a análise paralela, obteve-se 2 fatores e realizou-se a PAF.

A escala de Domínio apresentou 322 casos válidos, sem presença de casos omissos. Dadas as recomendações de Tabachnick et al. (2007), quando o total de casos omissos não ultrapassa 5\% dos dados, não é preciso realizar nenhuma análise ou alteração dos dados. As respostas não apresentaram casos extremos univariados. Foram identificados 16 casos extremos multivariados. Optou-se por mantê-los por não afetar a AFE.

A matriz de covariância foi elaborada e analisada, o que possibilitou a verificação de que não houve relacionamentos lineares entre as variáveis (linearidade), nem a presença de singularidade e multicolinearidade. Em relação a fatorabilidade, o tamanho das correlações e a adequação da amostra foram analisados. Foram encontrados valores de correlação superiores a 0,30 em mais de 50\% dos casos, indicando que uma matriz provavelmente fatorável. O teste de KMO também foi realizado e obteve-se um valor de 0,919, considerado um bom índice de adequação da amostra. A extração inicial de fatores foi feita mediante 
análise dos componentes principais. Foi realizado o tratamento pairwise para os casos omissos.

A análise dos componentes principais sugeriu uma estrutura empírica com até cinco componentes, que explicam, em conjunto, 54\% da variância total das respostas dos participantes aos itens do questionário. Foi seguido o critério dos eigenvalues (valores próprios) dos fatores maiores ou iguais a 1 (um). Dessa maneira, chegou-se ao valor máximo de 5 fatores a serem extraídos. Ao realizar a análise do scree plot, foi verificada a existência de 1 a 2 fatores, como pode ser observado na Figura 9.

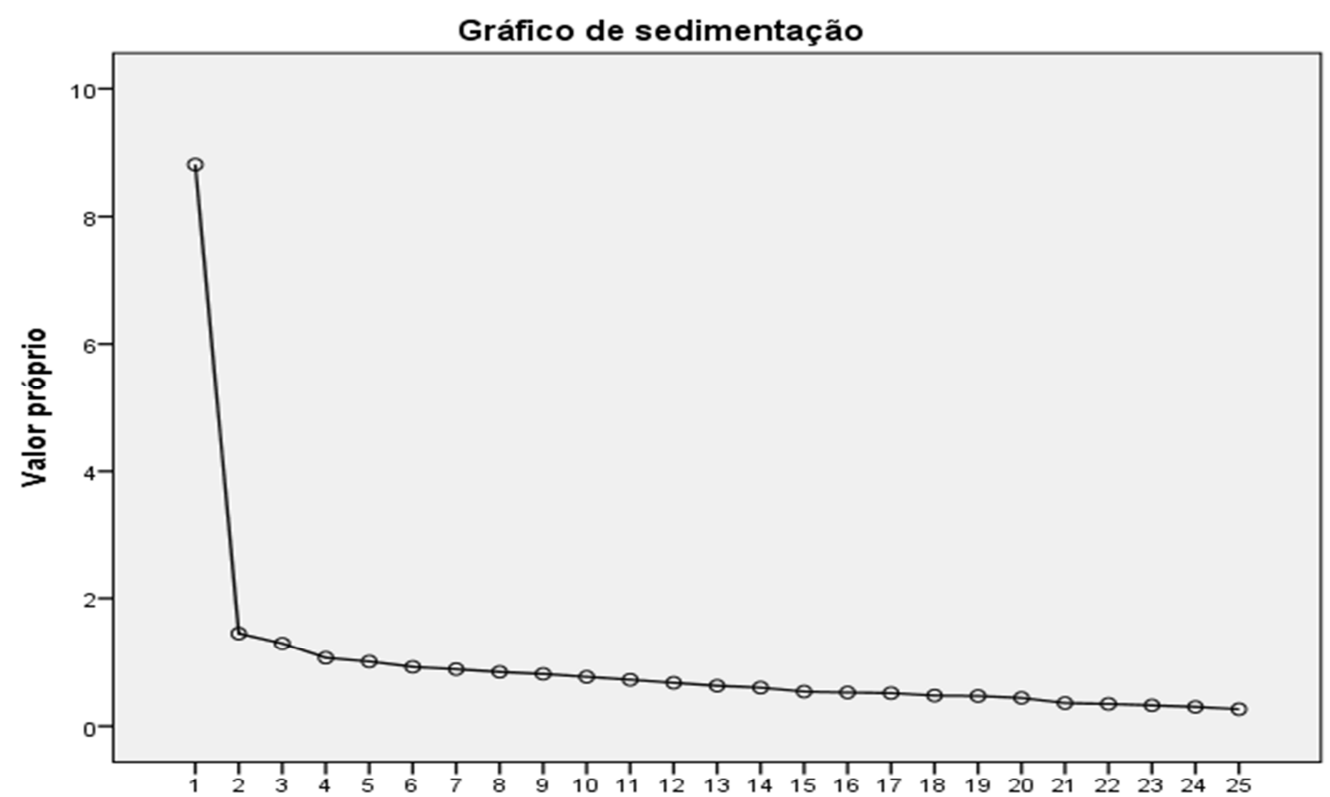

Figura 9: Distribuição dos valores próprios (scree plot) da escala de Domínio do CompLP.

A análise paralela de Horn, por sua vez, apontou 2 fatores para esta escala. Como demonstrado na Tabela 21, apenas os fatores com valores empíricos maiores ou iguais aos valores aleatórios são mantidos na estrutura.

Tabela 21. Valores próprios empíricos e aleatórios dos primeiros cinco componentes da escala de Domínio do CompLP.

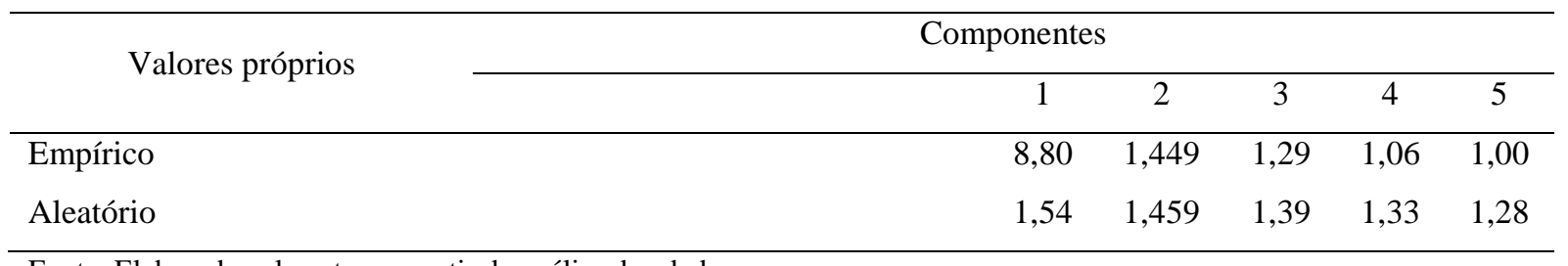

Fonte: Elaborada pela autora a partir da análise dos dados. 
A Tabela 22 demonstra que os dois primeiros fatores explicam maior variância do que os fatores correspondentes nos dados aleatórios. Sendo assim, a partir da análise paralela, foi possível confirmar uma estrutura com 2 fatores.

Para confirmar de maneira definitiva a estrutura fatorial do instrumento, foi realizada a PAF, com método de rotação oblíqua e tratamento pairwise para casos omissos. Todos os itens da escala possuem cargas fatoriais iguais ou superiores a 0,30. Tal análise permitiu a extração de 1 fator, que explica 35,22\% da variância total das respostas aos itens do instrumento. A Tabela 22 apresenta a estrutura empírica da escala, as cargas fatoriais, as comunalidades $\left(\mathrm{h}^{2}\right)$ dos itens, as médias e desvios-padrão, os índices de consistência interna, os valores próprios e percentuais de variância explicada do fator.

Tabela 22 - Estrutura empírica da escala de Domínio.

\begin{tabular}{|c|c|c|c|c|}
\hline \multirow{2}{*}{ Descrição dos itens } & Cargas fatoriais & \multirow{2}{*}{$\mathrm{h}^{2}$} & \multirow{2}{*}{$\mathrm{X}$} & \multirow{2}{*}{ DP } \\
\hline & 1 & & & \\
\hline $\begin{array}{l}\text { 1. Formular projetos de pesquisa, } \\
\text { desenvolvimento e inovação de acordo com } \\
\text { os objetivos e desafios institucionais. }\end{array}$ & ,485 & ,235 & 4,07 & ,756 \\
\hline $\begin{array}{l}\text { 2. Descrever no projeto detalhes sobre } \\
\text { investimentos (tais com produtos e serviços) } \\
\text { necessários à execução. }\end{array}$ & ,522 & ,272 & 3,88 & 815 \\
\hline $\begin{array}{l}\text { 3. Preparar os resultados do projeto para a sua } \\
\text { efetiva transferência ao público-alvo }\end{array}$ & ,578 & ,334 & 3,66 & ,884 \\
\hline $\begin{array}{l}\text { 4. Defender a importância do projeto às partes } \\
\text { envolvidas ("stakeholders"). }\end{array}$ & ,557, &, 311 & 3,85 & ,860 \\
\hline $\begin{array}{l}\text { 5. Promover reuniões periódicas para } \\
\text { acompanhamento das atividades do projeto. }\end{array}$ & ,477 & ,228 & 3,93 & 890 \\
\hline $\begin{array}{l}\text { 6. Associar as atividades previstas no projeto a } \\
\text { processos de trabalho desenvolvidos por } \\
\text { unidades da Empresa. }\end{array}$ & ,518 & ,268 & 3,45 & 903 \\
\hline $\begin{array}{l}\text { 7. Propor soluções às situações de risco que } \\
\text { possam dificultar a entrega de resultados do } \\
\text { projeto. }\end{array}$ & 625 & ,391 & 3,69 & 810 \\
\hline $\begin{array}{l}\text { 8. Planejar as atividades que compõem os } \\
\text { planos de ação de acordo com os recursos } \\
\text { previstos para o Projeto. }\end{array}$ & ,568 &, 322 & 4,13 & ,820 \\
\hline $\begin{array}{l}\text { 9. Compartilhar informações relevantes ao } \\
\text { projeto com sua equipe de trabalho. }\end{array}$ & ,576 &, 332 & 4,24 & 789, \\
\hline $\begin{array}{l}\text { 10. Monitorar os resultados } \text { do projeto } \\
\text { segundo o cronograma inicialmente } \\
\text { proposto. }\end{array}$ & 648, & ,419 & 3,87 & ,836 \\
\hline $\begin{array}{l}\text { 11. Explicar com clareza à equipe suas } \\
\text { propostas sobre o projeto. }\end{array}$ & ,594 &, 352 & 4,29 & ,719 \\
\hline $\begin{array}{l}\text { 12. Utilizar ferramentas de gestão de projetos } \\
\text { disponíveis na Empresa. }\end{array}$ & ,569 &, 324 & 3,12 & 1,036 \\
\hline
\end{tabular}


Tabela 22 - Estrutura empírica da escala de Domínio (cont.).

\begin{tabular}{|c|c|c|c|c|}
\hline \multirow{2}{*}{ Descrição dos itens } & Cargas fatoriais & \multirow{2}{*}{$h^{2}$} & \multirow{2}{*}{$X$} & \multirow{2}{*}{ DP } \\
\hline & 1 & & & \\
\hline $\begin{array}{l}\text { 13. Elaborar relatórios de resultados do } \\
\text { projeto com precisão, em conformidade } \\
\text { aos prazos estabelecidos pela Empresa. }\end{array}$ & ,596 & ,355 & 3,80 & ,920 \\
\hline $\begin{array}{l}\text { 14. Promover a captação de recursos externos } \\
\text { por meio de participação efetiva em } \\
\text { editais competitivos. }\end{array}$ & ,500 &, 250 & 3,58 & 1,068 \\
\hline $\begin{array}{l}\text { 15. Orientar a composição de equipes de } \\
\text { trabalho por meio de parcerias internas e } \\
\text { externas com profissionais de reconhecida } \\
\text { competência na área de atuação do } \\
\text { projeto. }\end{array}$ & ,626 & ,392 & 3,78 & ,930 \\
\hline $\begin{array}{l}\text { 16. Identificar os principais resultados obtidos } \\
\text { pelo projeto a serem entregues à } \\
\text { sociedade. }\end{array}$ & ,628 & ,394 & 4,04 & ,784 \\
\hline $\begin{array}{l}\text { 17. Organizar os planos de ação na } \\
\text { composição de um projeto, considerando a } \\
\text { interdependência entre eles. }\end{array}$ &, 562 & ,316 & 4,16 & ,781 \\
\hline $\begin{array}{l}\text { 18. Solucionar problemas no andamento do } \\
\text { projeto em colaboração com a equipe. }\end{array}$ &, 590 &, 348 & 3,97 & ,765 \\
\hline $\begin{array}{l}\text { 19. Analisar situações de risco/ameaças } \\
\text { internas e externas ao projeto de forma } \\
\text { antecipada. }\end{array}$ &, 644 & ,415 & 3,46 & ,879 \\
\hline $\begin{array}{l}\text { 20. Estimular os colegas de equipe do projeto } \\
\text { a darem sugestões sobre o trabalho } \\
\text { desenvolvido. }\end{array}$ & ,590 &, 348 & 3,85 & ,833 \\
\hline $\begin{array}{l}\text { 21. Organizar projetos em rede, considerando } \\
\text { a natureza multidisciplinar de seus } \\
\text { componentes. }\end{array}$ & ,522 & ,272 & 3,66 & ,971 \\
\hline $\begin{array}{l}\text { 22. Divulgar os resultados do projeto e seus } \\
\text { impactos para públicos diversos (Empresa } \\
\text { e sociedade). }\end{array}$ & ,565 & ,320 & 3,72 & ,902 \\
\hline $\begin{array}{l}\text { 23. Correlacionar as atividades a serem } \\
\text { desenvolvidas no projeto a resultados } \\
\text { negociados em parcerias externas. }\end{array}$ & ,643 & ,414 & 3,34 & ,999 \\
\hline $\begin{array}{l}\text { 24. Executar recursos do projeto segundo o } \\
\text { orçamento proposto. }\end{array}$ &, 538 & ,290 & 3,83 & 1,009 \\
\hline $\begin{array}{l}\text { 25. Utilizar novas técnicas de comunicação } \\
\text { com a equipe, como web conferencias, } \\
\text { redes sociais. }\end{array}$ & ,489 & ,239 & 3,52 & ,993 \\
\hline $\mathrm{N}$ & 322 & & & \\
\hline Eigenvalue (valor próprio) & 8,80 & & & \\
\hline \% da variância explicada & 35,22 & & & \\
\hline $\mathrm{N}^{\mathrm{o}}$ de itens & 25 & & & \\
\hline $\operatorname{Alfa}(\alpha)$ & 0,92 & & & \\
\hline
\end{tabular}

Fonte: Elaborada pela autora a partir da análise dos dados. 
A escala de Domínio do instrumento CompLP é formada por 1 fator, denominado "Gestão de projetos". A estrutura unifatorial apresenta um total de 25 itens e possui um bom índice de consistência interna $(\alpha=0,92)$, com cargas fatoriais variando entre ,485 e ,648.

\subsection{Cálculos dos índices de prioridades de treinamento}

Os índices de prioridade geral (IPG) de treinamento foram calculados para atender a um dos objetivos da pesquisa, de verificar as lacunas de competências dos líderes de projetos da Embrapa.

O modelo adotado nesta pesquisa é o de Análise do Papel Ocupacional desenvolvido por Borges-Andrade et al. (1983). O método propõe que os valores para as escalas de importância e domínio do instrumento de ANT formem um Índice de Prioridade Geral (IPG) de cada competência, de modo que os CHAs com valores de importância elevada e domínio baixo, são indicados a treinamento.

O índice de prioridade geral de treinamento (IPG) utilizado nesta pesquisa é o resultado da relação entre as escadas de importância e domínio das competências que integram o questionário CompLP, considerando a utilização de uma escala de julgamento de 1 a 5 , e valores de desvio-padrão superiores a $(\mathrm{DP}=1,15)$ - para excessiva divergência de opinião. Na segunda etapa do processo, uma matriz de combinação de resultados de importância e domínio foi gerada, podendo somar de 1 a 25 pontos, sugerindo-se um valor mínimo de prioridade para necessidade de treinamento de 13,8.

A Tabela 23 apresenta os resultados da análise realizada, utilizando para tanto toda a amostra de 322 respondentes.

Tabela 23 - Índice de prioridade geral de treinamento (IPG).

\begin{tabular}{|c|c|c|c|c|c|c|}
\hline Itens & $\begin{array}{c}\text { Média } \\
\text { de } \\
\text { Importância }\end{array}$ & DP & $\begin{array}{l}\text { Média } \\
\text { de } \\
\text { Domínio }\end{array}$ & DP & $\begin{array}{l}\text { IPG } \\
\text { geral }\end{array}$ & DP \\
\hline $\begin{array}{l}\text { 19. Analisar situações de risco/ameaças } \\
\text { internas e externas ao projeto de forma } \\
\text { antecipada }\end{array}$ & 4,32 & 0,761 & 3,66 & 0,884 & 10,86 & 4,116 \\
\hline $\begin{array}{l}\text { 3. Preparar os resultados do projeto para a } \\
\text { sua efetiva transferência ao público-alvo }\end{array}$ & 4,67 & 0,653 & 4,16 & 0,781 & 10,83 & 4,199 \\
\hline $\begin{array}{l}\text { 14. Promover a captação de recursos } \\
\text { externos por meio de participação efetiva } \\
\text { em editais competitivos. }\end{array}$ & 4,43 & 0,822 & 3,80 & 0,920 & 10,62 & 5,019 \\
\hline
\end{tabular}


Tabela 23 - Índice de prioridade geral de treinamento (IPG) (cont.).

\begin{tabular}{|c|c|c|c|c|c|c|}
\hline Itens & $\begin{array}{c}\text { Média } \\
\text { de } \\
\text { Importância }\end{array}$ & DP & $\begin{array}{l}\text { Média } \\
\text { de } \\
\text { Domínio }\end{array}$ & DP & $\begin{array}{l}\text { IPG } \\
\text { geral }\end{array}$ & DP \\
\hline $\begin{array}{l}\text { 22. Divulgar os resultados do projeto e } \\
\text { seus impactos para públicos diversos } \\
\text { (Empresa e sociedade). }\end{array}$ & 4,67 & 0,628 & 3,46 & 0,879 & 10,55 & 4,291 \\
\hline $\begin{array}{l}\text { 23. Correlacionar as atividades a serem } \\
\text { desenvolvidas no projeto a resultados } \\
\text { negociados em parcerias externas. }\end{array}$ & 4,04 & 0,949 & 3,45 & 0,903 & 10,41 & 4,124 \\
\hline $\begin{array}{l}\text { 12. Utilizar ferramentas de gestão de } \\
\text { projetos disponíveis na Empresa. }\end{array}$ & 3,69 & 1,164 & 3,85 & 0,860 & 10,28 & 4,483 \\
\hline $\begin{array}{l}\text { 25. Utilizar novas técnicas de comunicação } \\
\text { com a equipe, como web conferências, } \\
\text { redes sociais. }\end{array}$ & 4,17 & 0,899 & 3,12 & 1,036 & 10,13 & 4,416 \\
\hline $\begin{array}{l}\text { 7. Propor soluções às situações de risco } \\
\text { que possam dificultar a entrega de } \\
\text { resultados do projeto. }\end{array}$ & 4,38 & 0,753 & 3,97 & 0,765 & 10,03 & 3,913 \\
\hline
\end{tabular}

Os índices de prioridade geral (IPG) de treinamento apresentaram valores baixos (menores que 13,8) para as 25 competências que integram o instrumento. Desta forma, a amostra de respondentes não apresentou necessidades de treinamento de ordem superior. Todos os índices de desvio-padrão demonstram uma elevada de divergência de opinião entre os respondentes, em relação a todas as competências.

A Tabela 23 apresenta resultados das oito competências com os maiores valores de IPG geral, obtidos na faixa de 10,3 a 10,86, considerando o corte de IPG=10,3. Esse recorte ilustra o comportamento desses resultados obtidos sobre as 25 competências do questionário, todos abaixo do índice 13,8, com variação de 7,62 a 10,86 - como pode ser observado no gráfico da Figura 10.

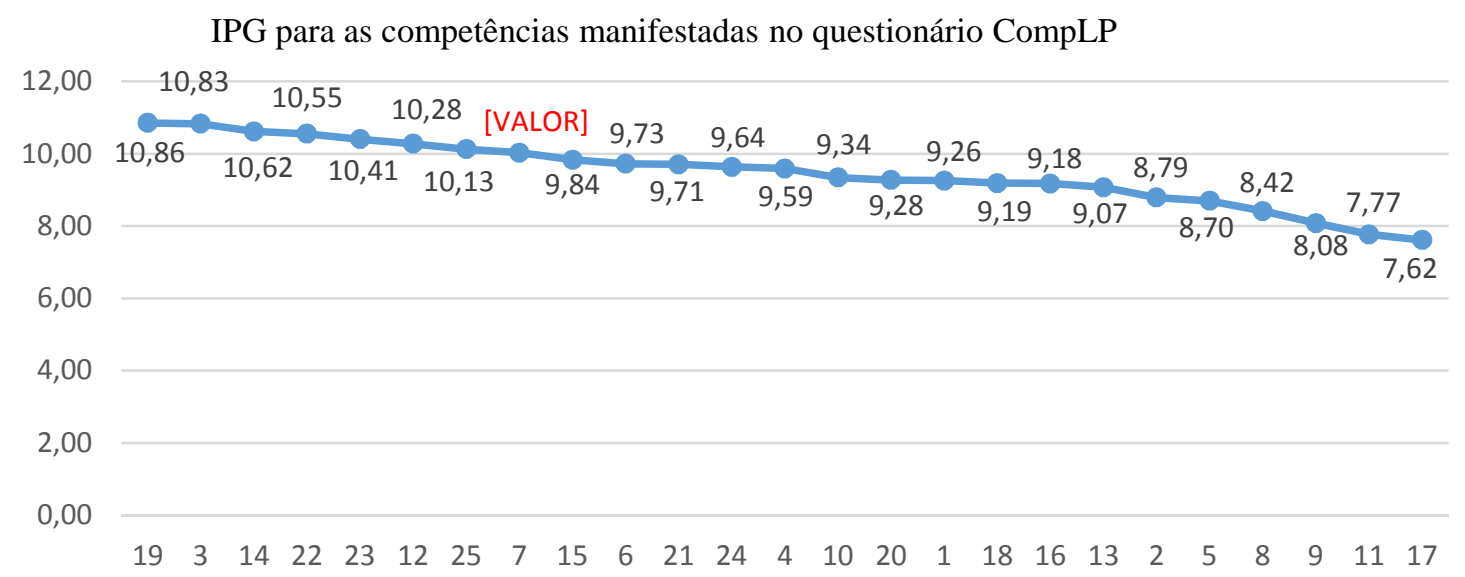

Figura 10 - Gráfico do IPG das competências do questionário CompLP. 
Na seção seguinte serão apresentados os resultados das análises de regressão com o objetivo de compreender as relações de predição entre as variáveis de interesse do modelo desta pesquisa.

\subsection{Análises de regressão}

As análises de regressão múltipla padrão foram realizadas para cumprir o objetivo de testagem do modelo proposto. As variáveis do modelo foram submetidas a análises exploratórias, segundo procedimentos de Tabachnick et al. (2007).

Foram estabelecidos modelos de explicação para as prioridades de treinamento nas oito competências com IPG de maior valor, de acordo com Tabela 24, em função das seguintes variáveis antecedentes: sexo; idade; titulação; cargo; tempo de trabalho (desde o início da atuação profissional); tempo de Empresa; área de atuação na Empresa; tempo de experiência como líder de projeto (desde o início da atuação profissional) e tempo de experiência como líder de projeto na Empresa. Desta forma, foi realizada a testagem do modelo.

Tabela 24 - Necessidades de treinamento identificadas.

Competências - prioridades de treinamento

19. Analisar situações de risco/ameaças internas e externas ao projeto de forma antecipada

3. Preparar os resultados do projeto para a sua efetiva transferência ao público-alvo

14. Promover a captação de recursos externos por meio de participação efetiva em editais competitivos.

22. Divulgar os resultados do projeto e seus impactos para públicos diversos (Empresa e sociedade).

23. Correlacionar as atividades a serem desenvolvidas no projeto a resultados negociados em parcerias externas.

12. Utilizar ferramentas de gestão de projetos disponíveis na Empresa.

25. Utilizar novas técnicas de comunicação com a equipe, como web conferencias, redes sociais.

7. Propor soluções às situações de risco que possam dificultar a entrega de resultados do projeto.

Fonte: Elaborada pela autora a partir da análise dos dados.

Os coeficientes de regressão não padronizados (B), os coeficientes de regressão padronizados $(\beta)$, a contribuição individual de cada variável $(\mathrm{Sr} 2)$, as médias das variáveis (X), os desvio-padrão (DP), a constante, o R2 (correlação entre todas as variáveis antecedentes com a variável critério - variância individual e compartilhada das variáveis antecedentes em relação à variável critério), o R2 ajustado (estimativa do R2 da população) e o R (correlação entre a variável critério e as variáveis antecedentes) estão apresentados na Tabela 25. 
Tabela 25. Regressão múltipla padrão para o modelo de investigação proposto.

\begin{tabular}{|c|c|c|c|c|c|c|c|c|c|c|}
\hline Variável & $\begin{array}{l}\text { Neces. } \\
\text { trein } \\
\text { (VD) }\end{array}$ & Sexo & Idade & Titul. & Cargo & $\begin{array}{l}\text { Temp } \\
\text { emp }\end{array}$ & $\begin{array}{l}\text { Temp } \\
\text { trab. }\end{array}$ & $\begin{array}{c}\text { Eixo } \\
\text { atuação }\end{array}$ & $\begin{array}{l}\text { Temp.líd. } \\
\text { pro.emp }\end{array}$ & $\begin{array}{l}\text { Temp. } \\
\text { líd.pro }\end{array}$ \\
\hline Sexo & $-0,028$ & & & & & & & & & \\
\hline Idade & $-0,126$ & $-0,007$ & & & & & & & & \\
\hline Titul. & $-0,044$ & $-0,071$ & $-0,044$ & & & & & & & \\
\hline Cargo & 0,076 & 0,038 & $-0,18$ & $-0,404$ & & & & & & \\
\hline Temp emp. & $-0,148$ & 0,060 & $0,816^{*}$ & $-0,065$ & $-0,051$ & & & & & \\
\hline Temp trab. & $-0,162$ & 0,034 & $0,843^{*}$ & $-0,160$ & 0,026 & $0,790^{*}$ & & & & \\
\hline Eixo atuação & 0,053 & $0,154^{*}$ & 0,029 & $-0,243$ & $0,545^{*}$ & 0,025 & 0,050 & & & \\
\hline Temp.líd.pro.emp & $-0,198$ & 0,046 & $0,635^{*}$ & $0,151^{*}$ & $0,225^{*}$ & $0,700^{*}$ & $0,575^{*}$ & $-0,137$ & & \\
\hline Temp.líd.pro & $-0,212$ & 0,082 & $0,610^{*}$ & $0,140^{*}$ & $0,255^{*}$ & $0,546^{*}$ & $0,607^{*}$ & $-0,162$ & $0,128^{*}$ & \\
\hline B & & 0,054 & $0,354^{*}$ & $-0,097$ & $0,823^{*}$ & $-0,061$ & $-0,297$ & $-1,096$ & $-0,137$ & $-0,280$ \\
\hline$\beta$ & & 0,012 & $\mathbf{0 , 1 5 1}$ & $-0,025$ & 0,100 & 0,027 & $-0,141$ & $-0,145$ & $-0,069$ & $-0,144$ \\
\hline $\mathrm{Sr} 2$ & & 0,011 & $\mathbf{0 , 0 7 0}$ & $-0,022$ & $\mathbf{0 , 0 7 8}$ & $-0,012$ & $-0,065$ & $-0,119$ & $-0,031$ & $-0,069$ \\
\hline $\mathrm{X}$ & 9,47 & 1,61 & 2,21 & $-3,12$ & 1,08 & 1,91 & 2,43 & 2,05 & 2,07 & 2,46 \\
\hline DP & 2,27 & 0,489 & 0,969 & 0,591 & 0,278 & 1,015 & 1,076 & 3,02 & 1,135 & 1,169 \\
\hline Constante $=12,076$ & \multicolumn{4}{|c|}{$\mathrm{R} 2=0,068$} & \multicolumn{2}{|c|}{$\mathrm{R}=0,261^{*}$} & & & & \\
\hline $\mathrm{p}<0,05 \mathrm{e}^{* *} \mathrm{p}<0,01$ & & & & & & & & & & \\
\hline
\end{tabular}

$\mathrm{O}$ coeficiente da regressão múltipla $\mathrm{R}$ foi diferente de zero, $\mathrm{F}(2,486)=0,261<0,001$, com limites de confiança de 95\%. A ANT foi explicada de forma geral pelo eixo de atuação da empresa $(\beta=-0,14)$, e as variáveis que contribuíram significativamente para a explicação da necessidade de capacitação foram idade $(\beta=0,15)$, cargo $(\beta=0,10)$, tempo de trabalho $(\beta=0,14)$, e tempo de experiência como líder de projeto $(\beta=0,14)$. Agrupadas, as 9 variáveis iniciais explicam 6,8\% (4\% ajustado) das necessidades de treinamento, enquanto as cinco variáveis que contribuem significativamente com a explicação da variável-critério explicam, somadas suas contribuições individuais $(\beta)$, cerca de $7 \%$ das necessidades de treinamento identificadas para os líderes de projeto da Embrapa. Na Figura 11 é possível visualizar o modelo de predição. 


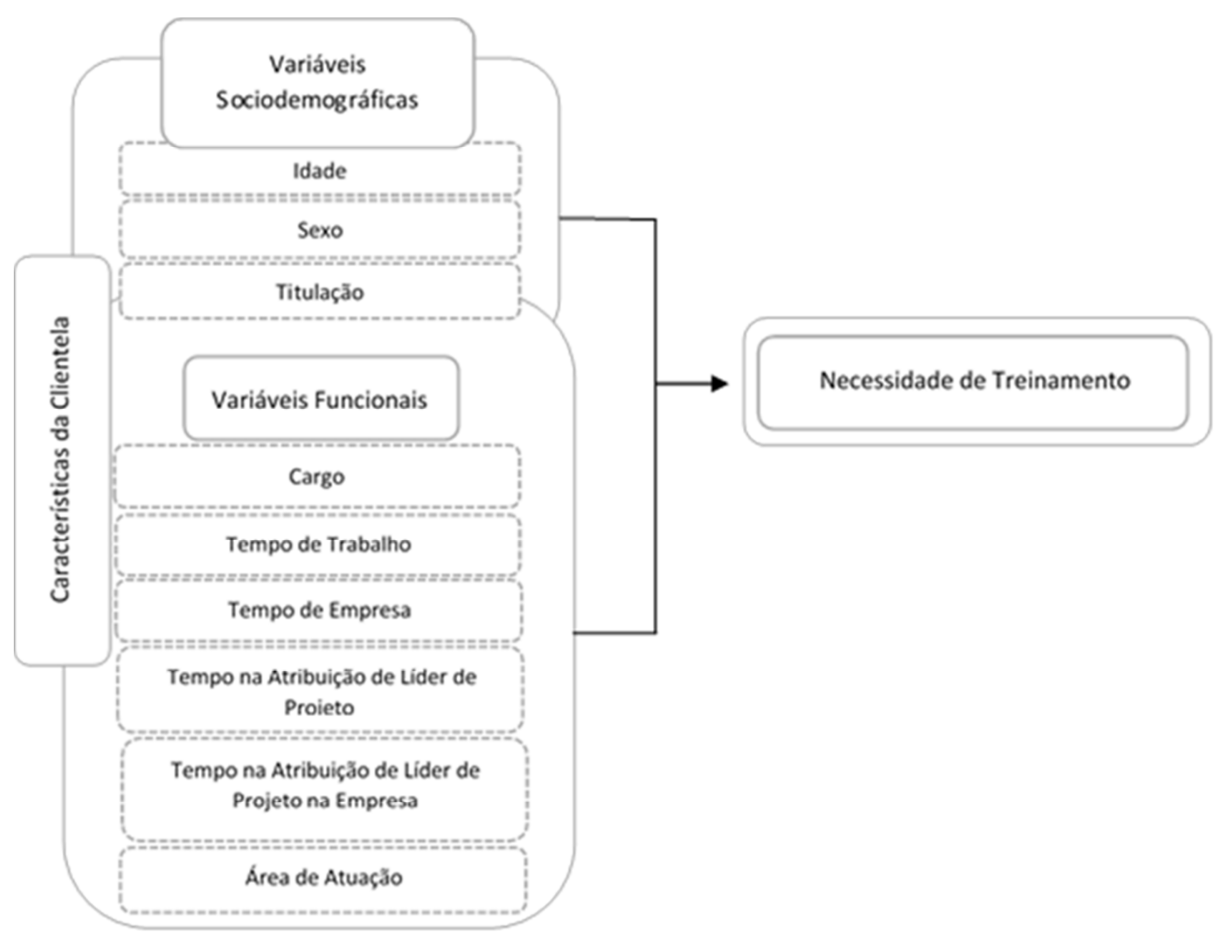

Figura 11 - Modelo de Predição proposto.

A Figura 12 demonstra os relacionamentos entre as variáveis que indicaram maior poder preditivo.

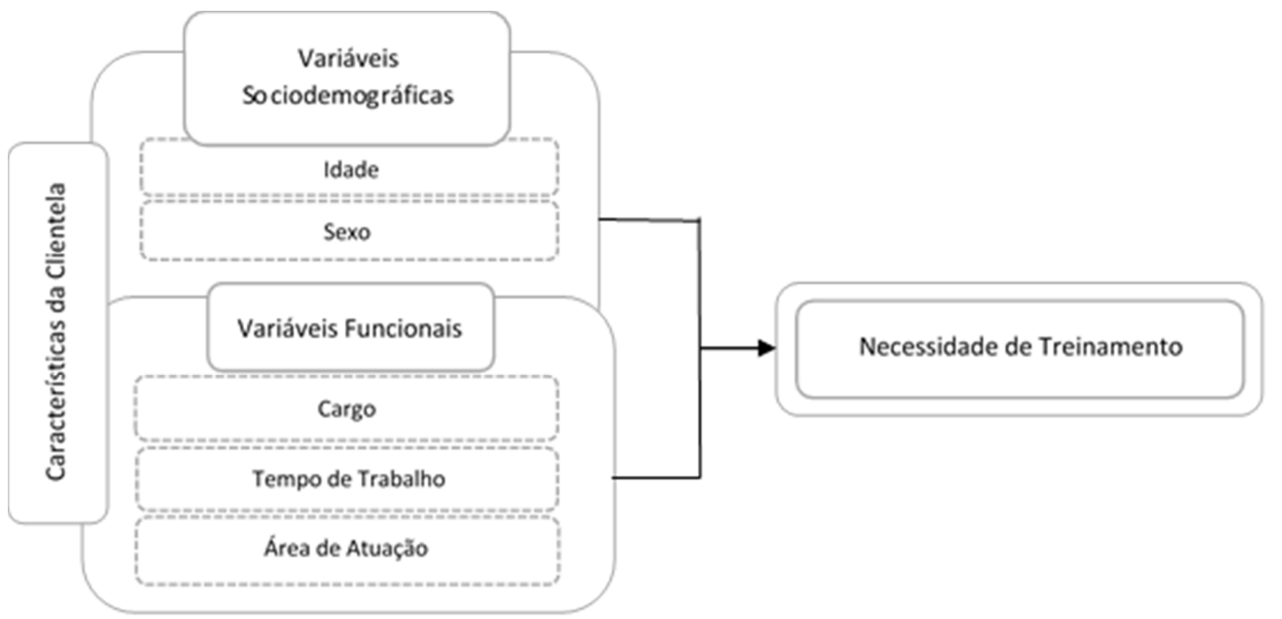

Figura 12 - Relacionamento entre as variáveis do Modelo que apresentaram maior poder preditivo.

Em uma análise detalhada dos modelos de explicação, verificou-se a influência das variáveis antecedentes sobre a necessidade de capacitação em cada uma das competências, observando-se que: a necessidade de treinamento em analisar situações de risco/ameaças internas e externas ao projeto de forma antecipada, é explicada pelo cargo $(\beta=0,16)$ e área de atuação $(\beta=0,13)$; a lacuna de competência em promover a captação de recursos externos por 
meio de participação efetiva em editais competitivos, sofre influência da idade $(\beta=0,22)$ e do eixo de atuação $(\beta=0,12)$; a necessidade de capacitação para divulgação dos resultados do projeto e seus impactos para públicos diversos (Empresa e sociedade) é explicada pelo tempo de trabalho $(\beta=0,29)$; a variável sexo $(\beta=-0,10)$ prediz a necessidade de capacitação em correlacionar as atividades a serem desenvolvidas no projeto a resultados negociados em parcerias externas; a necessidade de capacitação em utilizar ferramentas de gestão de projetos disponíveis na Empresa também é explicada pela variável sexo $(\beta=0,14)$; e, por último, idade $(\beta=0,23)$ e eixo de atuação $(\beta=-0,17)$ explicam a necessidade de capacitação em propor soluções às situações de risco que possam dificultar a entrega de resultados do projeto. 


\section{CAPÍTULO 6 - DISCUSSÃO}

\section{Objetivo do capítulo}

Este capítulo tem como objetivo discutir os principais resultados da pesquisa, de forma a associá-los aos objetivos propostos, e aos resultados obtidos em pesquisas descritas na revisão da literatura. Serão discutidos os resultados das análises descritivas e IPG, da análise fatorial, do modelo, além das implicações teóricas, empíricas e metodológicas e as implicações práticas da pesquisa.

Ao passo que foram traçados os seguintes objetivos de pesquisa:

1. Construir o instrumento de Competências de Líderes de Projeto (CompLP).

2. Verificar evidências de validade do instrumento CompLP.

3. Identificar as lacunas de competências dos líderes de projeto da Embrapa.

4. Analisar o perfil da clientela de líderes de projeto da Embrapa.

5. Identificar as variáveis que influenciam a aquisição de CHAs.

Com o intuito maior de propor e testar um modelo de identificação de lacunas de competências de líderes de projeto, objetivando identificar suas variáveis preditoras relacionadas às características da clientela (características sociodemográficas e funcionais) no contexto de instituições de PD\&I; entende-se que foram atingidos os resultados dos objetivos propostos, na medida em que:

1. O questionário foi construído para avaliar a necessidade de capacitação de líderes de projeto em contexto de pesquisa, desenvolvimento e inovação, conforme critérios psicométricos recomendados e a partir da identificação das competências características do papel ocupacional do líder de projeto (insumo de entrevistas com um grupo de especialistas), obtendo-se um questionário com 25 itens;

2. Verificados todos os critérios de validade, o instrumento foi validado por conteúdo (validade semântica e por juízes) e por critérios estatísticos, obtendo-se bons índices de confiabilidade e consistência interna, tanto na escala de importância quanto na de domínio;

3. Foram identificadas as lacunas de competências para a clientela-alvo, no entanto os índices de prioridade geral (IPG) de treinamento apresentaram valores baixos 
(menores que 13,8) para as 25 competências que integram o instrumento. Desta forma, de acordo com a autopercepção da amostra, não há necessidades de treinamento de ordem superior, apresentando, no entanto, elevada divergência de opinião entre os respondentes.

4. O perfil de líderes de projeto da Embrapa foi analisado, por meio da coleta de dados das entrevistas e identificação das competências inerentes ao papel ocupacional.

5. Após identificação das características da clientela estudada foi realizada a análise da influência dessas características na potencial necessidade de capacitação nas competências de líderes de projeto por meio da análise de regressão, concluindo-se que a ANT foi explicada de forma geral pela área de atuação da empresa, e as variáveis que contribuíram de forma significativa para a lacuna de competência foram idade, cargo, tempo de trabalho, e tempo de experiência como líder de projeto.

\subsection{Discussões dos resultados das análises descritivas e resultados da IPG}

Os resultados das estatísticas descritivas das escalas de Importância e Domínio indicam que a maioria dos respondentes perceberam as competências descritas nos itens do instrumento como importantes para sua atividade e atribuição de líder de projeto, assim como julgaram ter um grau de domínio elevado nas competências.

$\mathrm{Na}$ escala de importância as competências "Formular projetos de pesquisa, desenvolvimento e inovação de acordo com os objetivos e desafios institucionais" e "Identificar os principais resultados obtidos pelo projeto a serem entregues à sociedade" apresentaram igual índice acumulado de 97,2\% de concentração de respostas nos pontos mais altos da escala 4-5, em uma escala de 1 a 5 . O item que apresentou menor índice de concentração de respostas no ponto alto da escala foi o item "Utilizar ferramentas de gestão de projetos disponíveis na Empresa", com 59,9\% de respostas obtidas no par de pontos 4-5 da escala.

No que se refere à escala de domínio, as competências "Organizar os planos de ação na composição de um projeto, considerando a interdependência entre eles"; "Compartilhar informações relevantes ao projeto com sua equipe de trabalho"; "Planejar as atividades que compõem os planos de ação de acordo com os recursos previstos para o Projeto" e "Formular projetos de pesquisa, desenvolvimento e inovação de acordo com os objetivos e desafios 
institucionais" foram percebidas pela maioria dos líderes de projeto com domínio superior na escala; enquanto as competências "Utilizar ferramentas de gestão de projetos disponíveis na Empresa" "Correlacionar as atividades a serem desenvolvidas no projeto a resultados negociados em parcerias externas" "Associar as atividades previstas no projeto a processos de trabalho desenvolvidos por unidades da Empresa" e "Analisar situações de risco/ameaças internas e externas ao projeto de forma antecipada" foram associadas a domínios menores de capacidade por parte da maioria dos respondentes.

Com relação aos IPG obtidos, a partir do cálculo de Prioridade geral $(\mathrm{Pg})$ proposto pela metodologia de Borges-Andrade et al. (1983) - corte de 30\% (valor de IPG=10,3), não houve prioridade de treinamento de ordem superior pois, observando os resultados, ocorreu pouca diferenciação na resposta dos participantes entre as escalas de importância e domínio, gerando valores baixos do índice de prioridade de treinamento. Desta forma, foram identificadas oito competências com os maiores valores de IPG geral obtidos, na faixa de 10,3 a 10,86: "Analisar situações de risco/ameaças internas e externas ao projeto de forma antecipada"; "Preparar os resultados do projeto para a sua efetiva transferência ao públicoalvo"; "Promover a captação de recursos externos por meio de participação efetiva em editais competitivos"; "Divulgar os resultados do projeto e seus impactos para públicos diversos (Empresa e sociedade)"; "Correlacionar as atividades a serem desenvolvidas no projeto a resultados negociados em parcerias externas"; "Utilizar ferramentas de gestão de projetos disponíveis na Empresa"; "Utilizar novas técnicas de comunicação com a equipe, como web conferencias, redes sociais" e "Propor soluções às situações de risco que possam dificultar a entrega de resultados do projeto".

Cabe evidenciar que foram utilizados valores médios neste estudo, tendo em vista seu objetivo de discutir necessidades transversais de treinamento. Além de buscar contribuir para o planejamento de ações de treinamento que elevem o desempenho da instituição, promover o alinhamento de atuação ao direcionamento de negócio consiste de fato no elemento que eleva o processo de ANT ao patamar estratégico para o então desenvolvimento humano no cenário organizacional (Meneses et. al., 2010). No entanto, mesmo que estes tenham sido os valores encontrados para as médias dos itens, em virtude da dispersão acentuada dos dados, pode-se inferir que há casos da amostra os quais possuem necessidades individuais de treinamento em competências específicas para sua atuação profissional. 
Os resultados das análises descritivas e o IPG indicam a autopercepção de domínio elevado das competências dos líderes de projeto, o que pode indicar uma falta de compreensão por parte dos respondentes do real domínio dessas competências para o seu desempenho no trabalho, uma inadequação das escalas ou efeitos de desejabilidade social com uma tendência de avaliação mais positiva por parte dos respondentes. Esses resultados corroboram resultados de estudos anteriores obtidos por Araújo (2013) e Ferreira et al. (2014).

\subsection{Discussões dos resultados das análises fatoriais exploratórias}

As análises fatoriais exploratórias realizadas com as escalas de Importância e Domínio do Instrumento CompLP deste estudo permitiram estabelecer uma correlação entre as variáveis que integravam o constructo das competências da atribuição do líder de projetos. Considerando a escala de Importância, obteve-se 2 fatores - Fator 1 "Capacidade de iniciativa e comunicação" e Fator 2 "Orientação para gestão de processos e projetos". O Fator 1, "Capacidade de iniciativa e comunicação" abarcou 12 itens, com bom índice de consistência interna $(\alpha=0,864)$, e cargas fatoriais com índices de 0,319 a 0,673 . Os itens que integram o fator tratam de questões relativas à comunicação e motivação da equipe, solução de problemas, compartilhamento de informações, e ações que envolvem iniciativa do líder de projeto em situações de desempenho. E o Fator 2, "Orientação para gestão de processos e projetos" apresentou 12 itens, e $\alpha=0,868$ - boa consistência interna, com cargas fatoriais variando entre 0,306 e 0,847 . Os itens pertencentes a esse fator reúnem temas relativos a administração de atividades, processos e ferramentas associados a estrutura que envolve a gestão técnica de projetos. O item 1 "Formular projetos de pesquisa, desenvolvimento e inovação de acordo com os objetivos e desafios institucionais" não permaneceu na estrutura por não possuir carga fatorial. Supõe-se que este fenômeno se deve ao fato de os respondentes analisarem a competência como intrínseca à atividade e desconsiderarem sua relevância no contexto.

Para a escala de Domínio, as análises resultaram em uma estrutura unifatorial, denominada "Gestão de projetos”, composta por 25 itens, envolvendo, desta forma, uma única dimensão do construto de interesse e é, portanto, unidimensional. Apresenta índice de consistência interna $(\alpha=0,92)$, indicando, segundo Freire e Motokane (2016) a confiabilidade, ou seja, com que consistência uma determinada medida ou um determinado alvo são 
alcançados. As cargas fatoriais variaram entre 0,485 e 0,648 , alcançando os valores recomendados maiores de 0,30, que se agruparam para explicar o mesmo conceito (Pasquali, 2004).

Para essa diferenciação de percepção de constructo da escala de Importância com relação à de Domínio, que tiveram soluções fatoriais distintas, sugere-se que os respondentes perceberam o constructo de domínio da competência de gestão de projetos em sua totalidade sem, no entanto, distinguir as facetas da iniciativa e comunicação, ou gestão de processos e projetos, como percebeu ao julgar a importância das competências para o bom desempenho do trabanho na atribuição. Essa hipótese vem a corroborar a percepção dos participantes da pesquisa de possuir um alto grau de domínio das competências descritas no instrumento.

Verifica-se, desta forma, que a análise fatorial possibilitou a validação empírica do instrumento e que, pela solução fatorial das escalas, os fatores identificados, tanto da estrutura bifatorial da escala de Importância, quanto da estrutura unifatorial da escala de Domínio foram interpretados como variável latente subjacente às variáveis observadas em cada um deles. Pode-se dizer, assim, que os respondentes perceberam que o conjunto de itens media o mesmo conceito ou dimensão, de acordo com o principal intuito da técnica fatorial, a de condensar dados (Pasquali, 2004; Laros, 2005).

\subsection{Discussões dos resultados das análises de regressão}

Esta pesquisa propôs um modelo de predição com oito competências identificadas para desenvolvimento e as variáveis sociodemográficas dos líderes de projeto. Estudos anteriores testaram modelos preditivos com ANT, como os de Magalhães et al. (2001), realizado na Caixa Econômica, relacionando ANT com tempo de trabalho; Cunha et al (2010), com treinadores de futebol, relacionando as variáveis experiência profissional e formação federativa; Silva at al. (2012) relacionando motivação e complexidade de necessidades de treinamento; e Mourão et al. (2013), que testou a própria ANT como preditiva do impacto no treinamento.

Identificou-se que eixo de atuação na empresa $(\beta=-0,14)$ tem relação causal com a necessidade de capacitação como um todo. Observa-se, também, a influência das variáveis antecedentes sobre a necessidade de capacitação em cada uma das competências priorizadas para capacitação, conforme a Tabela 26. 
Tabela 26 - Relação de predição das variáveis antecedentes (variáveis sociodemográficas da clientela) para as necessidades de treinamento identificadas.

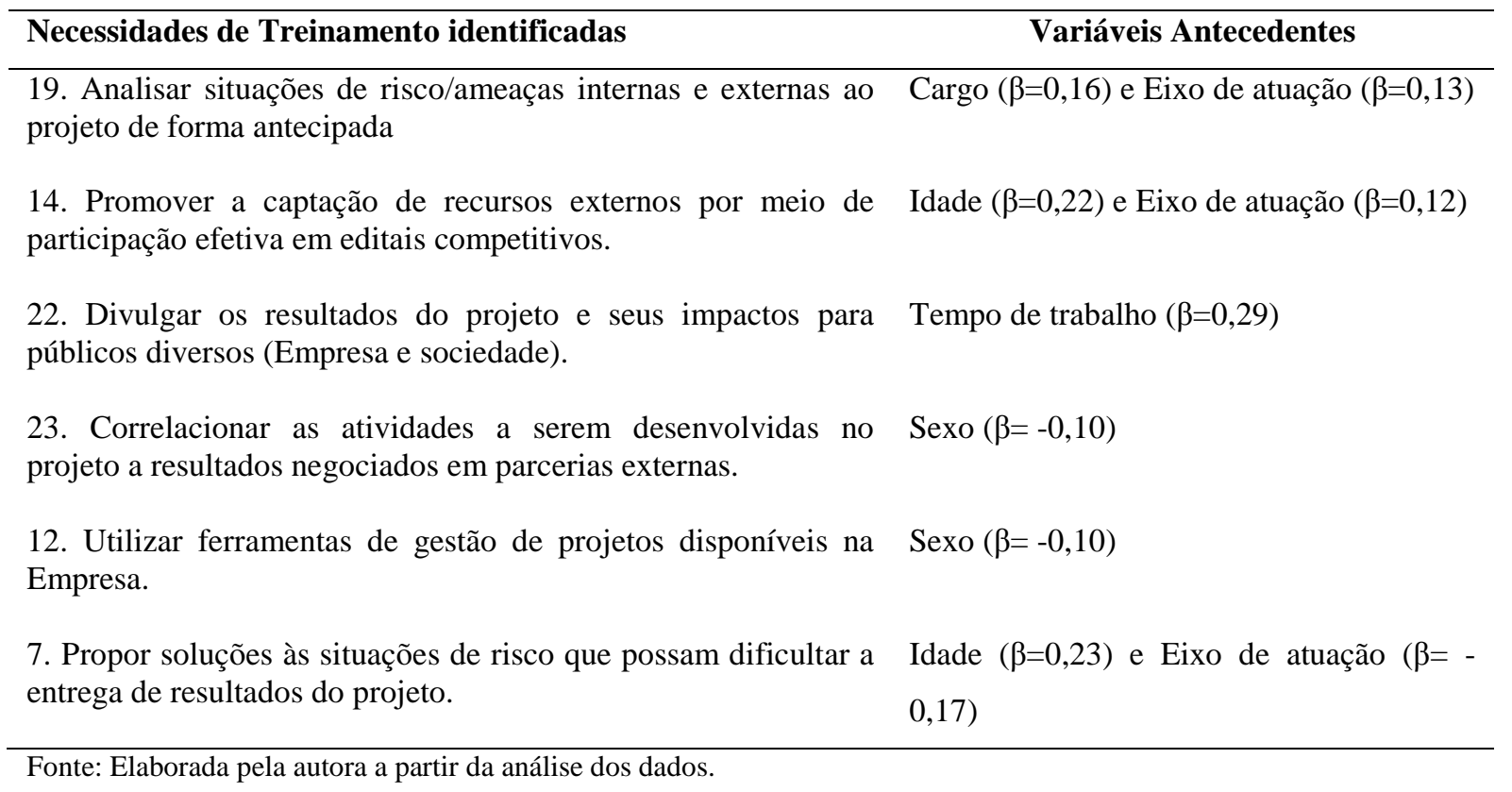

Os resultados evidenciaram, desta forma, que a variação do cargo (analista ou pesquisador) e do eixo de atuação (Comunicação e Desenvolvimento Institucional, Pesquisa e Desenvolvimento ou Transferência e Tecnologia) tem uma relação preditiva sobre a necessidade de treinar os líderes de projeto em analisar situações de risco/ameaças internas e externas ao projeto de forma antecipada. A faixa etária e novamente o eixo em que os líderes de projeto atuam na Embrapa explicam em parte a lacuna de competência em promover a captação de recursos externos por meio de participação efetiva em editais competitivos. A necessidade de capacitação em divulgar resultados do projeto e seus impactos para públicos diversos é explicada pelo tempo de trabalho. Este resultado de pesquisa, em particular, confirmou resultados de estudos anteriores de modelos de predição, testados por Magalhães et al. (2001) e Silva at al. (2012), e que identificaram o tempo de trabalho como boa variável preditora de necessidades de treinamento. A variável sexo influencia a necessidade de capacitação de duas competências: correlacionar as atividades a serem desenvolvidas no projeto a resultados negociados em parcerias externas e utilizar ferramentas de gestão de projetos disponíveis na Empresa. E, por último, a idade o eixo de atuação explicam a necessidade de capacitação em propor soluções às situações de risco que possam dificultar a 
entrega de resultados do projeto. Implicações práticas desses achados serão abordadas posteriormente.

\subsection{Implicações teóricas}

A descrição e o mapeamento das competências dos líderes de projeto da Embrapa, realizada por meio dos comportamentos observáveis, de acordo com orientações de Brandão et al. (2001), Abbad et al. (2006), e Meneses et al. (2010), produziram elementos característicos da atribuição e da instituição estudada. Desta forma, contribuíram não somente para a construção do instrumento de medida, mas constituem parâmetros para os avanços dos estudos sobre competências de líderes de projeto.

$\mathrm{Na}$ abordagem de competências, esta pesquisa adotou como referencial o conceito: conjunto de conhecimentos (corpo organizado de informações requerido para o desempenho da atividade); habilidades (atividades de natureza psicomotoras ou cognitivas) e atitudes (conjunto de crenças, normas, valores e regras que orientam o comportamento individual) necessárias ao desempenho esperado no trabalho (Meneses et al., 2010).

\subsection{Implicações empíricas e metodológicas}

A sistematização de práticas de ANT preconiza a adoção de métodos de mensuração para necessidades de capacitação. A literatura indica poucos registros de instrumentos validados orientados à avaliação de necessidades de treinamento (Borges-Andrade et al.,1993; HicKs \& Henessy,1997; Henessy \& Hicks, 1998, apud Ferreira, 2009), devido às frequentes abordagens ad-hoc utilizadas nas instituições.

As implicações metodológicas obtidas por meio dos resultados deste estudo apontam para consolidar o cuidado metodológico na construção e validação do instrumento de medida. Considerando os excelentes indicadores psicométricos de validade e confiabilidade que o instrumento apresentou, cabe salientar ainda que foi construído especificamente para a clientela-alvo da pesquisa, considerando todos os aspectos que tangem a atribuição. 


\subsection{Implicações práticas da pesquisa}

Acredita-se que este estudo promova subsídios à instituição-alvo para facilitar o processo de planejamento e tomada de decisões a fim de realizar ações educacionais direcionadas às necessidades fomentadas. Apesar de constituir em uma demanda pontual, os resultados apontam relações causais importantes para a instituição, superando a concepção estratégica.

Ao construir e validar um instrumento voltado à realidade da PD\&I, à atribuição da clientela, inclusive com a participação de profissionais de outras empresas do ramo da pesquisa no processo de construção e validação, o trabalho contribui para a utilização do questionário em qualquer instituição de pesquisa.

Desta forma, os investimentos na área TD\&E podem se tornar melhor aproveitados, e que este estudo possa contribuir para a ANT, considerando as lacunas identificadas na literatura de estudos na área (Magalhães et al., 2001; Silva et al., 2012). 


\section{CAPÍTULO 7 - CONSIDERAÇÕES FINAIS}

\section{Objetivo do capítulo}

Este capítulo tem como objetivo concluir o presente estudo, identificando-se suas principais contribuições e limitações, propondo, por fim, uma agenda de pesquisa.

Este trabalho teve como objetivo identificação de lacunas de competências de líderes de projeto, e verificar a relação de predição entre as características da clientela (características sociodemográficas e funcionais) e essas necessidades de treinamento no contexto de instituições de PD\&I.

Os objetivos propostos para este estudo foram alcançados e, acerca das perguntas de pesquisa, pode-se dizer que:

1. Qual o perfil dos líderes de projeto das empresas que atuam com Pesquisa, Desenvolvimento e Inovação - PD\&I? O perfil dos líderes de projeto das empresas que atuam em PD\&I não pôde ser identificado de forma generalizada, pois o número de empresas de PD\&I envolvidas no estudo foi insipiente para este propósito. A proposta inicial era entrevistar cinco empresas privadas e institutos públicos de pesquisa, com orientação voltada a PD\&I, além da Embrapa. No entanto, foram acessadas apenas três empresas, o que limitou o intuito de ampliar a dimensão do perfil do líder de projeto a profissionais de empresas de PD\&I.

2. Qual o perfil dos líderes de projeto da Embrapa? O perfil dos líderes de projeto da Embrapa foi delineado por meio de comportamentos observáveis de seu papel ocupacional, e então realizado mapeamento das competências. As competências foram transformadas em 25 itens para compor o instrumento de medida.

3. Há demanda de capacitação entre os líderes de projeto que atuam na Embrapa? Foram identificadas como necessidade de capacitação as competências: “Analisar situações de risco/ameaças internas e externas ao projeto de forma antecipada; "Preparar os resultados do projeto para a sua efetiva transferência ao público-alvo"; " Promover a captação de recursos externos por meio de participação efetiva em editais competitivos"; "Divulgar os resultados do projeto e seus impactos para públicos diversos (Empresa e sociedade)"; "Correlacionar as atividades a serem desenvolvidas no projeto a resultados negociados em parcerias externas"; "Utilizar ferramentas de 
gestão de projetos disponíveis na Empresa"; "Utilizar novas técnicas de comunicação com a equipe, como web conferencias, redes sociais"; e "Propor soluções às situações de risco que possam dificultar a entrega de resultados do projeto".

4. O que pode causar uma eventual lacuna de competências entre os líderes de projeto que atuam na Embrapa? A necessidade de capacitação foi explicada de forma geral neste estudo pelo eixo de atuação, e por meio de modelos de explicação detalhados foram estabelecidas relações causais entre as lacunas de competências e as variáveis sóciodemográficas: idade, sexo, cargo, tempo de trabalho e eixo de atuação.

Apesar de reconhecida relevância como processo essencial no planejamento e desenho de ações de TD\&E (Aguinis et al., 2009; Iqbal \& Khan, 2011; Latham, 1988; Salas et al., 2001; Tannenbaum et al., 1992), as práticas de ANT têm sido realizadas por abordagens ad hoc e pelo improviso (Ferreira, 2009; Taylor, Driscoll \& Binning, 1998), o que implica em impactos negativos ou desperdícios de investimentos, desconsiderando o potencial estratégico do processo, que fomenta o aprimoramento de conhecimentos, habilidades e atitudes dos indivíduos na instituição.

Considerando que, tanto a produção científica quanto a prática nas organizações a área de ANT revelam poucos avanços na área, este estudo contribui com as pesquisas da área, com a proprosição do modelo de investigação, por meio de sua testagem de relações de predição estabelecidas, e a elaboração e a validação do instrumento.

O instrumento de medida, elaborado e validado, que apresentou excelentes indicadores psicométricos, sendo pertinente a qualquer tipo de organização na área de pesquisa, constituiu em uma contribuição, visto que a literatura registra poucos instrumentos validados na área.

Do ponto de vista institucional, espera-se que esta pesquisa tenha contribuído também ao construir e validar um questionário carcterístico do papel ocupacional do líder de projeto, que possa ser utilizado em qualquer instituição da área de pesquisa que tenha o objetivo de realizar ANT para aquela clientela.

Embora tenha gerado tais contribuições, o trabalho apresentou algumas limitações. Do ponto de vista metodológico, a baixa amplitude de acesso a empresas de pesquisa na fase de construção do instrumento limitou a construção de dimensão mais generalista do perfil do líder de projeto. Foram realizadas nesta fase três entrevistas com profissionais de empresas de pesquisa e seis com profissionais da Embrapa. Apesar da coleta de dados não ter inviabilizado 
a proposta inicial de mapeamento de competências da atribuição de líder de projeto com a participação de representantes de outras empresas de pesquisa, um maior número de entrevistados ampliaria a ótica acerca da atribuição.

Outro ponto de limitação relevante no tocante ao instrumento é o aspecto estratégico e prospectivo que as competências deveriam abordar, considerando a natureza da instituição. Este intento foi abordado por um membro da banca no exame de qualificação desta pesquisadora e, no intuito de garantir essa característica aos itens do questionário, foram acessados profissionais do corpo estratégico para uma fase de validação do instrumento, cumprido a tempo.

Do ponto de vista do diagnóstico de ANT, constatou-se que os respondentes avaliaram ter alto domínio na maioria das competências identificadas, o que resultou em IPGs abaixo do proposto pela metodologia de Borges-Andrade et al. (1983) - corte de 30\% (valor de IPG=10,3). Essa consideração indica que a autopercepção no julgamento do domínio das competências pode indicar leniência, desejabilidade social ou até falta de entendimento da escala. A ANT, com foco somente no indivíduo pode não ser a melhor ou a única forma de se avaliar as necessidades de treinamento; de acordo com Meneses et al. (2009), é preciso estender o nível de análise para além do individual, considerando equipes de trabalho e a própria organização.

Com base nos resultados obtidos e nas limitações encontradas nesta pesquisa recomenda-se que pesquisas futuras:

1. Empreguem medidas de heteroavaliação para ANT, no caso de líderes de projeto abordando a equipe;

2. Aprofundem a compreensão das relações estratégicas da instituição, que possibilite identificar variáveis mediadoras ou moderadoras dos aspectos ou práticas de ANT;

3. Estratifiquem o mapeamento das competências de líderes de projeto por tipo de projeto.

Finalmente, espera-se que este trabalho tenha contribuído com a área de TD\&E, especificamente com as pesquisas no campo da avaliação de necessidades de treinamento, apresentando contribuições a pesquisadores e profissionais para uma melhor compreensão e aprimoramento do processo que, de acordo com a literatura, é uma etapa essencial para o sucesso de qualquer programa de treinamento. 


\section{Referências}

Abbad, G. (1999). Um modelo integrado de avaliação de impacto do treinamento no trabalho - IMPACT. Tese de Doutorado, Instituto de Psicologia, Universidade de Brasília, Brasília.

Abbad, G. \& Borges-Andrade, J. E. (2004). Aprendizagem humana em organizações de trabalho. In J. C. Zanelli, J. E. Borges-Andrade \& A.V. B. Bastos (Orgs.), Psicologia, Organizações e Trabalho no Brasil (pp. 237-275). Porto Alegre: Artmed.

Abbad, G., Carvalho, R. S., \& Zerbini, T. (2006). Evasão em curso via internet: explorando variáveis explicativas. $R A E$-eletrônica, $5(2)$.

Abbad, G. S., Freitas, I. \& Pilati, R. (2006). Contexto de Trabalho, Desempenho Competente e Necessidades em TD\&E. In: Borges-Andrade, J. E.; Abbad, G. S., Mourão, L. (Orgs.), Treinamento, Desenvolvimento e Educação em Organizações e Trabalho: Fundamentos para a Gestão de Pessoas (pp 231-254) Porto Alegre, RS.

Abbad, G. S., Loiola, E., Zerbine, T., \& Borges-Andrade, J. (2013). Aprendizagem em Organizações e no Trabalho. In L. O. Borges, \& L. Mourão (Orgs.). O Trabalho e as Organizações - Atuações a partir da Psicologia (Vol. 1, pp. 497-527). Porto Alegre: Artmed.

Abbad, G. S. \& Mourão, L. (2012). A avaliação de necessidades de TD\&E: proposição de um novo modelo. RAM, Revista de Administração Mackenzie, 13(6), Edição Especial, 107137.

Abbad, G., Nogueira, R., \& Walter, A. M. (2006). Abordagens instrucionais em planejamento de TD\&E. Treinamento, desenvolvimento e educação em organizações e trabalho: fundamentos para a gestão de pessoas, 255-281.

Abbad, G. D. S., Zerbini, T., \& Souza, D. B. L. D. (2010). Panorama das pesquisas em educação a distância no Brasil. Estudos de Psicologia (Natal), 15(3), 291-298.

Aguinis, H., \& Kraiger, K. (2009). Benefits of training and development for individuals and teams, organizations, and society. Annual review of psychology, 60, 451-474.

Agut, S., \& Grau, R. (2002). Managerial competency needs and training requests: The case of the Spanish tourist industry. Human Resource Development Quarterly, 13(1), 31-52.

Araújo, C., \& Pedron, C. (2016). The Importance of Soft Skills and it Project Managers' Personality Type.Int. J. Prof. Business Review, 1(1), 40-59.

Bardin, L. (2008). Análise de conteúdo 4ªed. Lisboa: Edições, 70.

Bartram, S., \& Gibson, B. (1994). Training Needs Analysis. A Resource for Identifying Training Needs, Selecting Training Strategies, and Developing Training Plans. Gower, Old Post Road, Brookfield, VT. 
Bell, B. S., Tannenbaum, S. I., Ford, J. K., Noe, R. A., \& Kraiger, K. (2017). 100 years of training and development research: What we know and where we should go.

Bloom, B. S. (1972). Innocence in education. The School Review, v. 80, n. 3, p. 333-352.

Borges-Andrade, J. E. (2006). Avaliação integrada e somativa em TD\&E. In J. E. BorgesAndrade, G. Abbad, L. Mourão (Orgs.), Treinamento, desenvolvimento e educação em organizações e trabalho: fundamentos para a gestão de pessoas (pp. 343-358). Porto Alegre: Artmed.

Borges-Andrade, J. E. \& Abbad, G. (1996). Treinamento e desenvolvimento: reflexões sobre suas pesquisas. Revista de Administração da USP, 31, 112-125.

Borges-Andrade, J. E. \& Lima, S. V. L. (1983). Avaliação de necessidades de treinamento: um método de análise de papel ocupacional. Tecnologia Educacional, 12(54), 6-22.

Boyatzis, R. E. (1982). The competent manager: A model for effective performance. New York: John Wiley \& Sons.

Brandão, H. P. (2012). Mapeamento de competências: métodos, técnicas e aplicações em gestão de pessoas. São Paulo: Atlas.

Brandão, H. P., \& Borges-Andrade, J. E. (2008). Causas e efeitos da expressão de competências no trabalho: para entender melhor a noção de competência. Revista de Administração Mackenzie, 8(3).

Brandão, H. P. \& Guimarães, T. A. (2001) Gestão de competências e gestão de desempenho: tecnologias distintas ou instrumentos de um mesmo construto? Revista de Administração de Empresas, 41(1), 8-15.

Brandão, H. P., Borges-Andrade, J. E., de Freitas, I. A., \& Vieira, F. T. (2010). Desenvolvimento e estrutura interna de uma escala de competências gerenciais. Psicologia: Teoria e Pesquisa, 26(1), 171.

Brito, L. M. P., Paiva, I. C. B., \& Leone, N. M. C. P. G. (2012). Perfil de competências gerenciais no Ensino Superior Tecnológico. Revista Ciências Administrativas, 18(1).

Campbell, J. P. (1971). Personnel trainning and development. Annual Review of Psychology, $22,565-602$.

Campos, E. B. D. (2012). Avaliação de necessidades de treinamento de empresários juniores brasileiros. Dissertação de mestrado, Universidade de Brasília, Brasília, DF, Brasil.

Campos, E. B. D. (2015). Competências Empreendedoras: uma Avaliação no Contexto de Empresas Juniores Brasileiras. Tese de Doutorado, Universidade de Brasília, Brasília, DF, Brasil. 
Campos, E. B. D., Abbad, G. D. S., Ferreira, C. Z., \& Negreiros, J. L. X. M. D. (2014). Empresas juniores como espaços de apoio à formação profissional de estudantes universitários brasileiros. Revista Psicologia Organizações e Trabalho, 14(4), 452-463.

Carbone, P. P., Brandão, H. P., Leite, J. B. L., \& Vilhena, R. M. P. (2005). A Gestão por Competências. Gestão por competências e gestão do conhecimento, 41-77.

Castro, P. D., \& Borges-Andrade, J. E. (2004). Identificação das necessidades de capacitação profissional: o caso dos assistentes administrativos da Universidade de Brasília. Revista de Administração da USP, 39(1), 96-108.

Cartwright, C. \& Yinger, M. (2007). Project management competence development framework-second edition. Paper presented at PMI ${ }^{\circledR}$ Global Congress 2007-Asia Pacific, Hong Kong, People's Republic of China. Newtown Square, PA: Project Management Institute.

Carvalho, R. S., \& Abbad, G. (2006). Avaliação de treinamento a distância: reação, suporte à transferência e impactos no trabalho. Revista de Administração contemporânea, 10(1), 95116.

Cesnik, V. M. (2014). Avaliação de necessidades de treinamento com profissionais de enfermagem na área da sexualidade. Tese de Doutorado, Departamento de Psicologia, Universidade de São Paulo, Ribeirão Preto.

Chen, H. M., Hung, S. T. (2012). The Utility of O-T-P Model in Taiwan Coast Guard. Public Personnel Management, 41(1), 15-43.

Chouhan, V. S., \& Srivastava, S. (2014). Understanding competencies and competency modeling-A literature survey. IOSR Journal of Business and Management, 16(1), 14-22.

Clarke, N. (2003). The politics of training needs analysis. Journal of Workplace Learning, 15(4), 141-153.

Crawford, L. (2005). Senior Management perceptions of project management perceptions. International Journal of Project Management, 23(1) 7-16.

Cunha, G. B. D., Mesquita, I. M. R., Rosado, A. F. B., Sousa, T. \& Pereira, P. (2010). Necessidades de formação para o exercício profissional na perspectiva do treinador de Futebol em função da sua experiência e nível de formação. Motriz Revista de Educação Física, 16(4), 931-941.

Dendena, A. C. M.; Ferreira, M. A. T.; Guimarães, L. O.; Castro, J. M.; Versiani, A. F. (2013). Processo de gestão de projetos de P\&D: um estudo de caso na Cemig. Revista Economia \& Gestão, Belo Horizonte, v. 13, n. 31, p. 138-161, jan.-abr.

Dubois, D. D. (1993). Competency-based performance improvement: A strategy for organizational change. HRD Press, Inc., 22 Amherst Road, Amherst, MA 01002. 
Dutra, J. S. (2004). Competências: conceitos e instrumentos para a gestão de pessoas na empresa moderna. Atlas.

Ferdous, T., \& Razzak, B. M. (2012). Importance of training needs assessment in the banking sector of Bangladesh: a case study on National Bank Limited (NBL). International Journal of Business and Management,7(10), 63.

Ferreira, R. R. (2009). Avaliação de necessidades de treinamento: proposição e aplicação de um modelo teórico-metodológico nos níveis macro e meso organizacionais. Dissertação de Mestrado, Instituto de Psicologia, Universidade de Brasília, Brasília, DF.

Ferreira, R. R., \& Abbad, G. (2014). Avaliação de necessidades de treinamento no trabalho: ensaio de um método prospectivo. Revista Psicologia Organizações e Trabalho, 14(1), 0117.

Ferreira, R. R., Abbad, G., Pagotto, C., P. \& Meneses, P. P. M. (2009). Avaliação de necessidades organizacionais de treinamento: o caso de uma empresa latino-americana de administração aeroportuária. Revista Eletrônica de Administração, 15(2), 349-375.

Fleury, M. T. L. \& Fleury, A. (2000). Em busca da competência. Encontro de estudos Organizacionais, $1 . \quad$ Retrieved from http://www.anpad.org.br/diversos/trabalhos/EnEO/eneo_2000/2000_ENEO24.pdf

Fleury, M. T. L. \& Fleury, A. (2001). Construindo o conceito de competência. Revista de Administração Contemporânea, Edição Especial, 183-196.

Fleury, M. T. L. \& Fleury, A. (2004). Alinhando estratégia e competência. Revista de Administração de Empresas, 44(1), 44-57.

Flick, U. (2002). Qualitative research-state of the art. Social science information, 41(1), 5-24.

Folha da Embrapa, Ano XXII, outubro - dezembro/2015, nº 188. Impresso.

Freire, C. C., \& Motokane, M. T. (2016). Análise fatorial e análise de agrupamento no mapeamento de concepções epistemológicas de professores sobre a ciência e a ecologia. Investigações em Ensino de Ciências, 21(3), 152.

Gallagher, K., Cass, H., Black, R. \& Norridge, M. (2012). A training needs analysis of neonatal and pediatric health-care staff in a tertiary children's hospital. International Journal of Palliative Nursing, 18(4), 197-201.

Gilbert, T.F. (1978). Human Competence: Engineering worthy Performance. New York: McGraw-Hill.

Goldstein, I.L. (1980). Training in work organizations. Annual Review of Psychology, v. 31, p. 229-272.

Gonczi, A. (1999). 12 Competency-based learning. Understanding learning at work, 180. 
Hair, J. F., Anderson, R. L., Tatham, R. L. \& Black, W. C. (2005). Análise Multivariada de dados (5a ed.). Porto Alegre: Bookman.

Hoffman-Câmara, R., Abbad, G., Meneses, P. P. M., \& Ferreira, R. R. (2010). Necessidades educacionais complementares do bacharel em turismo: aplicação do método da análise do papel ocupacional. COMITÉ EDITORIAL DIRECTOR: Agustín Santana Talavera, 8, 305.

Iqbal, M. Z. \& Khan, R. A. (2011). The growing concept and uses of training needs assessment: a review with proposed model. Journal of European Industrial Training, $35(5), 439-466$.

Jordão, R. V. D., Pelegrini, F. G., Jordão, A. C. T., \& Jeunon, E. E. (2015). Critical factors in project management: a case study in a big latin american world class company. Gestão \& Produção, 22(2), 280-294.

Jovchelovitch, S., \& Bauer, M. W. (2002). Entrevista narrativa. Pesquisa qualitativa com texto, imagem e som: um manual prático, 4, 90-113.

Junior, F. A. C., \& Borges-Andrade, J. E. (2008). Uso do conceito de aprendizagem em estudos relacionados ao trabalho e organizações. Paidéia, 18(40), 221-234.

Kerlinger, F. N. (1980). Metodologia da pesquisa em ciências sociais: um tratamento conceitual. Epu.

Lacerda, É. R. M., \& Abbad, G. (2003). Impacto do treinamento no trabalho: investigando variáveis motivacionais e organizacionais como suas preditoras. Revista de Administração contemporânea, 7(4), 77-96.

Lampel, J. (2001). The competencies of effective of the project execution: the challenge of diversity. International Journal of Project Management, 18(8), 471-483.

Laros, J. A. (2005). O uso da análise fatorial: algumas diretrizes para pesquisadores. Em L. Pasquali (Org.), Análise fatorial para pesquisadores (pp. 163-184). Brasília: LabPAM.

Latham, G. (1988). Human resource training and development. Annual Review of Psychology, v. 39 , p. $545-582$.

Le Bortef, G. (2003). Desenvolvendo a competência dos profissionais. Porto Alegre: Artmed.

Lima, S. M. V. \& Borges-Andrade, J. E. (2006). Bases conceituais e teóricas de avaliação de necessidades em TD\&E. In J. E. Borges-Andrade, G. Abbad, L. Mourão (Orgs.), Treinamento, desenvolvimento e educação em organizações e trabalho: fundamentos para a gestão de pessoas (pp. 199-215). Porto Alegre: Artmed.

Magalhães, M. L., \& Borges-Andrade, J. E. (2001). Auto e hetero-avaliação no diagnóstico de necessidades de treinamento. Estudos de psicologia, 6(1), 33-50. 
Mager, R. F. \& Pipe, P. (1983). Análise de Problemas de Desempenho. Porto Alegre, RS. Editora Globo.

Manzini, E. J. (2004). Entrevista semi-estruturada: análise de objetivos e de roteiros. Seminário internacional sobre pesquisa e estudos qualitativos, 2, 58-59.

Marzagão, D. S., \& Carvalho, M. M. (2016). A influência das competências comportamentais dos líderes de projetos no desempenho de projetos seis sigma. Revista Brasileira de Gestão de Negócios-RBGN, 18(62), 609-632.

McClelland, D. C. (1973) Testing for Competence Rather Than for "Intelligence". American Psychologist, 28(1), 1-14.

McGehee, M., \& Thayer, P. W. (1999). Training in business and industry. New York: John Wiley \& Sons

Meneses, P.P.M.\& Abbad, G.S. (2003). Comprometimento Organizacional: o estado da arte da pesquisa no Brasil. Revista de Administração Contemporânea - RAC, Rio de Janeiro, v. 7, Edição Especial, p. 185-204.

Meneses, P. P. M. \& Zerbini, T. (2009). Levantamento de necessidades de treinamento: Reflexões atuais. Análise, 20(2): 50-64.

Meneses, P. P. M., Zerbini, T. \& Abbad, G. (2010). Manual de Treinamento Organizacional. Porto Alegre: Artmed.

Moraes, R., O. \& Kruglianskasb, I. (2012). O gerente de projetos de TI em organizações com níveis de maturidade diferenciados. Production, 22(4), 839-850.

Müller, R., \& Turner, J. R. (2007). Matching the project manager's leadership style to project type. International journal of project management, 25(1), 21-32.

Müller, R., \& Turner, R. (2010). Leadership competency profiles of successful project managers. International Journal of Project Management, 28(5), 437-448.

Nadler, L. (1984). The handbook of human resource development. John Wiley \& Sons.

Newton, R. (2011). O gestor de projetos. Pearson Educación.

Noe, R. A., Clarke, A. D., \& Klein, H. J. (2013). Learning in the Twenty-First-Century Workplace. Annual Review of Organizational Psychology and Organizational Behavior.

Oderich, C. (2005). Gestão de competências gerenciais: noções e processos de desenvolvimento. Os novos horizontes da gestão: aprendizagem organizacional $e$ competências. Porto Alegre: Bookman, 88-115. 
Oliveira, E. C. B. D., Alencar, L. H., \& Costa, A. P. C. S. (2016). A decision model for energy companies that sorts projects, classifies the project manager and recommends the final match between project and project manager. Production, 26(1), 91-104.

Ostroff, C., \& Ford, J. K. (1989). Assessing training needs: Critical levels of analysis. In I. L. Golsdtein \& Associates (Eds). Training and development in organizations: 25-62. San Francisco: Josey-Bass.

Pasquali, L. (1996). Teoria e métodos de medida em ciências do comportamento. Brasília: Laboratório de Pesquisa em Avaliação e Medida.

Pasquali, L. (1998). Princípios de elaboração de escalas psicológicas. Revista de Psiquiatria Clínica, 25(5), 206-213.

Pasquali, L. (1999). Escalas psicométricas. Instrumentos psicológicos: manual prático de elaboração, 105-126.

Pasquali, L. (2004). Análise fatorial para pesquisadores. Petrópolis: Vozes.

Pilati, R. (2006). História e importância de TD\&E. Treinamento, desenvolvimento e educação em organizações e trabalho: Fundamentos para gestão de pessoas, 159-176.

Portal da Embrapa. Disponível em https://www.embrapa.br/pesquisa-e-desenvolvimento.

Prahalad, C., \& Hamel, G. (1990). A competência Essencial das Organizações. Harvard Business Review, 79-91.

Rolstadas, A.; Tommelein, I.; Schiefloe, P. M., \& Ballard, G. (2014). Understanding project success through analysis of project management approach. International Journal of Managing Projects in Business, 7(4), 638.

Rosa, A. P., Dal Cortivo, L., \& Godoi, C. K. (2006). Competências profissionais: uma análise da produção científica brasileira de 1999 a 2004. Revista de Negócios, 11(1).

Russo, R. D. F. S. M., Ruiz, J. M., \& Cunha, R. P. (2005). Liderança e influência nas fases da gestão de projetos. Production, 15(3), 362-375.

Salas, E. \& Cannon-Bowers, J. A. (2001). The science of training: a decade of progress. Annual Review of Psychology, 52, 471-499.

Sallorenzo, L. (2000). Avaliação do Impacto de Treinamento no Trabalho: analisando e comparando modelos de predição. Brasília, 2000. Dissertação de Mestrado, Instituto de Psicologia, Universidade de Brasília, Brasília.

Silva, G. (2010). Necessidades de Treinamento e Motivação para Trabalhar: Análise do Relacionamento. Dissertação de Mestrado, Departamento de Administração, Universidade de Brasília, Brasília. 
Silva, G. G. \& Meneses, P. P. M. (2012). Necessidades de treinamento organizacional e motivação para trabalhar. REAd, 71(1), 27-62.

Silva, L. M. D. (2016). Diagnóstico de competências profissionais considerando fatores que influenciam sua expressão.

Stevens, J. P. (2012). Applied multivariate statistics for the social sciences. Routledge.

Succar, B., Sher, W., \& Williams, A. (2013). An integrated approach to BIM competency assessment, acquisition and application. Automation in Construction, 35, 174-189.

Tabachnick, B. G., \& Fidell, L.S. (2007). Using multivariate statistics. New York: HarperCollins College Publishers.

Tannenbaum, S.I. \& Yukl, G. (1992). Training and development in work organizations. Annual Review of Psychology, 43, 399-441.

Taylor, P., O’Driscoll, M., \& Binning, J. (1998). A new integrated framework for training needs analysis. Human Resource Management Journal, 8(2), 29-50.

Toledo, J. D., Silva, S. D., Mendes, G. H. S., \& Jugend, D. (2008). Fatores críticos de sucesso no gerenciamento de projetos de desenvolvimento de produto em empresas de base tecnológica de pequeno e médio porte. Gestão \& Produção, 15(1), 117-134.

Vargas, M. R. M. e Abbad, G. S. (2006) Bases Conceituais em Treinamento, Desenvolvimento e Educação - TD\&E. Em: J. E. Borges-Andrade, G. Abbad, L. Mourão \& colaboradores, Treinamento, desenvolvimento e educação em organizações e trabalho: fundamentos para a gestão de pessoas (pp. 137-158). Porto Alegre: Artmed.

Wexley, K. N. (1984). Personnel training. Annual Review of Psychology, v. 35, p. 519-551.

Wright, P. C., \& Geroy, G. D. (1992). Needs analysis theory and the effectiveness of largescale government-sponsored training programmes: A case study. Journal of Management Development, 11(5), 16-27.

Yang, L. R.; Huang, C. F.; Wu, K. S. (2011). The association among project manager's leadership style, teamwork and project success. International Journal of Project Management, v. 29, n. 3,p. 258-267.

Zarifian, P. (2001). Objetivo competência: por uma lógica. São Paulo: Atlas, 10.

Zanelli, J. C., Borges-Andrade, J. E., \& Bastos, A. V. B. (2014). Psicologia, Organizações e Trabalho no Brasil-2. AMGH Editora.

Zemke, R. (1982). Job competencies: can they help you design better training? Training.

Zerbini, T., \& Abbad, G. (2005). Impacto de treinamento no trabalho via internet. RAEeletrônica, 4(2). 


\section{Anexos}

Anexo I - Aprovação da Pesquisa no Comitê de Ética de Pesquisa da USP

\section{Universidado de Sáo Paulo}

Facuidade de Filosofia, Cióncias e Letras de Ribeiräo Preto

Comitê de ENica em Pesquisa

Campus de N kbeirîa Preto

Ot.CETP/FFCLRP-USP/121/-dgts

Ribeinta Preto, 11 do dozembre de 2015

Prezado(a) Peaquisador[a]

Cemunicamos a V. Sa nue o projoto de pesquisa intetulado "Pertis de Lideres de Projeto: Proposta de um Modelo de ldentificaçäo" fai anaisado pelo Comith de Etica em Pesquige da FFCLRP-USP, en sua $151^{*}$ Resuniabo Ordinäris; realizada am 10.12.2015, a enquadrado na cofegaria. APROVADO (CAAE $n$ " 50569015.2.0000.5407).

Solicitamas que eventuas modificaptes ou emendse ao projeto de pesquisa sejam apresentadas ao CEP, de forma sucinta. identificando a parte do grojete a ser medrcada e suas justificativas, s que, ao têrmino do estudo, um relatonio final soja ontregue. via Patalorma Brasil

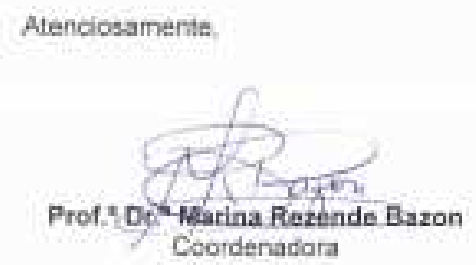

\footnotetext{
A senhora

Monica Aun De Azevedo

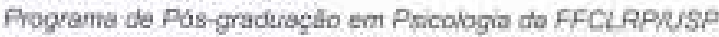

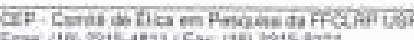

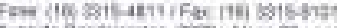

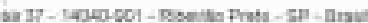

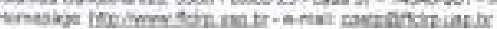


Anexo II - Autorização da Embrapa para coleta de dados da pesquisa

\section{Embrapa}

\section{AUTORIZAÇÃO}

A Empresa Brasileira de Pesquisa Agropecuária - Embrapa - autoriza Mônica Aun de Azevedo, aluna do Programa de Mestrado do curso de Pós-Graduação em Psicologia da FFCLRP-USP, a realizar, sob a supervisão da Profa. Dra. Thais Zerbini, a coleta de dados para a pesquisa intitulada "Perfis de Líderes de Projeto: Proposta de um Modelo de Identificação" na Sede da Empresa, em Brasília-DF.

Estamos cientes de que tal coleta consiste na aplicação de um questionário para compreender as necessidades de treinamento dos profissionais da Empresa na função de líder de projeto, e de que a pesquisa buscará informações sobre o dia-a-dia no trabalho, por meio da autoavaliação do domínio das competências (conhecimentos, habilidades e atitudes) desses profissionais. A aplicação será realizada a distância, pela internet, e cada profissional receberá um convite em seu e-mail corporativo para responder à pesquisa, de forma voluntária.

A coleta de dados tem duração prevista de aproximadamente dois meses e somente terá início após a aprovação do projeto de pesquisa pelo Comitê de Ética em Pesquisa da FFCLRP, com garantia de sigilo das informações, assegurada pelo pesquisador.

Brasília, 18 de junho de 2015.

Paule Jeanne Vieira Mendes

Chefe do Departamento de Gestão de Pessoas 


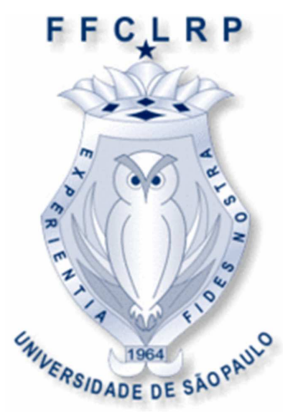

\section{Embrapa}

Anexo III - Roteiro de entrevista

\section{COMPETÊNCIAS DE LÍDERES DE PROJETO}

\section{Competência}

É o conjunto de conhecimentos, habilidades e atitudes (recursos) necessários ao desempenho esperado no trabalho.

\section{Dica:}

As competências devem refletir um desempenho observável, indicado a partir da utilização de verbos de ação mensuráveis e concretos.

\section{Ficha do Cargo}

A. Nome do Cargo

B. Categoria Funcional

C. Pré-Requisitos (Escolaridade e/ou Experiência Profissional)

\section{Condições de Trabalho}

A. Jornada de Trabalho:

B. Ambiente Social:

Composição do Grupo de Trabalho

Posição do Cargo na Estrutura de Cargos

Comunicação Exigida

Participação nas Decisões

Dependência / Autonomia / Supervisão.

$\checkmark$ Sob sua percepção, quais são as atividades que os líderes de projeto realizam? (Atividades inerentes ao papel).

$\checkmark$ Para realizarem essas atividades, o que esses profissionais devem saber fazer? Quais conhecimentos devem ter?

$\checkmark$ Existe alguma outra competência ou capacidade que considere importante?

$\checkmark \mathrm{O}$ que considera mais importante nesse profissional para executar seu papel de forma exemplar? Cite um exemplo de desempenho que possa ser observável, sob essa perspectiva. 